Florida International University FIU Digital Commons

\title{
In-Vivo Corrosion and Fretting of Modular TI-6AL-4V/CO-CR-MO Hip Prostheses: The Influence of Microstructure and Design Parameters
}

Jose Luis Gonzalez Jr

Florida International University, jgonz121@fiu.edu

DOI: $10.25148 /$ etd.FI15032195

Follow this and additional works at: https://digitalcommons.fiu.edu/etd

Part of the Applied Mechanics Commons, Biomaterials Commons, Biomedical Devices and Instrumentation Commons, Metallurgy Commons, Other Materials Science and Engineering Commons, and the Tribology Commons

\section{Recommended Citation}

Gonzalez, Jose Luis Jr, "In-Vivo Corrosion and Fretting of Modular TI-6AL-4V/CO-CR-MO Hip Prostheses: The Influence of Microstructure and Design Parameters" (2015). FIU Electronic Theses and Dissertations. 1756.

https://digitalcommons.fiu.edu/etd/1756 


\section{FLORIDA INTERNATIONAL UNIVERSITY}

Miami, Florida

\section{IN-VIVO CORROSION AND FRETTING OF MODULAR TI-6AL-4V/CO-CR-MO HIP PROSTHESES: THE INFLUENCE OF MICROSTRUCTURE AND DESIGN \\ PARAMETERS}

A thesis submitted in partial fulfillment of the

requirements for the degree of

MASTER OF SCIENCE

in

MATERIALS SCIENCE AND ENGINEERING

by

Jose Luis Gonzalez Jr. 


\section{To: Dean Amir Mirmiran}

College of Engineering and Computing

This thesis, written by Jose Luis Gonzalez Jr., and entitled In-Vivo Corrosion and Fretting of Modular Ti-6Al-4V/Co-Cr-Mo Hip Prostheses: The Influence of Microstructure and Design Parameters, having been approved in respect to style and intellectual content, is referred to you for judgment.

We have read this thesis and recommend that it be approved.

$\begin{array}{r}\hline \text { Benjamin Boesl } \\ \hline \text { Norman Munroe } \\ \hline \text { William Kinzy Jones, Major Professor }\end{array}$

Date of Defense: April 16, 2015

The thesis of Jose Luis Gonzalez Jr. is approved.

$\begin{array}{r}\text { Dean Amir Mirmiran } \\ \text { College of Engineering and Computing } \\ \hline \begin{array}{r}\text { Dean Lakshmi N. Reddi } \\ \text { University Graduate School }\end{array}\end{array}$

Florida International University, 2015 


\section{DEDICATION}

I dedicate this thesis to my parents and grandparents, for without their endless love and example, none of this would be possible. 


\begin{abstract}
OF THE THESIS
IN-VIVO CORROSION AND FRETTING OF MODULAR TI-6AL-4V/CO-CR-MO

HIP PROSTHESES: THE INFLUENCE OF MICROSTRUCTURE AND DESIGN

PARAMETERS

by

Jose Luis Gonzalez Jr.
\end{abstract}

Florida International University, 2015

Miami, Florida

Professor William Kinzy Jones, Major Professor

The purpose of this study was to evaluate the incidence of corrosion and fretting in 48 retrieved titanium-6aluminum-4vanadium and/or cobalt-chromium-molybdenum modular total hip prosthesis with respect to alloy material microstructure and design parameters. The results revealed vastly different performance results for the wide array of microstructures examined. Severe corrosion/fretting was seen in $100 \%$ of as-cast, $24 \%$ of low carbon wrought, $9 \%$ of high carbon wrought and $5 \%$ of solution heat treated cobaltchrome. Severe corrosion/fretting was observed in $60 \%$ of Ti-6Al-4V components. Design features which allow for fluid entry and stagnation, amplification of contact pressure and/or increased micromotion were also shown to play a role. $75 \%$ of prosthesis with high femoral head-trunnion offset exhibited poor performance compared to $15 \%$ with a low offset. Large femoral heads $(>32 \mathrm{~mm})$ did not exhibit poor corrosion or fretting. Implantation time was not sufficient to cause poor performance; $54 \%$ of prosthesis with greater than 10 years in-vivo demonstrated none or mild corrosion/fretting. 


\section{TABLE OF CONTENTS}

CHAPTER

PAGE

CHAPTER I: INTRODUCTION 1

1 1.1. Total Hip Replacement and Revisions: Clinical Need 1

1.2. Modular Total Hip Prostheses: The New Optimization 3

Challenge

2 2. Research Objectives Summary $\quad 7$

CHAPTER II: $\quad$ BACKGROUND AND LITERATURE REVIEW 8

1 1. Cobalt-Chrome-Molybdenum Processing, Microstructural 8

Evolution \& Properties

1.1. Cast Processing 9

1.1.1. Investment casting and As-Cast Microstructures 9

1.1.2. Hot-Isostatic Pressing 12

1.1.3. Solution Heat Treatment 12

1.2. Wrought Processing 16

1.3. Porous Coating Application 18

2 2. Titanium-6Aluminum-4 Vanadium Processing, 20

Microstructural Evolution \& Properties

3 3. Modular Total Hip Prosthesis Design 26

3.1. Morse Taper 26

3.2. Neck and Taper Diameter $\quad 27$

3.3. Trunnion-Head Interface Parameters 27

3.4. Femoral Head Size $\quad 30$

4 4. Fretting Wear 31

5 5. Corrosion 33

5.1 Passivation 34

5.2. Galvanic Corrosion 34

5.2.1. Mixed alloy couples 34

5.2.2. Surface Area effects $\quad 34$

$\begin{array}{lll}5.3 \text { Sensitization } & 35\end{array}$

5.4. Pitting Corrosion $\quad 36$

5.5. Crevice Corrosion 37

5.6. Mechanically Assisted Corrosion 40

6 6. Summary of Past Retrieval Studies 43

CHAPTER III: $\quad$ EXPERIMENTAL METHODS 46

1 1. Retrieved Implant Cleaning and Sterilization 47

2 2. Non-Destructive Examination 49

2.1.Cataloging, Initial Condition Assessment 49

2.2. Dimensional Measurements and Design Features $\quad 50$

4 4. Destructive Examination and Materials Characterization 57 
4.1.Sectioning $\quad 57$

4.2. Corrosion and Fretting Imaging and Scoring 58

4.3. Microstructural Characterization 63

4.3.1. Etching and Microscopic Examination 63 of Grain Morphology

4.3.2. Energy Dispersive Spectroscopy 64

4.3.3. Crystallography and X-ray Diffraction 64

4.3.4. Microhardness Testing 69

4.3.5. Focused Ion Beam and Transmission $\quad 70$

Electron Microscopy

CHAPTER IV: RESULTS AND ANALYSIS

1 1.1. Statistical Summary of Retrieval Sample Set 71

1.2. Statistical Summary of Basic Patient Data 72

1.3 Statistical Summary of Corrosion/Fretting Scores by 73

Alloy Couple Type

2 2.1. Summary of Corrosion/Fretting Scores by Microstructure 74

2.2. Typical Microstructure Morphology 77

3 3.1. Summary of Corrosion/Fretting Scores by Microstructure $\quad 80$

3.2. High Moment Arms and Skirted Heads 82

3.3. Variable Contact Length Tapers and Crevice Corrosion $\quad 84$

3.4. As-Cast/Dendritic Microstructure: Sensitization and 86

Intergranular Corrosion

3.5. Titanium on Titanium Couples: Discerning The role of 93

4 4.1. Influence of Moment Arm Length 94

4.2. Influence of Femoral Head Size 96

5 5. Influence of Clinical Variables 99

6 6. Damage Co-Occurrence in Coupled Heads and Trunnions 101

$\begin{array}{ll}\text { CHAPTER V: } & 102\end{array}$

$\begin{array}{lll}\text { CHAPTER VI: } & \text { FUTURE RESEARCH } & 105\end{array}$

$\begin{array}{ll}\text { REFERENCES } & 106\end{array}$ 


\section{LIST OF TABLES}

TABLE

PAGE

Table 2.1 Typical beam fatigue strength of ASTM 75 Co-Cr alloy by heat treatment

Table 2.2 Mechanical properties of cast Co-Cr-Mo by processing route

Table 2.3 Minimum Mechanical Properties for Cast, Forged, and Wrought 18 Co-Cr-Mo alloys as Specified by ASTM Standards

Table 2.4 Advantages provided by the various microstructural features seen in Ti-6Al-4V

Table 2.5 Effect of heat treatments on Ti-6Al-4V microstructure.

Table 2.6 Effect of heat treatments on Ti-6Al-4V mechanical properties

Table 2.7 Fracture toughness values for equiaxed and highly transformed microstructures

Table 2.8 Ti-6Al-4V ASTM mechanical and compositional requirements

Table 2.9 Summary of modular total hip prosthesis retrieval studies during the past 25 years.

Table $3.1 \quad$ As-received prostheses cataloging

Table 3.2 General prostheses feature cataloging

Table 3.3 Macroscopic Examination. Overall implant examination, i.e. 51 non-surface specific.

Table 3.4 Porous Surface Coating Types 52

Table 3.5 Femoral head and femoral stem dimensional variables $\quad 54$

Table 3.6 Modular junction dimensional variables 56

Table 3.7 Corrosion and Fretting Scoring Criteria 58

Table 3.8 Table of structure factor parameters for Ti-6Al-4V alpha and $\quad 68$ beta phase fraction calculation. 
Table 4.1 Summary of samples by microstructure and design features.

Table 4.2 Summary of samples by patient age and weight and in-vivo time.

Table 4.3 Corrosion/Fretting score distribution by alloy couple type

Table 4.4 Microstructure, phase fraction, grain size, couple type and fretting/corrosion score for all 48 samples scored. W LC = Wrought Low Carbon, W HC = Wrought High Carbon, Cast ST $=$ Cast Solution Treated, $\mathrm{U}=$ Microstructure unexamined

Table 4.5 Worst fretting or corrosion score distribution by microstructure for all couple types

Table 4.6 Worst fretting or corrosion score distribution by microstructure for similar alloy couple types only.

Table 4.7 Worst fretting or corrosion score distribution by moment arm length.

Table 4.8 Worst fretting/corrosion score distribution for either head or trunnion by implantation time in-vivo. 


\section{LIST OF FIGURES}

FIGURE

PAGE

Figure 1.1 Intraoperative photograph demonstrating corrosion at the headneck interface, showing a hypertrophic and avascular pseudocapsule typical of adverse local tissue reaction. (Right). Radiograph demonstrating extensive femoral stress shielding after 9 years. Note decreased bone density

Figure 2.1 Equilibrium Phase Diagram of the Binary Co-Cr System

Figure 2.2 Dendritic pattern formed during slow Co-Cr solidification

Figure 2.3 ASTM F75 As-cast microstructure with increasing amounts of carbon content. (a) 0.26 wt.\% C (b) 0.36 wt.\% C (c) 0.45 wt.\% $\mathrm{C}$

Figure 2.4 Microstructural phases visible in as-cast $\mathrm{Co}-\mathrm{Cr}$ revealed by etching.

Figure 2.5 Melting of interdendritic material in $\mathrm{Co}-\mathrm{Cr}$ during short heat treatments at $1300^{\circ} \mathrm{C}$

Figure 2.6 (Left) Solution treated cast Co-Cr microstructure showing fine and dispersed second phases. (Right) Carbide content dissolution during solution treatment throughout time and at different cooling rates.

Figure 2.7 Mechanical properties with increasing solution treatment time.

Figure 2.8 Microstructure of HIP+ST cast alloy at $1250^{\circ} \mathrm{C}$. (a) furnace cooled (b) quenched.

Figure 2.9 Cobalt-Carbon phase diagram illustrating the lever rule principle that dictates the fraction $\mathrm{AB} / \mathrm{AC}$ of the constituent phases which will be liquid at the sintering temperature AC. i.e. an increase in carbon content will decrease the temperature required for adhering porous coatings.

Figure 2.10 Porous coated as-cast cobalt-chrome stem

Figure 2.11 Effect of Cooling Rates and Highest Temperature on Ti-6Al-4V Microstructure 
Figure 2.12 Morse Taper Parameters and Surface Finish 26

Figure 2.13 Mini morse taper with reduced contact area 28

Figure 2.14 Prostheses neck angle, medial-lateral offset, and neck length 29

Figure 2.15 Skirted and non-skirted heads with various penetration and 29 coverage

Figure 2.16 Finite element analysis predicting greater wear at the trunnion $\quad 30$ surface as femoral head is increased from $32 \mathrm{~mm}$ to $56 \mathrm{~mm}$.

Figure 2.17 Material, contact conditions and environmental variables 32 governing potential for fretting wear.

Figure 2.18 Pitting corrosion phenomena and associated reactions and surface features.

Figure 2.19 Pourbaix diagram illustrating Eh/pH relationship for chromium 39

Figure 2.20 Schematic demonstrating corrosion half-cell reactions occurring 39 outside the crevice

Figure 2.21 (Left) Drawing showing the location of corrosion products. A thin interfacial layer of mixed oxides and chlorides, $\mathrm{B}=$ thicker deposits of chromium-orthophospate hydrate-rich corrosion products around the opening of the crevice. (Right) Explanted Co-Cr prosthesis shown with green-white deposit outside the taper, identified by XPS analysis as a combination of chromium phosphate and chromium oxide with bone minerals and polypeptides and many other compounds of chromium, molybdenum, and cobalt.

Figure 2.22 Synergistic relationship between fretting wear and corrosion processes

Figure 3.1 As-received retrieved total hip prosthesis with bone grafting and extensive osseointegration

Figure 3.2 Sterilized retrieved prosthesis in CrosstTex pouch with indicators visible

Figure 3.3 Dimensions for Typical Total Hip Prosthesis. (Left) Anterior/Posterior View. (Right) Mediolateral view 
Figure 3.4 Key Dimensions for Femoral Head and Head-Trunnion Mating. (Top) Typical skirtless head with engaged taper. (Center)

Skirted Head with engaged taper. (Bottom) Taper dimensions

Figure 3.5 Cross-sectioned engaged head-trunnion couple in sectioning holder.

Figure 3.6 SEM image of worn and corroded trunnion taper (left half) and the unworn region that protruded from the femoral head (right half)

Figure 3.7 SEM images of machining groove fretting, highlighting the range of severity. a) no fretting. b) mild fretting c) moderate fretting d) severe fretting

Figure 3.8 Backscattering Scanning Electron Microscope image of pitting corrosion seen in as-cast Co-Cr-Mo femoral head tape

Figure 3.9 Femoral tapers demonstrating varying degrees of corrosion damage as determined by the Goldberg criteria. (0) None,(1) Mild, (2) Moderate (3) Severe

Figure 3.10 (top) XRD patterns of Co-Cr-Mo-C alloys with different $\mathrm{C}$ content. (bottom) Volume fraction of the HCP phase in $\mathrm{Co}-\mathrm{Cr}-$ Mo-C alloys with different $\mathrm{C}$ content

Figure 3.11 Effect of annealing temperature on the X-ray diffraction patterns of low carbon $\mathrm{Co}-27 \mathrm{Cr}-5 \mathrm{Mo}-0.05 \mathrm{C}$ alloy (a) asreceived, (b) $500{ }^{\circ} \mathrm{C}$, (c) $1100{ }^{\circ} \mathrm{C}$, and (d) $1250{ }^{\circ} \mathrm{C}$

Figure 3.12 Typical diffraction pattern for Ti-6Al-4V with corresponding beta and alpha peaks.

Figure 3.13 (a) HXD-1000 TMC micro-hardness instrument. (b). Sample indentation as imaged by optical microscope showing diagonal length (L).

Figure 4.1 As-cast Co-Cr microstructure revealed after 50ml HCL + 4g $\mathrm{K} 2 \mathrm{~S} 2 \mathrm{O} 5$ (Potassium Metabisulfite) $+4 \mathrm{~g} \mathrm{NaOH}+50 \mathrm{ml}$ water a) 50x magnification (b) Different as-cast sample at 100x magnification with larger dendritic arm spacing 
Figure 4.2 Solution Treated (ST) Co-Cr microstructure revealed after $50 \mathrm{ml}$ $\mathrm{HCL}+4 \mathrm{~g} \mathrm{~K} 2 \mathrm{~S} 2 \mathrm{O} 5$ (Potassium Metabisulfite) $+4 \mathrm{~g} \mathrm{NaOH}$ $+50 \mathrm{ml}$ water (a) Nearly $100 \%$ ST sample at 50x magnification showing small amounts of secondary phases within the grain boundaries. (b) Different ST sample at 50x magnification showing large $>500 \mu \mathrm{m}$ grains and miniscule amounts of secondary phases visible likely due to double ST and/or annealing

Figure 4.3 Solution Treated Co-Cr microstructure revealed after 50ml HCL $+4 \mathrm{~g} \mathrm{~K} 2 \mathrm{~S} 2 \mathrm{O} 5$ (Potassium Metabisulfite) $+4 \mathrm{~g} \mathrm{NaOH}+50 \mathrm{ml}$ water (a) ST sample at 200x magnification after slow cooling (b) Partially ST sample at 50x magnification

Figure 4.4 Wrought High Carbon Co-Cr microstructure revealed after $50 \mathrm{ml} \mathrm{HCL}+4 \mathrm{~g} \mathrm{~K} 2 \mathrm{~S} 2 \mathrm{O} 5$ (Potassium Metabisulfite) + $4 \mathrm{~g} \mathrm{NaOH}+50 \mathrm{ml}$ water (a) 1000x magnification (b) 100x magnification

Figure 4.5 Wrought Low Carbon Co-Cr microstructure revealed after 50ml $\mathrm{HCL}+4 \mathrm{~g} \mathrm{~K} 2 \mathrm{~S} 2 \mathrm{O} 5$ (Potassium Metabisulfite) $+4 \mathrm{~g} \mathrm{NaOH}$ $+50 \mathrm{ml}$ water (a) 1000x magnification (b) 500x magnification. Dark striations indicative of highly strained wrought $\mathrm{Co}-\mathrm{Cr}$

Figure 4.6 Ti-6Al-4v Microstructure a Co-Cr after $1.5 \mathrm{ml} \mathrm{HF}: 2.5 \mathrm{ml}$ $\mathrm{HNO}_{3}: 100 \mathrm{ml} \mathrm{H}_{2} \mathrm{O}$ (Kroll's reagent) (a) Acicular microstructure at $1000 \mathrm{x}$ magnification (b) Equiaxed microstructure at 500x magnification

Figure 4.7 Sample \#14. (Top-left) trunnion-head assembly. Note very high offset. (Top-right) Etched ST Co-Cr microstructure at 500X magnification revealing secondary phases at grain boundaries. (Bottom-Left) Disengaged trunnion revealing uniformly distributed corrosion black corrosion products on both tapers. (Bottom-Right) SEM image of machine lines demonstrating extensive fretting and corrosion.

Figure 4.8 Extensive Corrosion seen in Titanium Sample with a Variable Taper Contact Length. (Lower-Left inset) Taper showing significant loss of material at the taper edge, indicative of crevice corrosion. (Upper-Right inset) Large and deep corrosion pit approximately $2 \mathrm{~mm}$ in length and $1 \mathrm{~mm}$ in width.

Figure 4.9 (Left) Notch extending deep into femoral head. (Center and Right) Crevice at the trunnion-head interface. 
Figure 4.10 (Left) As-Cast Co-Cr trunnion taper exhibiting severe corrosion and fretting. (Right) Revealed dendritic microstructure at $100 \mathrm{X}$ magnification after etching with 50ml HCL + 4g K2S2O5 + $4 \mathrm{~g} \mathrm{NaOH}+50 \mathrm{ml}$ water

Figure 4.11 1,400X magnification SEM image of as-retrieved as-cast $\mathrm{Co}-\mathrm{Cr}$ trunnion taper, revealing the dendritic microstructure etched invivo. Note absence of machining lines.

Figure 4.12 Ion channeling contrast enhanced image of taper subsurface at 88 $6,000 \mathrm{X}$ magnification, revealing differences in morphology near the surface.

Figure 4.13 FIB trench subsurface regions selected for energy dispersive spectroscopy analysis.

Figure 4.14 Cobalt, chromium, and molybdenum elemental weight percent at different depths as determined by EDS.

Figure 4.15 (Left to right) 1. FIB sample pull out of as-cast carbide in 91 matrix. 2. Areas from which EDS and TEM diffraction patterns were taken. 3. TEM image of carbide and matrix. 4. SAED pattern of matrix. 5. SAED of region between second phase and matrix 6. SAED of second phase particle.

Figure 4.16 Extensive corrosion seen in mixed-alloy couple. (Left) Titanium 92 trunnion showing severe corrosion near bore opening. (Right) As-cast Co-Cr femoral head exhibiting severe corrosion attack.

Figure 4.17 Scatter plot of taper contact surface area versus head-trunnion 95 moment arm length.

Figure 4.18 Scatter plot of contact surface area versus worse fretting or 96 corrosion score.

Figure 4.19 Scatter plot of femoral head size versus worse fretting or corrosion score.

Figure 4.20 Scatter plot of femoral head size versus head-trunnion moment- 98 arm length.

Figure 4.21 Scatter plot of femoral head size versus contact surface area. 
Figure 4.22 Scatter plot of femoral head size proximal trunnion taper diameter.

Figure 4.23 Scatter plot of time in-vivo versus worst fretting/corrosion score for either coupled component.

Figure 4.24 Scatter plot of time in-vivo versus worst fretting/corrosion score for either coupled component.

Figure 4.25 Scatter plot of patient weight versus worst fretting/corrosion score for either coupled component.

Figure 4.26 Scatter plot of head corrosion score versus stem corrosion scores for similar and mixed alloy couples.

Figure 4.27 Scatter plot of head fretting score versus stem fretting scores for similar and mixed alloy couples. 


\section{CHAPTER I: INTRODUCTION}

\subsection{Total Hip Replacement and Revisions: Clinical Need}

Artificial hip prostheses have been highly successful in alleviating severe osteoarthritis pain and joint damage. Their efficacy is foretold by the sheer number of recipients; in the U.S. alone, over 332,000 patients undergo total hip replacement (THR) every year[1]. However, this success has been dampened by their poor long term performance which has led to over 40,000 revision surgeries per year to correct for implant failure [2]. Further exacerbating the incidence of implant failure is the increasing number of younger patients undergoing THR, whose more active lifestyles place greater demands on their prosthetic joints[3].

The primary cause of revision surgery is the loosening of the femoral component at the bone-stem interface, a condition known aseptic loosening. The two primary causes of aseptic loosening is the physiological phenomena known as stress shielding and osteolysis. In the case of stress shielding, the introduction of the femoral implant shifts the load once borne by the bone towards the much higher modulus implant, thereby removing the mechanical stimulus that is needed for bone formation. The result is bone resorption and reduced bone density in the areas surrounding the implant, ultimately leading to a loss of implant fixation. The second cause of aseptic loosening is a more complex physiological process initiated by metal ion release and wear particles originating from the implant. Through a variety of indirect and direct pathways, these metal ions and foreign debris affect the immune system and bone metabolism[4, 5], 
causing pseudotumors, adverse immune reactions, and infections that lower the $\mathrm{pH}$ of nearby periprosthetic tissues.

Partly in an attempt to reduce stress shielding, modular prosthesis were developed allowing for the femoral stem to be manufactured from lower modulus materials, thus more closely matching the modulus of bone. The result was a modular two piece design that has seen overwhelming adoption over the past 25 years and has all but completely replaced the previous monoblock design. However, although the introduction of lower modulus materials has improved incidence rates of aseptic loosening, it has far from eliminated it.

A consequence of the new modular design was the introduction of a new source of metal ion release at the interface between the femoral head and stem resulting from fretting and corrosion[6-13].The prevalence of these material degrading processes occurring at the modular interface have been widely reported since their inception [6-13]. While delineating the exact cause of aseptic loosening in any particular case is difficult and in many cases impossible, an increasing number of studies have confirmed severe modular interface corrosion co-occurring with adverse local tissue reaction (ALTR), including soft tissue damage and loss of implant fixation.[6-9, 13, 14]. 

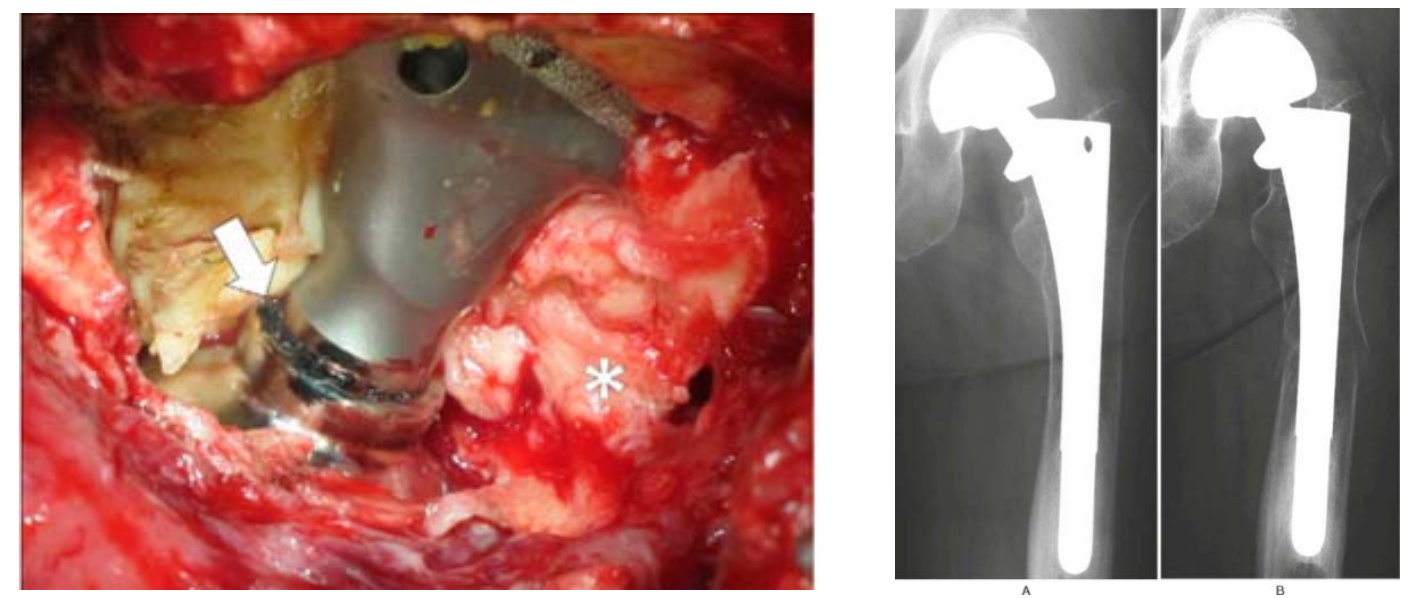

Figure 1.1. (Left) Intraoperative photograph demonstrating corrosion at the head-neck interface, showing a hypertrophic and avascular pseudocapsule typical of adverse local tissue reaction. (Right). Radiograph demonstrating extensive femoral stress shielding after 9 years. Note decreased bone density.[14]

Understanding the material and design factors that contribute to metal ion release at modular implant interfaces will enable a new generation of hip prosthesis with even lower modulus materials, and less metal ion release and wear debris; ultimately enabling implantable devices that can outlive patients without regular revision surgery.

\subsection{Modular Total Hip Prostheses: The New Optimization Challenge}

Modular total hip prosthesis were developed as a potential solution to the variety of performance and logistical challenges plaguing earlier monoblock designs. These early prostheses were manufactured from a single casting or two components welded at the femoral head to stem interface. In contrast, the flexibility provided by modular implants allows surgeons to intraoperatively select femoral head and neck components with dimensions that more closely recreate natural limb length, offset, neck length and 
anteversion, while also minimizing incision length and surgical dissection. The modular design also provides prosthesis engineers with a wider array of possible material combinations and post-processing treatments to match the vastly different mechanical properties required by the various implant surfaces. Further providing an impetus for the adoption of modular systems is the reduction in inventory levels implant manufacturers need to maintain in order to meet the wide array of dimensional options demanded[15].

As the original and only wear susceptible mating surface present, the bearing surface of the femoral head has traditionally been seen as the predominant source of released metal ions and debris. As a result there has been a significant multi-decade research effort to optimize femoral head materials for sliding wear and tribocorrosion resistance.

However, the electrochemical and mechanical processes underlying tribocorrosion at the femoral bearing surface are fundamentally different from the chemically enclosed, micron displacement prone and mixed-metal environment seen at the interface of the femoral head and the femoral stem interface. The modular interface presents galvanic effects, fretting induced oxygen depletion (crevice corrosion promoting) and fluid stagnation that is not seen on the femoral head, where the open environment provides oxygen for repassivation and fresh electrolyte-maintaining sliding action (i.e. preventing corrodents like $\mathrm{Cl}$ - from accumulating) and an galvanic-free metalon-polymer or metal-on-similar-metal mating.

Given the differences seen with the underlying causes of corrosion and wear at the bearing surface versus the modular junctions, it serves to ask the question: Can the 
materials used on the femoral head and femoral stem be optimized so as to reduce metal ion and wear release from the overall construct, not just the bearing surface? From extensive literature review, there are strong indications that there is indeed a discrepancy between the optimal material design for each prosthesis surface. High carbon cobaltchromium-molybdenum alloys, with extensive and well adhered blocky carbides to protect the matrix, seem to be the optimal choice for bearing surfaces. However, the resulting inhomogeneities in the microstructures are prone to selective attack (sensitization) and are likely poor candidates for low $\mathrm{pH}$ and $\mathrm{O} 2$ crevices and galvanic couples. As for the femoral stem, can the microstructure be optimized in such a manner as to prevent taper corrosion and fretting while not sacrificing the low modulus and high fatigue strength necessary for the stem? Even further, what is the role design features such taper-interface mating and dimensional parameters, relative neck thickness (i.e. relative flexural rigidity), relative taper roughness and range of motion extending features?

Answering these questions thoroughly is more challenging than practitioners from others domains might expect. For one, there is a severe deficit of standardization in the orthopedic industry. Unlike the high-performance alloys used in the aerospace industry, where every processing step is precisely controlled and standardized, the material standards often cited by prosthesis manufacturers to regulatory bodies and physicians are vague and only specify compositional bounds and lower limits on mechanical properties[16]. 
Simulating the tribocorrosion phenomena expected in physiological environments is notoriously difficult. Overall, simulated testing of prostheses has a poor track record, evidenced by recent high profile failures with metal-on-metal prosthesis [17]. This lack of confidence in traditional testing places a priority on retrieval studies, which involve the analysis of explanted prostheses post-mortem or after revision surgeries. However, unlike simulated testing, in-vivo testing cannot be accelerated and variables cannot be fully controlled. Furthermore, there is an inevitable delay between the introduction of a new feature or material change and performance results. This delay increases the product development cycle significantly and creates a hesitance to introduce any significant changes to prostheses designs.

Despite the well established differences in material properties resulting from microstructural variations, as of today, the vast majority of retrieval studies do not perform microstructural characterizations on retrieved prosthesis or even the less categorize prosthesis according to ASTM standards [6-9, 13, 14]. Furthermore, there is a lack of comprehensive dimensional analysis that is be necessary to delineate whether the observed damage is a result of prosthesis design or material properties and clinical factors.

Any retrieval study incorporating microstructural analysis would face one daunting challenge: understanding and categorizing the observed grain morphology and crystallographic results. Titanium-6Aluminum-4Vanadium microstructures are well understood and extensive resources are available to aide in their analysis. However, cobalt-chrome alloys are not as common as Ti-6Al-4V and there is a deficit of well 
organized resources to assist in characterizing $\mathrm{Co}-\mathrm{Cr}$ and to draw microstructure-toproperty relationships.

\section{Research Objectives Summary}

The goal of this study is to develop a protocol for the evaluation ofthe microstructure, design, and clinical history of retrieved modular total hip prosthesis and to relate these parameters to their corrosion and fretting performance. Second, will be the application of this protocol to a sample set of 48 retrieved hip prosthesis.

A further goal is a thorough literature review of the relevant processing-tomicrostructure and microstructure-to-mechanical relationships, and microstructure-tocorrosion relationships that have been investigated for the most common cobalt-chromemolybdenum and titanium-4aluminum-6vanadium alloys. As well as a literature review of the known relationship between design features and damage at the modular interface. 


\section{CHAPTER II: BACKGROUND AND LITERATURE REVIEW}

\section{Cobalt-Chrome-Molybdenum Processing, Microstructural Evolution \& Properties}

The most common alloys used in modern total hip prosthesis are the cobaltchromium-molybdenum (Co-28Cr-6Mo) alloys, particularly for the femoral head components where excellent wear and corrosion resistance is paramount. Three primary processing routes, namely, casting, forging/wrought processing and powder sintering, have been widely adopted for Co-Cr implant production. Additionally a plethora of postprocessing and elemental options that have not been fully standardized but can significantly alter key material properties, are also commonly implemented. The most commonly cited standards, ASTM F1537, ASTM 799 and ASTM F75 establish broad constraints for alloy composition, ingot source, some microstructural features such as grain size, and mechanical properties depending on the processing route.

Generally, 28\% by weight of chromium is added, for passive Cr2O3oxide layer formation, $7-8 \%$ of molybdenum is added for solid solution strengthening and improved localized corrosion resistance andcarbon levels are generally kept below .5\%. Processing parameters and mechanical properties are highly sensitive to carbon content. Aside from carbon's role in forming carbides that drastically improve wear resistance and control grain growth, it also serves as a stabilizer for the metastable FCC phase. While carbon levels can dramatically effect $\mathrm{Co}-\mathrm{Cr}$ properties, carbon weight percent alone is not sufficient to predict its mechanical and microstructural effects. Processing parameters and their role in carbide precipitation and their resulting morphology have been the center of many research studies, for its dramatic effect on cobalt chrome. Indeed, low carbon 
varieties can perform similar to high carbon varieties, if processing is tailored accordingly.

\subsection{Cast Processing}

\subsubsection{Investment casting and As-Cast Microstructures}

Investment casting cobalt-chrome has the significant advantage of allowing detailed features to be directly produced which reduces machining time and material wastage. The casting process begins with the melting of a $\mathrm{Co}-\mathrm{Cr}$ billet in an induction furnace heated to $1550^{\circ} \mathrm{C}$, which is then poured into a cast mold preheated to $1000^{\circ} \mathrm{C}$. Cooling and solidification begins at the surface of the colder mold. It is at this step, as the liquidus temperature $\left(\sim 1395^{\circ} \mathrm{C}\right)$ is reached, that the as-cast microstructure begins to form (Figure 2.1).

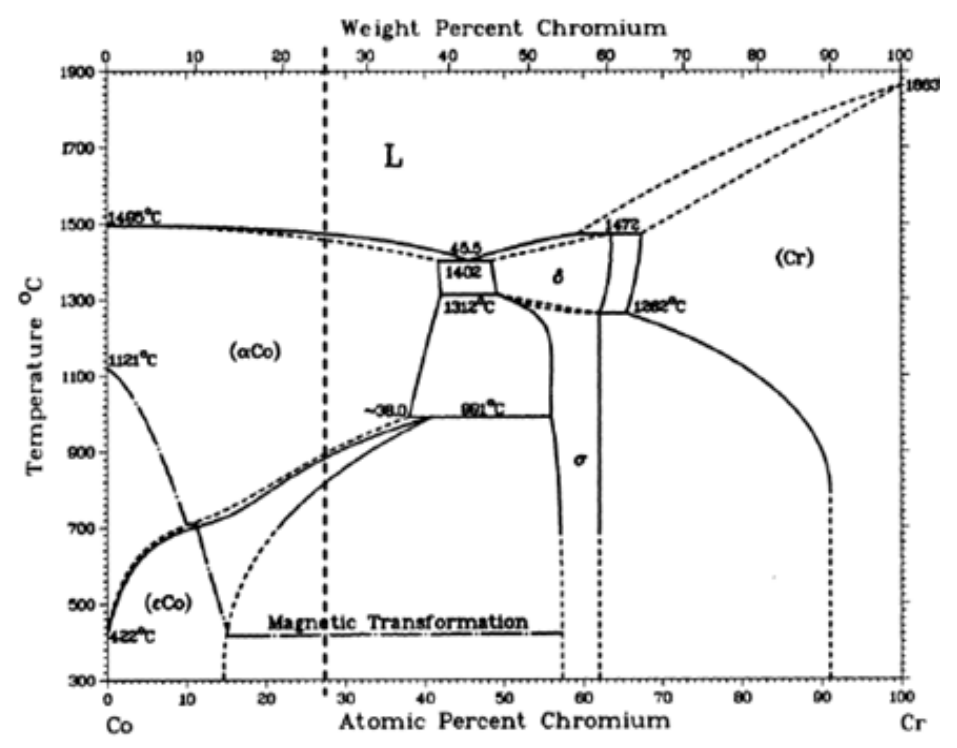

Figure 2.1. Equilibrium Phase Diagram of the Binary Co-Cr System. [14] 


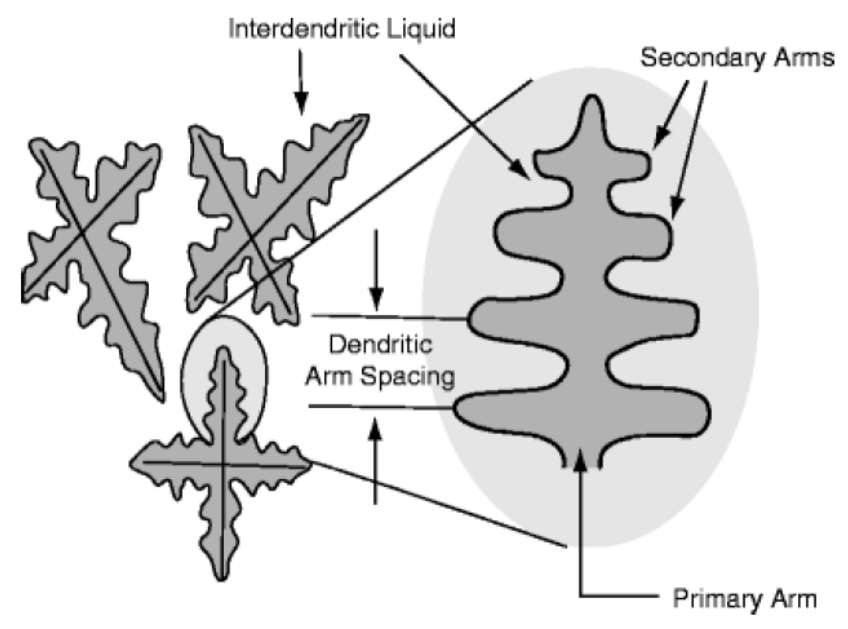

Figure 2.2. Dendritic pattern formed during slow Co-Cr solidification [18]

The slow cooling temperatures that are generally required during the initial casting allow for the segregation of elements by their melting points. The dendritic pattern formed is predominately composed of higher melting point elements, while the residual liquid is composed of lower melting point elements. As this residual liquid solidifies, it forms the interdendritic carbide phase, rich in carbon, molybdenum and chromium[19]. This eutectic phase consists of FCC cobalt, brittle $\sigma$ phase, and M23C6 and $\mathrm{M} 7 \mathrm{C} 3$ carbides[20-23]. The resulting microstructure is a coarse dendritic structure as seen in Figure 2.2 and 2.3. 

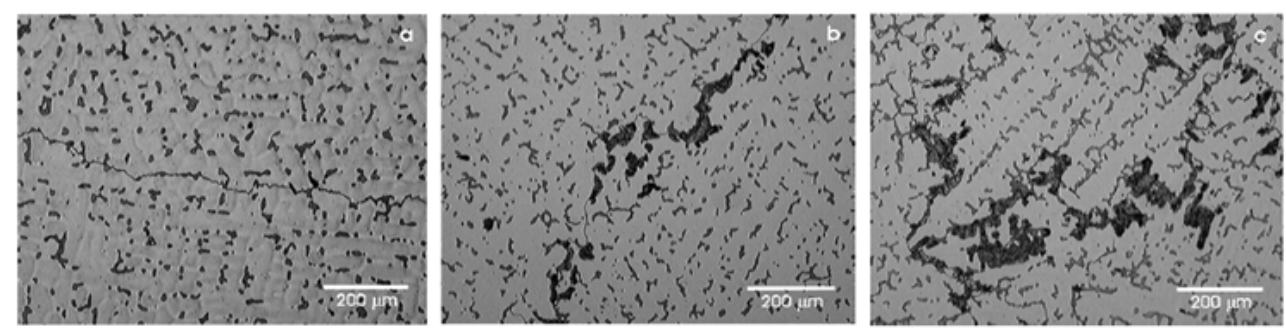

Figure 2.3. ASTM F75 As-cast microstructure with increasing amounts of carbon content. (a) 0.26 wt. $\%$ C (b) 0.36 wt. $\%$ C (c) 0.45 wt. $\%$ C

ASTM F-75 standards require a minimum ultimate tensile limit (UTS) of 655 $\mathrm{MPa}$, a yield strength (YS) of $450 \mathrm{MPa}$, and $8 \%$ elongation. Carbide precipitation represents the primary strengthening mechanism in the as-cast state[24]. Along with the brittle sigma phase, these carbides are also responsible for the relatively low mechanical properties seen in the as-cast state[19, 25].

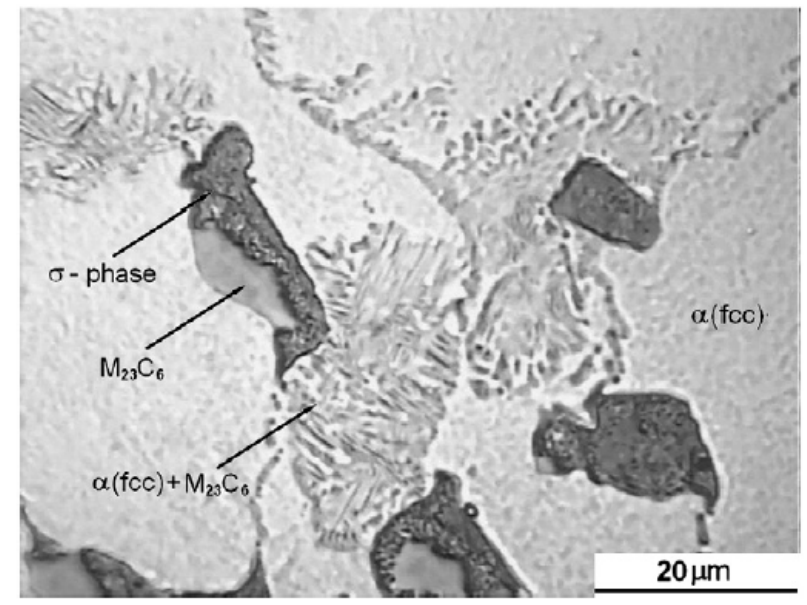

Figure 2.4. Microstructural phases visible in as-cast $\mathrm{Co}-\mathrm{Cr}$ revealed by etching. 


\subsubsection{Hot-Isostatic Pressing}

Hot isostatic pressing (HIP) and solution treatment (ST) are commonly applied to as-cast $\mathrm{Co}-\mathrm{Cr}$ to improve ductility, fatigue strength, reduce microporosity, and homogenize microstructural features[26, 27]. Partial carbide dissolution improves ductility and fatigue strength, properties of particular importance in the femoral-stem component[25].The hot isostatic pressing process can vary by manufacturer and exact parameters are unknown, but generally occur near $1200^{\circ} \mathrm{C}$, within the solidus temperature, and at pressures of $103 \mathrm{MPa}$ for a period totaling 4 hours $[18,27]$. This temperature is sufficiently close to the solidus point to start the diffusion of $\mathrm{Cr}$ and $\mathrm{Mo}$ from the carbides into the FCC matrix and carbon into the interstitial spaces of the lattice. Due to technical limitations, HIP requires slow cooling, which allowing carbides to reprecipitate, although not in the original as-cast morphology. Instead, carbides reform at the grain boundaries. The goal for the HIP treatment is primarily to reduce the porosity throughout the casting and on the surface, thereby improving surface roughness and overall fatigue strength. Despite the reduced porosity, HIP alone reduces overall mechanical properties as compared to the as-cast state[26].

\subsubsection{Solution Heat Treatment}

HIP is usually followed by a solution heat treatment, with a similar heat profile, i.e. $1200^{\circ} \mathrm{C}$ for 4 hours, except with a rapid quench to $800^{\circ} \mathrm{C}$ in less than 8 minute and without the high pressures. The rapid quench kinetically restricts carbide reprecipitation, the result of which is a dramatic reduction in second phases visible and a homogenized microstructure $[18,25]$. The relationship between carbide phase and heat treatment time is 
described by the Larson-Miller parameter. Further solution treatments cycles can dramatically reduce carbide phase fraction, resulting in a finely dispersed carbide morphology. This reduction dramatically improves mechanical properties such fatigue and ductility[25]. However, these improvements come at the expense of wear resistance and hardness, likely due to the reduction in hard matrix protecting phases and less mechanically supported carbides that are more susceptible to extraction[18]. Solution treatment beyond $1300^{\circ} \mathrm{C}$ has been shown to lead to carbide incipient melting, carbide fusion, and their resolidification as brittle $\sigma$ phase and M6C carbides[22, 27]. Given the narrow temperature range throughout which the desired carbide dissolution takes place, achieving the desired mechanical properties is challenging as it requires precise control of all the process variables.

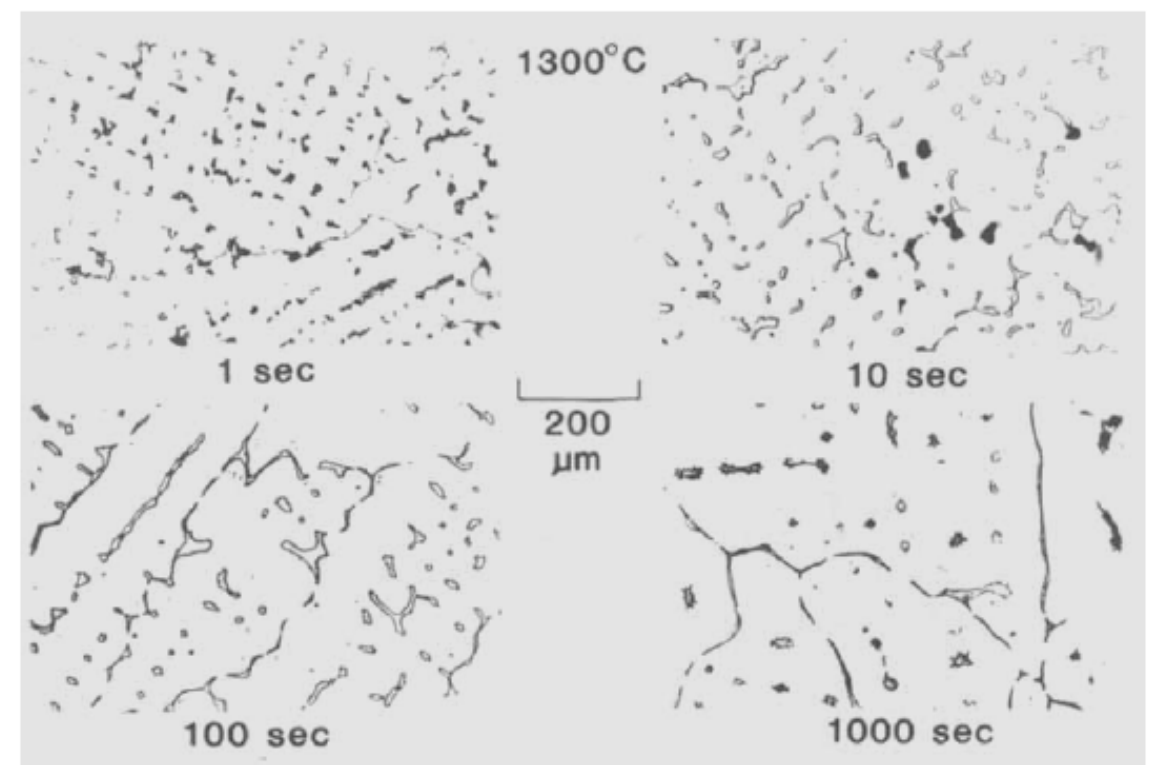

Figure 2.5: Melting of interdendritic material in $\mathrm{Co}-\mathrm{Cr}$ during short heat treatments at $1300^{\circ} \mathrm{C}$.[22] 

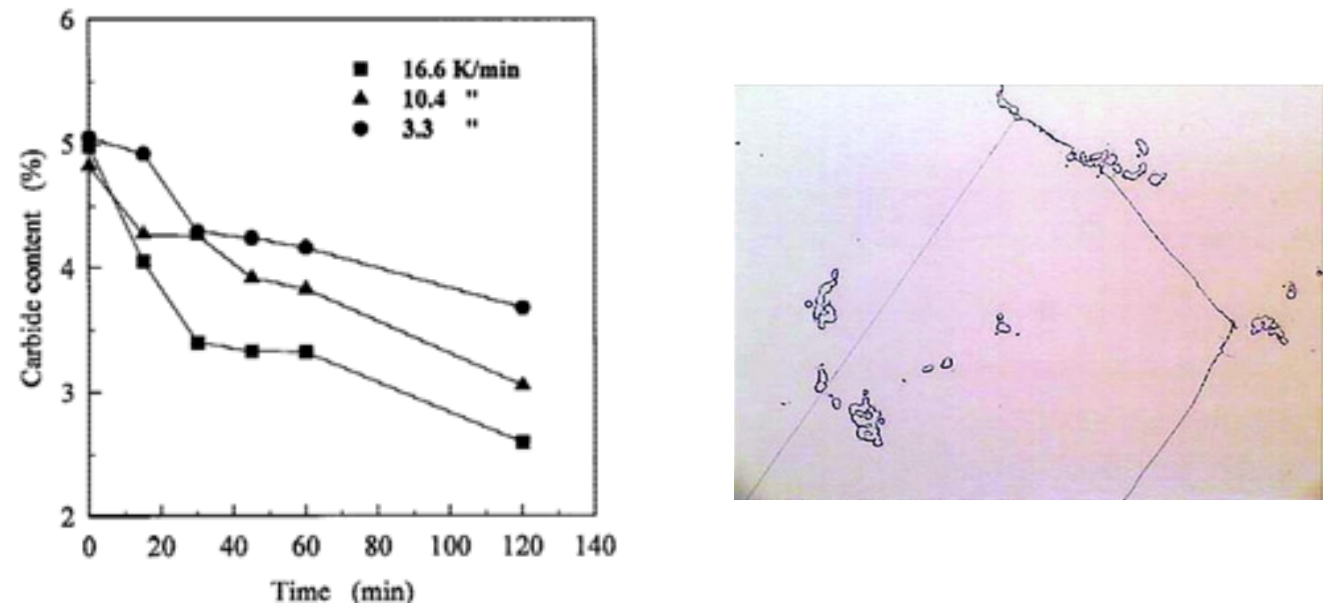

Figure 2.6. (Left) Solution treated cast $\mathrm{Co}-\mathrm{Cr}$ microstructure showing fine and dispersed second phases. (Right) Carbide content dissolution during solution treatment throughout time and at different cooling rates.

Solution treatments with rapid quenching result in nearly 100\% FCC phase fraction due to the sluggish transformation of FCC to HCP [28]. The as-cast condition typically displays less than $5 \%$ HCP. Slow cooling after solution treatment has a marked effect on the amount of complex carbides visible within the grain boundaries. The grain boundary constituents are slightly richer in $\mathrm{Cr}$ and Mo than the Co matrix due to the slow diffusivity of $\mathrm{Cr}$ and $\mathrm{Mo}$ in the FCC matrix. The intragranular carbides that remain are generally poor in Co and high in Mo. 

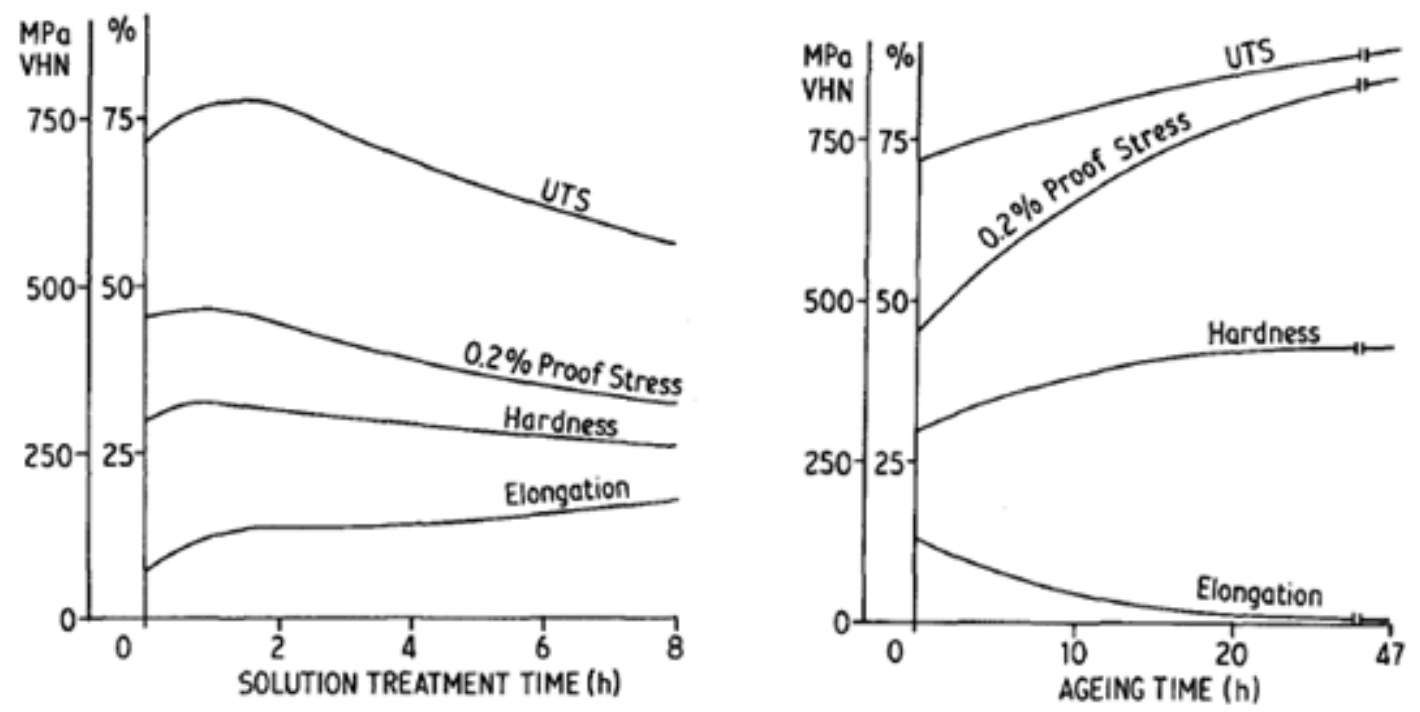

Figure 2.7. Mechanical properties with increasing solution treatment time.[24]

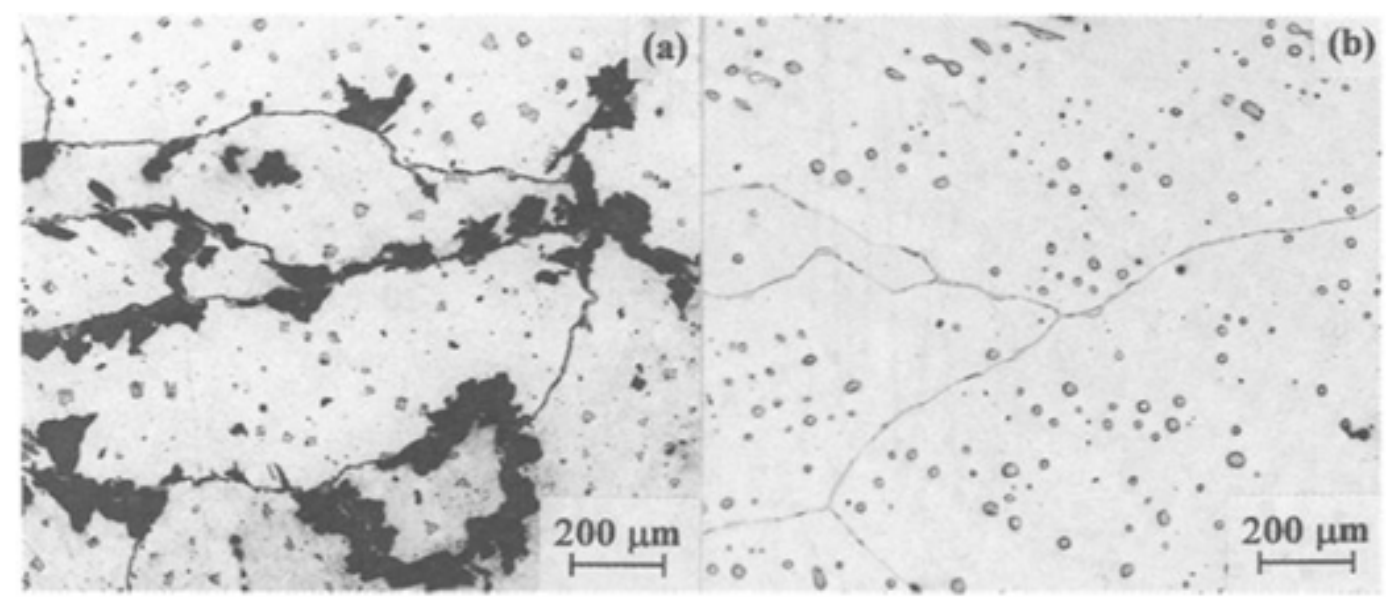

Figure 2.8. Microstructure of $\mathrm{HIP}+\mathrm{ST}$ cast alloy at $1250^{\circ} \mathrm{C}$. (a) furnace cooled (b) quenched. [24]

Table 2.1 Typical beam fatigue strength of ASTM $75 \mathrm{Co}-\mathrm{Cr}$ alloy by heat treatment

\begin{tabular}{|c|c|}
\hline Condition & Fatigue Strength at $\mathbf{1 0}^{\mathbf{7}}$ Cycles \\
\hline As Cast & $345-480$ \\
\hline Solution Treated (ST) & $380-450$ \\
\hline Sintered & $210-275$ \\
\hline Sintered + HIP + ST & $345-380$ \\
\hline
\end{tabular}


Table 2.2. Mechanical properties of cast Co-Cr-Mo by processing route

\begin{tabular}{|c|c|c|c|c|}
\hline Condition & $\begin{array}{c}\text { UTS } \\
\text { (MPa) }\end{array}$ & $\begin{array}{c}\mathbf{0 . 2 \%} \\
\text { YS(MPa) }\end{array}$ & El. (\%) & RA (\%) \\
\hline As Cast & 731 & 559 & 9.3 & 12.0 \\
\hline Solution Treated (ST) & 842 & 531 & 17.3 & 16.5 \\
\hline Sintered & 787 & 524 & 12.3 & 11.9 \\
\hline Sintered + HIP + ST & 752 & 508 & 16.4 & 13.6 \\
\hline
\end{tabular}

\subsection{Wrought Processing}

While cast Co-Cr offers the advantage of near net-shape processing, the resulting mechanical properties are far from ideal. The development of wrought $\mathrm{Co}-\mathrm{Cr}$ provided improved elasticity and mechanical strength, and significantly increased bulk hardness. Wrought alloy production begins in a similar manner to casting with vacuum induction melting (VIM) of the primary alloy components. VIM is followed by the electroslag method to improve ingot cleanliness and structure. The ingots are then homogenized at $1250^{\circ} \mathrm{C}$ for 5 hours (similar to the solution treatment seen with cast $\mathrm{Co}-\mathrm{Cr}$ ). The key distinction between the casting and wrought production paths is the forging that follows solution treatment. After ingots are homogenized, they are forged into a reroll billet and rolled to final size. This is followed by a precisely controlled warm/hot working or annealing step which determines the alloy's final properties[29].

The primary strengthening mechanism in wrought $\mathrm{Co}-\mathrm{Cr}$ is stored strain energy from deformation and its fine grain size, as predicted by the Hall-Petch relationship. This differs from cast $\mathrm{Co}-\mathrm{Cr}$ where carbide precipitation is the primary strengthener. As explained in the next section, wrought Co-Cr's dependence on stored strain energy precludes it from the high temperatures required for applying porous coatings without resulting dramatic reductions in all mechanical properties. Otherwise, wrought $\mathrm{Co}-\mathrm{Cr}$ 
conforming to ASTM F1537, has at a minimum a yield strength of $827 \mathrm{MPa}$, nearly twice the requirement for as-cast $\mathrm{Co}-\mathrm{Cr}$, and a 50\% higher elongation and significantly higher hardness. Cold working can further increase strength at the expense of reduced elongation.[29]

Wrought Co-Cr is produced in two compositions, namely low carbon $(<.15 \% \mathrm{wt}$. C) and high carbon ( $\sim .35 \%$ wt. C). While both varieties satisfy the mechanical requirements of ASTM F1537 and significantly exceed as-cast Co-Cr performance, the high carbon version has improved wear properties at the expense of lower ductility due to grain boundary carbide precipitation[29-31].

Both $\mathrm{HC}$ and LC versions have similar microstructures, with uniform and equiaxed grain structure, and grains sizes between 11 and 5 microns. The matrix is a metastable FCC crystal structure. The most significant difference between the HC and LC microstructure is the presence of fine, $<3$ micron carbides at the grain boundaries seen in the $\mathrm{HC}$ wrought version[29, 31]. These fine carbides are predominantly chromium-rich M23C6. Occasionally large blocky chromium and molybdenum-rich particles are present at the grain boundaries. Carbides are noticeably absent from LC wrought Co-Cr microstructure[29]. 
Table 2.3. Minimum mechanical properties for cast, forged, and wrought Co-Cr-Mo alloys as specified by ASTM standards [24]

\begin{tabular}{|c|c|c|c|c|c|}
\hline Condition & $\begin{array}{c}\text { ASTM } \\
\text { Standard }\end{array}$ & $\begin{array}{c}\text { Yield } \\
\text { Strength } \\
\text { (MPa) }\end{array}$ & $\begin{array}{c}\text { Ultimate } \\
\text { Tensile } \\
\text { Strength } \\
\text { (MPa) }\end{array}$ & $\begin{array}{c}\text { El. } \\
(\%)\end{array}$ & $\begin{array}{c}\text { HRC } \\
\text { Typical }\end{array}$ \\
\hline Casting & F75 & 450 & 655 & 8 & N/A \\
\hline Forged & F799 & 827 & 1172 & 12 & 35 \\
\hline $\begin{array}{c}\text { Wrought and } \\
\text { annealed }\end{array}$ & F1537 & 517 & 897 & 20 & 25 \\
\hline $\begin{array}{c}\text { Wrought and } \\
\text { hot-worked }\end{array}$ & F1537 & 700 & 1000 & 12 & 28 \\
\hline $\begin{array}{c}\text { Wrought warm- } \\
\text { worked }\end{array}$ & F1537 & 827 & 1172 & 12 & 35 \\
\hline
\end{tabular}

\subsection{Porous Coating Application}

The application of a porous coating to the femoral stem is sought by manufacturers in order to promote osseointegration and reduce aseptic loosening. However, the high temperatures required for bead sintering or plasma coating are sufficient to significantly degrade the mechanical and microstructural properties of CoCr. In the case of solution treated cast $\mathrm{Co}-\mathrm{Cr}$, care must be taken to avoid undoing the advantages offered by solution treatment i.e. reprecipitating the various second phases and inducing further grain growth[32]. The work strengthened nature of wrought $\mathrm{Co}-\mathrm{Cr}$ means that the exposure to the high temperatures required for the coating application will release all the stored deformation energy, negating the advantages provided by wrought processing[20,33].

The cobalt-carbon phase diagram demonstrates that as carbon is increased, the amount of liquid phase available for bonding during sintering increases (Figure 2.9). 
Therefore in theory, increasing the carbon content of Co-Cr castings can allow for lower coating sintering temperatures. Interstitial carbon also serves to pin the grain boundaries, inhibiting further grain growth. Despite the significant performance improvements offered by wrought $\mathrm{Co}-\mathrm{Cr}$, cast processing is generally the only $\mathrm{Co}-\mathrm{Cr}$ processing route suitable for porous coating applications[20].

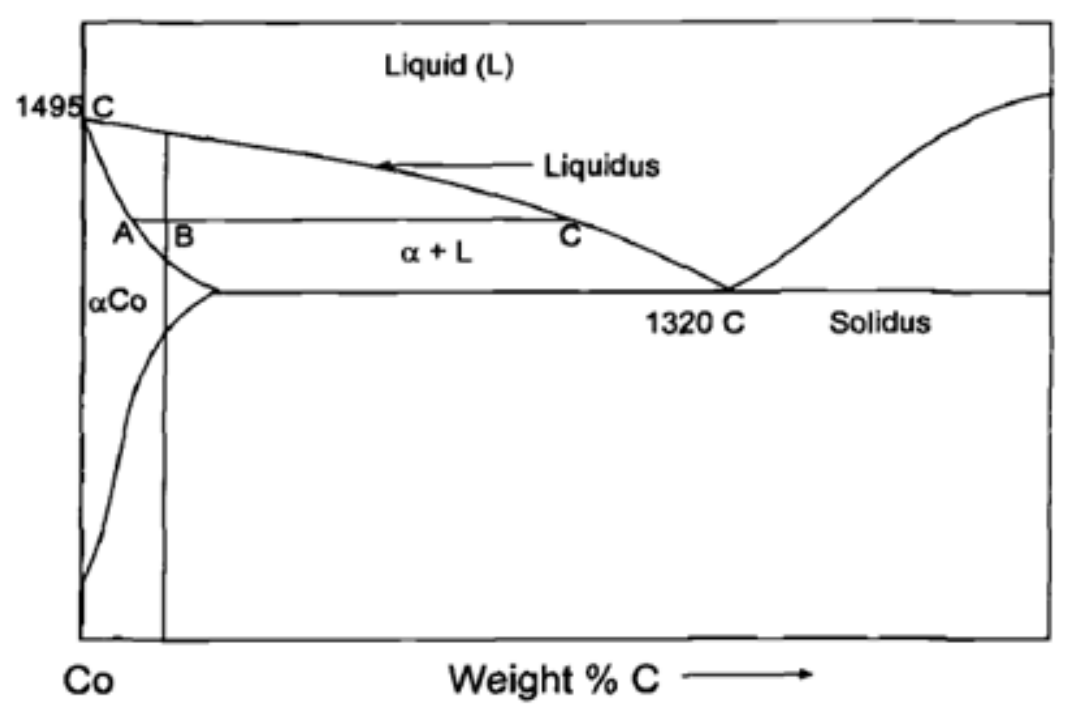

Figure 2.9. Cobalt-Carbon phase diagram illustrating the lever rule principle that dictates the fraction $\mathrm{AB} / \mathrm{AC}$ of the constituent phases which will be liquid at the sintering temperature $\mathrm{AC}$. i.e. an increase in carbon content will decrease the temperature required for adhering porous coatings. [29] 


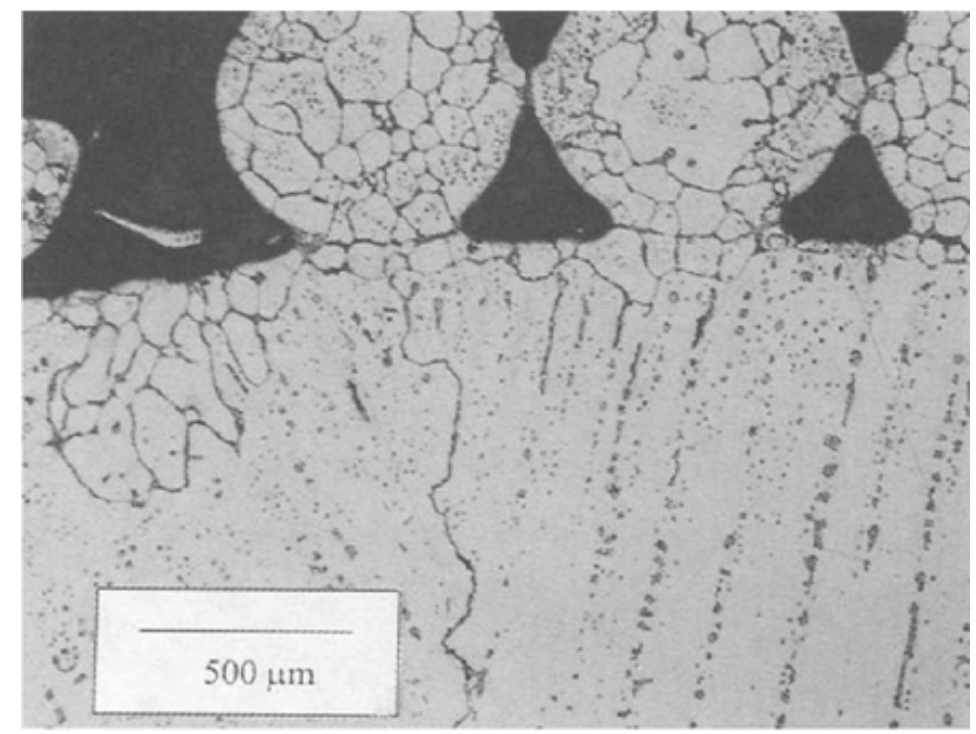

Figure 2.10. Porous coated as-cast cobalt-chrome stem. [29]

\section{Titanium-6Aluminum-4Vanadium Processing, Microstructural Evolution \& Properties}

Titanium-6aluminum-4vanadium has seen increasing adoption as the material of choice for the femoral stem component due to its elastic modulus of $110 \mathrm{GPa}$, half the modulus seen in Co-Cr alloys. The lower elastic modulus is preferred for its role in reducing stress shielding at the stem-bone interface, the primary cause of aseptic loosening. While Ti-6Al-4V retains very high tensile strength and fatigue strength, its poor shear strength and tendency to gall has for the most part precluded its use in bearing surface materials[34].

As a widely used alloy in the aerospace industry, Ti-6Al-4V processing, microstructure and mechanical properties are well understood and thoroughly standardized. Ti-6Al-4V is known as a alpha + beta alloy, in that both the HCP and the 
BCC phases are present. The presence of the ductile alpha phase and the less ductile but stronger metastable beta phase is enabled by the addition of phase stabilizers, aluminum and the vanadium, respectively. However, the exact amount of alpha and beta phases ultimately present and their microstructural morphology is largely a function of processing parameters. While grain size and shape play a role, the mechanical properties found in these alloys are mostly determined by alpha and beta crystal structure transformations. The added aluminum is distributed approximately equally between the alpha and beta phases and is not prone to segregation, as is seen with Co-Cr. Vanadium is beta isomorphous with bcc titanium and does not form intermetallic compounds. The trace amounts of carbon, oxygen and nitrogen remain as interstitial elements and serve to stabilize the alpha phase

A wide variety of microstructures can be generated in Ti- $6 \mathrm{Al}-4 \mathrm{~V}$ by careful control of thermomechanical process parameters. As seen in Figure 2.11, the two key factors is the highest temperature achieved beyond the beta-transus temperature and the rate of cooling that follows. The alpha phase present at the time of cooling can remain relatively equiaxed (globular with equal axis). Any beta phase transformed to alpha or martensite upon cooling from above the beta-transus is referred to as transformed beta. This transformed beta can be very acicular or elongated. The amount of equiaxed alpha and the coarseness or fineness of the transformed beta products affect mechanical properties.

Beta is transformed by a diffusionless or martensitic transformation. This transformation results in to two forms of martensite, namely $\alpha^{\prime}$ and $\alpha^{\prime \prime} . \alpha^{\prime}$ has an HCP crystal structure and appears as an acicular phase, similar in appearance to acicular 
alpha. The second martensite is the $\alpha^{\prime \prime}$ with an orthorhombic crystal structure. Upon aging $\alpha^{\prime}$ and $\alpha^{\prime \prime}$ transform to alpha and beta phases. Some degree of beta is necessary for strengthening by solution treatment and aging.

Table 2.4. Advantages provided by the various microstructural features seen in Ti-6Al-4V. [31]

\begin{tabular}{|c|l|}
\hline Microstructure & \multicolumn{1}{c|}{ Advantage } \\
\hline \multirow{3}{*}{ Equiaxed } & Higher Ductility and formability \\
\cline { 2 - 2 } & Higher strength (for equivalent heat treatment) \\
\cline { 2 - 2 } & Better hydrogen tolerance \\
\cline { 2 - 2 } & Better low-cycle fatigue (initiation) properties \\
\hline \multirow{2}{*}{ Acicular } & Superior creep properties \\
\cline { 2 - 2 } & Higher fracture toughness values \\
\hline
\end{tabular}




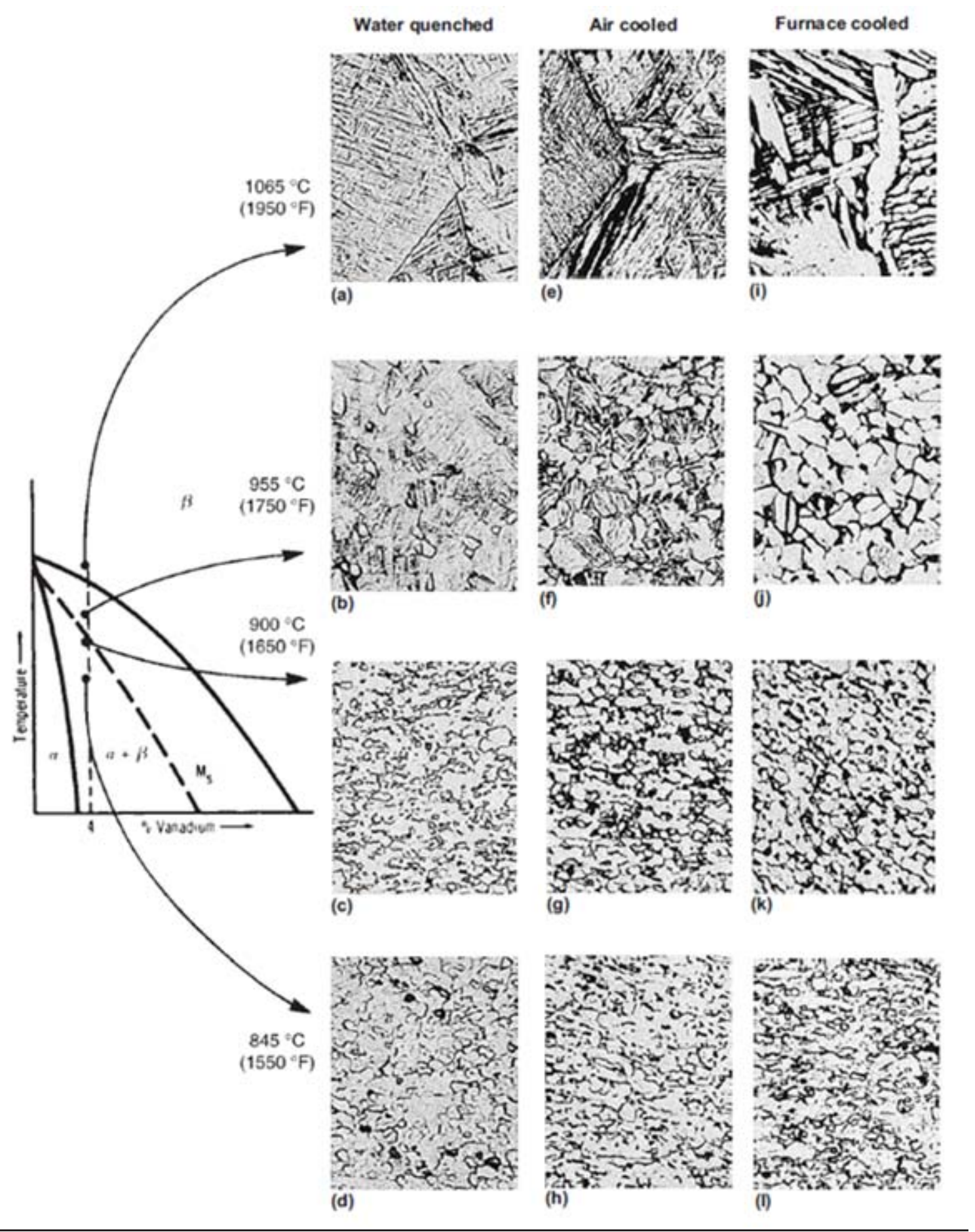

Figure 2.11. Effect of maximum heating temperature and subsequent cooling rate on Ti-6Al-4V microstructures.[31] 
Solution treatment followed by aging can increase Ti-6Al-4V strength by 30 to $50 \%$. Generally solution treatments take place at temperatures within the alpha-beta field and are followed by quenching and aging. However, achieving sufficiently rapid quenching and the desired strength improvements are often difficult to achieve unless section sizes are small. Water quenching is not rapid enough to significantly harden sections thicker than about 1 in and larger sections will result in a non-uniform transformation. Other heat treatments can be selected based on specific needs, as seen in Tables 2.5 and 2.6. For example, mill annealing, is chosen for its ability to produce a relatively soft and machinable work piece that still retains high tensile strength.

Table 2.5. Effect of heat treatments on Ti-6Al-4V microstructure. [31]

\begin{tabular}{|l|l|}
\hline Heat treatment designation & Resulting Microstructure \\
\hline Duplex anneal & Primary $\alpha$, plus widmanstätten $\alpha$ - $\beta$ regions \\
\hline $\begin{array}{l}\text { Solution treatment and } \\
\text { ageing }\end{array}$ & Primary $\alpha$, plus tempered $\alpha^{\prime}$ or a $\beta$ mixture \\
\hline Beta anneal & Widmanstätten $\alpha$ - $\beta$ colony microstructure \\
\hline Beta quench & Tempered $\alpha^{\prime}$ \\
\hline Recrystallization anneal & $\begin{array}{l}\text { Equiaxed } \alpha \text { with } \beta \text { at grain-boundary triple } \\
\text { points }\end{array}$ \\
\hline Mill anneal & $\begin{array}{l}\text { Incompletely recrystallized } \alpha \text { with a small } \\
\text { volume fraction of small } \beta \text { particles }\end{array}$ \\
\hline
\end{tabular}

Table 2.6. Effect of heat treatments on Ti-6Al-4V mechanical properties. [31]

\begin{tabular}{|c|c|c|c|c|c|}
\hline \multirow[b]{2}{*}{ Condition } & \multicolumn{2}{|c|}{$\begin{array}{c}\text { Yield } \\
\text { strength }\end{array}$} & \multicolumn{2}{|c|}{$\begin{array}{l}\text { Tensile } \\
\text { strength }\end{array}$} & \multirow{2}{*}{$\begin{array}{c}\text { Elongation } \\
\text { at fracture, } \\
\% \\
\end{array}$} \\
\hline & MPa & ksi & MPa & ksi & \\
\hline Mill annealed & 945 & 137 & 1069 & 155 & 10 \\
\hline Duplex annealed & 917 & 133 & 965 & 140 & 18 \\
\hline $\begin{array}{l}\text { Solution treated } \\
\text { and aged }\end{array}$ & 1103 & 160 & 1151 & 167 & 13 \\
\hline
\end{tabular}


If high fracture toughness is a priority, low oxygen and nitrogen as in Ti-6Al-4VELI (ASTM F-136) should be considered. Highly transformed microstructures which provide tortuous crack paths demonstrate the highest fracture toughness. Likewise, recrystallization-annealed structures, with equiaxed grain structures composed of regrowth alpha also improve fracture toughness, although not to the extent seen with transformed structures (See Table 2.7).

Table 2.7. Fracture toughness values for equiaxed and highly transformed microstructures.[31]

\begin{tabular}{|c|c|c|c|}
\hline Alloy & $\begin{array}{c}\text { Alpha } \\
\text { Morphology }\end{array}$ & $\begin{array}{c}\text { Yield } \\
\text { Strength } \\
(\mathbf{M P a})\end{array}$ & $\begin{array}{c}\text { Fracture } \\
\text { Toughness } \\
(\mathbf{M P a} \sqrt{\boldsymbol{m}})\end{array}$ \\
\hline Ti-6Al-4V & Equiaxed & 910 & $44-66$ \\
\hline & Transformed & 875 & $88-110$ \\
\hline
\end{tabular}

Table 2.8. Ti-6Al-4V ASTM mechanical and compositional requirements.[31]

\begin{tabular}{|c|c|c|c|c|}
\hline $\begin{array}{c}\text { ASTM } \\
\quad \#\end{array}$ & Description & $\begin{array}{l}\text { Microstructure/Special } \\
\text { Requirements }\end{array}$ & $\begin{array}{l}\text { Interstitial } \\
\text { Tolerances } \\
\text { (Max) }\end{array}$ & Mechanical Requirements \\
\hline F-136 & $\begin{array}{l}\text { Wrought Ti- } \\
6 \mathrm{Al}-4 \mathrm{~V} \text { ELI } \\
\text { (Extra Low } \\
\text { Interstitial) }\end{array}$ & $\begin{array}{l}\text { Fine dispersion of alpha and } \\
\text { beta phases. No continuous } \\
\text { alpha network at prior beta } \\
\text { grain boundaries. } \\
\text { No coarse, elongated alpha } \\
\text { platelets. }\end{array}$ & $\begin{array}{l}\text { Carbon:..08\% } \\
\text { Hydrogen: } \\
.012 \% \\
\text { Iron: .25\% } \\
\text { Oxygen: .13\% }\end{array}$ & $\begin{array}{l}\text { Tensile Strength (Min) :825- } \\
860 \mathrm{MPa} \\
\text { Yield Strength }(.2 \% \text { Offset) } \\
\text { Min, } \mathrm{MPa}: 760-790 \mathrm{MPa} \\
\text { Elongation: } 10-8\end{array}$ \\
\hline F-1108 & $\begin{array}{l}\text { Ti-6Al-4V } \\
\text { Castings }\end{array}$ & $\begin{array}{l}\text { Fine dispersion of alpha and } \\
\text { beta phases. No continuous } \\
\text { alpha network at prior beta } \\
\text { grain boundaries. } \\
\text { No coarse, elongated alpha } \\
\text { platelets. }\end{array}$ & $\begin{array}{l}\text { Carbon:. } 1 \% \\
\text { Hydrogen: } .015 \% \\
\text { Iron: .30\% } \\
\text { Oxygen: } .20 \%\end{array}$ & $\begin{array}{l}\text { Tensile Strength (Min) :860 } \\
\mathrm{MPa} \\
\text { Yield Strength (.2\% Offset) } \\
\text { Min, MPa: } 758 \mathrm{MPa} \\
\text { Elongation: } 8\end{array}$ \\
\hline F-1472 & $\begin{array}{l}\text { Wrought Ti- } \\
6 \mathrm{Al}-4 \mathrm{~V}\end{array}$ & $\begin{array}{l}\text { Fine dispersion of alpha and } \\
\text { beta phases. No continuous } \\
\text { alpha network at prior beta } \\
\text { grain boundaries. } \\
\text { No coarse, elongated alpha } \\
\text { platelets. }\end{array}$ & $\begin{array}{l}\text { Carbon:..08\% } \\
\text { Hydrogen: } \\
.015 \% \\
\text { Iron: } .30 \% \\
\text { Oxygen: } .20 \% \\
\text { Yttrium: } 005 \%\end{array}$ & $\begin{array}{l}\text { (Bars and Forging) } \\
\text { Tensile Strength (Min) :895- } \\
930 \mathrm{MPa} \\
\text { Yield Strength (.2\% Offset) } \\
\text { Min, MPa: } 825-869 \mathrm{MPa} \\
\text { Elongation: } 10\end{array}$ \\
\hline
\end{tabular}




\section{$\underline{\text { 3. Modular Total Hip Prosthesis Design }}$}

\subsection{Morse Taper}

The overwhelming majority of total hip prosthesis manufacturers have adopted the "morse taper" design for affixing the femoral head to the trunnion. This design consists of self-holding male and female tapers wedged together by impaction at the time of surgery[35]. The impaction firmly seats the femoral head onto the trunnion, providing frictional resistance to any moment or force that might tend to rotate or axially dislodge the femoral head during gait. Prosthesis taper angles generally vary from 4 to 6 degrees and have variable contact lengths, depending on the manufacturer and product model[3537]. As such, femoral heads from one manufacturer are generally not compatible with the trunnion taper of another manufacturer, unless otherwise specified[38]. The taper surface finish can also vary; some models have a smooth finish while others have a rough screwlike finish of varying pitch and depth.[36, 38].

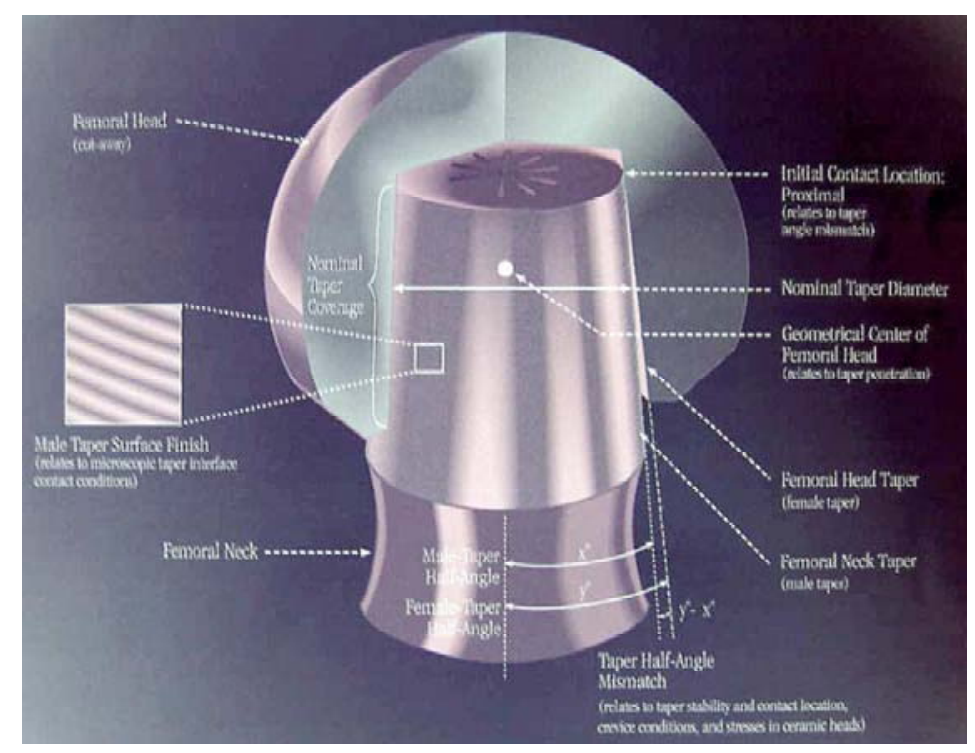

Figure 2.12. Morse Taper Parameters and Surface Finish 


\subsection{Neck and Taper Diameter}

Small increases in taper and neck diameters have been shown to reduce taper fretting by increasing neck rigidity $[39,40]$. This follows from basic mechanics where the bending stress and strain in a cylindrical cantilever increase inversely with the third power of the neck diameter, as shown in the following relationship, where $M$ is the applied bending moment, $\mathrm{E}$ is elastic modulus, $\mathrm{r}$ is the neck/taper radius:

$$
\varepsilon_{\max }=\frac{4 M}{E \pi r^{3}}
$$

It also follows that low modulus alloys such as Ti-6Al-4V will experience twice the stress and strain as $\mathrm{Co}-\mathrm{Cr}$ for the same neck diameter.

\subsection{Trunnion-Head Interface Parameters}

Manufacturers must balance the mechanical factors favoring larger neck diameters versusthe need to reduce impingement andincrease the range of motion[41]. To this end,various design features have been introduced to increase range of motion without reducing overall neck diameter, such as flattened neck-taper regions and "mini tapers" with reduced taper contact area[37, 42]. It is not clear whether the reduced contact area associated with mini-tapers decreases wear by decreasing the surface area available for fretting damage or increases wear by increasing contact pressure[37, 42, 43]. While any factor that controls contact pressure and the propensity for micromotion can indirectly influence corrosion through tribological mechanisms, features such as flat taper regions and taper roughness can control corrosion rates directly by affecting the rate of fluid 
transfer into the head-trunnion interface and by creating corrosion prone crevices $[40,43$, 44].
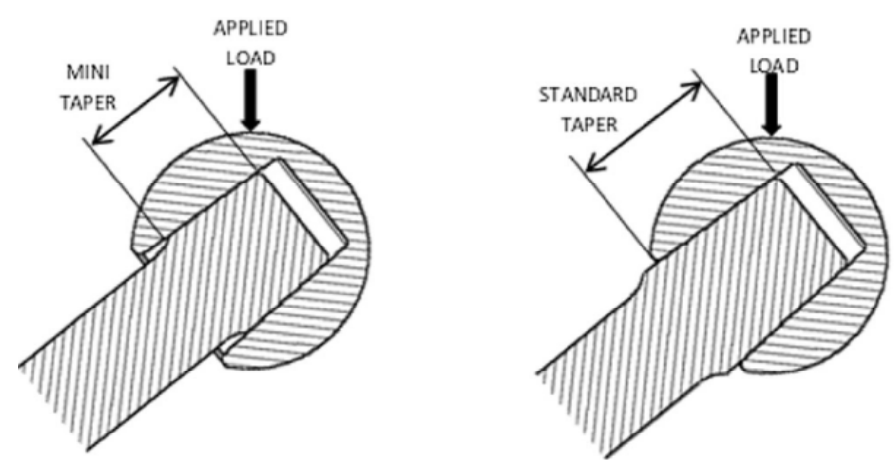

Figure 2.13. Mini morse taper with reduced contact area. [42]

Various other geometric design variables can affect the stress borne by the headtrunnion taper interface. While overall prosthesis dimensions need to be matched to the patient in order to ensure natural joint biomechanics, with modular prostheses there is more flexibility in how these dimensions are achieved. For example, given a femoral stem with a fixed trunnion length, overall neck length can be controlled simply by varying the trunnion-head offset (i.e. less head bore penetration) and to some extent head diameters. The primary disadvantage associated with longer trunnion-head offset is the increased moment arm from the center of the head to the end of the neck, thereby increasing taper stress and the potential for fretting $[39,45]$. All else equal, patient neck length and medial-lateral (ML) offset requirements need not determine the stresses at the trunnion-head interface, provided that femoral stems with the necessary trunnion lengths are available. However, acursory review of currently available prosthesis options indicates that manufacturers generally offer limited femoral trunnion length options (i.e. 
Standard and Extended). Instead, manufacturers meet the various neck length requirementsby increasing or decreasing the trunnion-head offset as needed[41]. Trunnion-head offsets are often long enough as to necessitate the presence of "skirts" in order to allow for the reduced head penetration without also reducing taper contact surface area (Figure 2.15)[45].

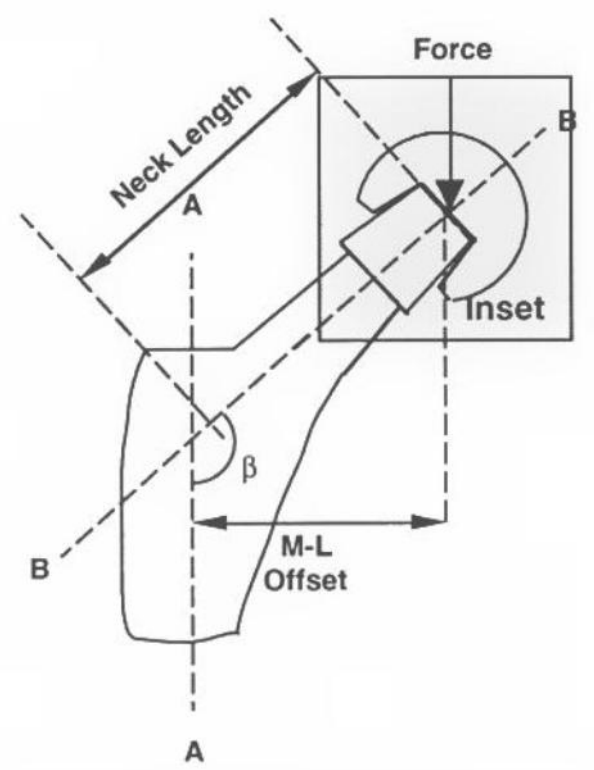

Figure 2.14. Prostheses neck angle, medial-lateral offset, and neck length [39]

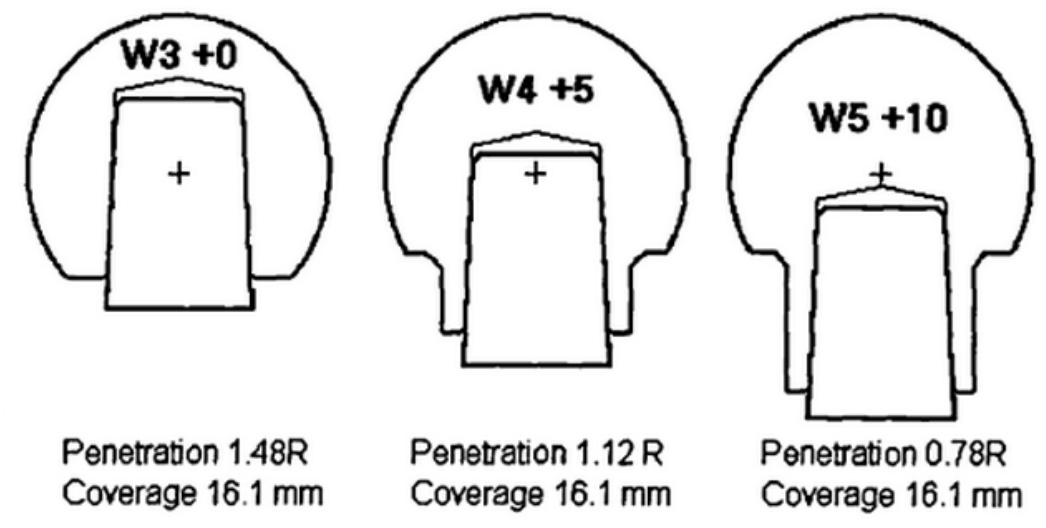

Figure 2.15. Skirted and non-skirted heads with various penetration and coverage [42] 


\subsection{Femoral Head Size}

Large diameter femoral heads $(>32 \mathrm{~mm})$ have seen increased adoption in recent years. It is well established that larger head diameters reduce impingement (contact between the metal femoral neck and the acetabular cup liner), increases the range of motion[41], improves stability and enhances the hydrodynamics of bearing surface lubrication $[9,17,46]$. However, numerous studies have raised concern with the added trunnion stress associated with larger heads and their role in increased wear at the trunnion-head interface as a result of longer moment arm and the increased frictional torque originating at the bearing surface[46, 47].

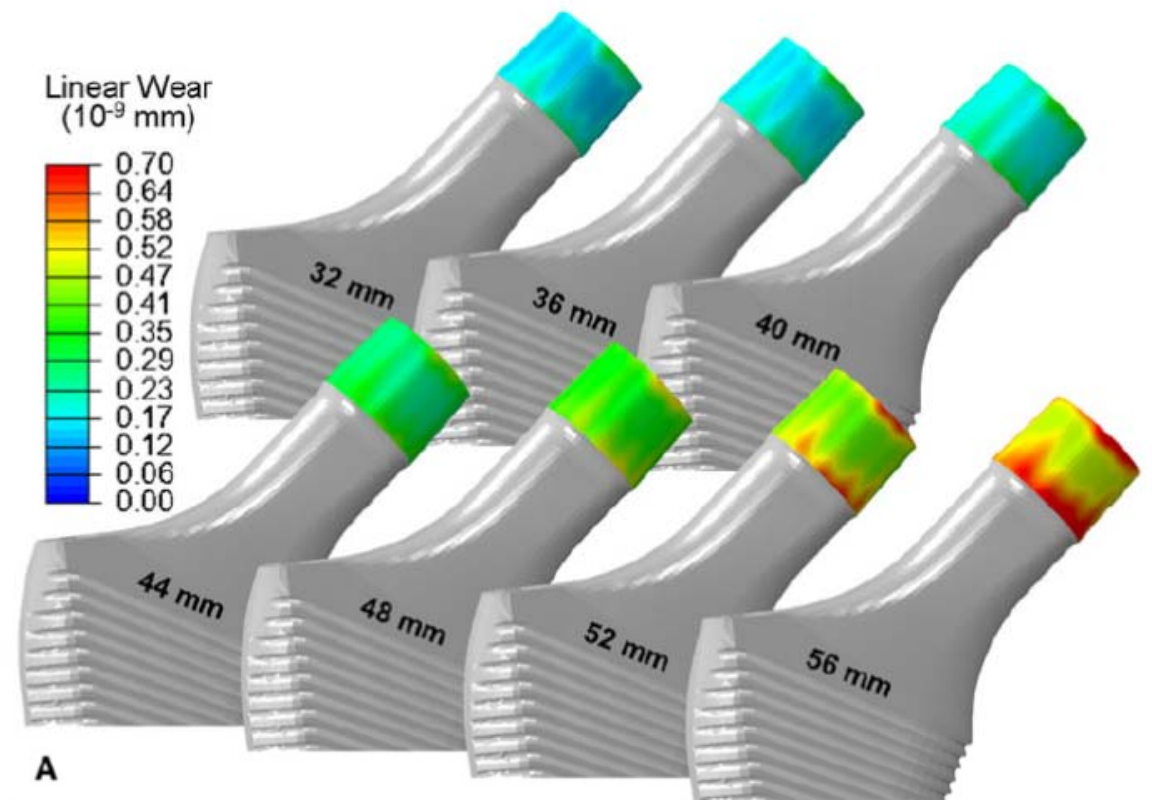

Figure 2.16. Finite element analysis predicting greater wear at the trunnion surface as femoral head is increased from $32 \mathrm{~mm}$ to $56 \mathrm{~mm}$.[46] 


\section{Fretting Wear}

Fretting is a type of surface damage caused by low-amplitude oscillatory sliding between two contacting surfaces[48]. Although the trunnion and head tapers junction is designed for maximal fixation, there is inevitably some degree of micromotion that results from microscopically imperfect mating surfaces. Fretting is distinct from the wear damage that occurs during reciprocating sliding, such as with the femoral head sliding on the acetabular cup. The upper limit on the displacement amplitude demarcating fretting associated motion from sliding wear is difficult to define exactly, but is generally accepted to lie in the range of $150-300 \mu \mathrm{m}[49-51]$. It has been shown that fretting damage can occur for displacement amplitudes as low as $1 \mu \mathrm{m}$ [52]. While the distinction between low and high amplitude surface sliding might appear superficial, the electrochemical and mechanics belying the resulting surface damage are distinct. In the case of fretting, the contacting surfaces are confined and not in contact with ambient atmosphere or bodily fluids. As a result, wear debris and gases released during corrosive processes are never released[51]. While the protective oxide films are partially ruptured at both the head bearing surface and the taper surfaces during motion, the limited oxygen found in the trapped cavities of the taper prevent the abraded surfaces from reoxidizing. As residual oxygen is consumed within these confined areas, there is a dramatic drop in $\mathrm{pH}$, ultimately leading to further passivation breakdown and corrosion[12, 53]. 


\begin{tabular}{|l|}
\hline Contact Conditions \\
Load \\
Amplitude \\
Frequency \\
Duration (e. g. no. of cycles) \\
Geometry \\
\hline
\end{tabular}

Environmental Conditions

Temperature

Humidity

Chemical potential

Lubricant

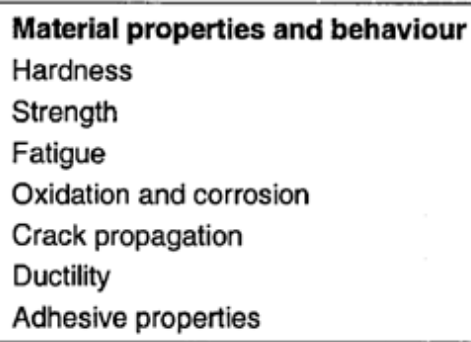

Figure 2.17. Material, contact conditions and environmental variables governing potential for fretting wear.

The primary parameters governing the potential for fretting damage are coefficient of friction, contact pressure, and the extent of the slip area at the opposing interfaces[54]. The extent of the slip area is mostly determined by the precision with which the female and male tapers were machined. This slip area is not constant as it can increase as fretting progresses. Various parameters effect contact pressure indirectly, such as contact geometry, head-trunnion moment arm and patient specific variables such as weight and activity[55]. The response to the stress field at the interface, as determined by these primary and secondary parameters, depends on the material properties. Relative bulk and microhardness, thickness of oxide layers, surface roughness, surface workhardening, microstructure, elastic modulus, and plasticity, are all important factors in determining a materials susceptibility to fretting damage[54, 56, 57]. 


\section{Corrosion}

Corrosion plays a key role in increasing metal ion release and in degrading the mechanical integrity and performance of hip prostheses. In its most fundamental form, corrosion is an electrochemical process by which the atoms of a metal undergo oxidation, resulting in the formation of metal ions, which can subsequently form metal oxides, metal chlorides or organometallic compounds. These reaction products can remain adherent to the metal surface or form non-adherent compounds that precipitate out or remain in a soluble form. The electrons that are produced in the oxidation reaction must be consumed in a cathodic reaction such as the reduction of oxygen or water. Various corrosion mechanisms are possible and the exact mechanism depends on the nature of the corrosive environment. At the modular interfaces of hip prostheses, there is evidence for a variety of corrosive mechanisms and reactions at work at any one time[44].

\subsection{Passivation}

The exceptional corrosion resistance often attributed to titanium and cobaltchromium alloys results from the strongly adherent and inert metal-oxide layers that spontaneously form on their surface. The reaction leading to these passive films is itself an anodic reaction, albeit a favorable one, resulting in a kinetic barrier that prevents electron and ion transfer from occurring between the active metal surface and the environment. The formation and maintenance of these passive metal-oxides is contingent on the proper $\mathrm{pH}$, oxygen, electrode potential and mechanical stability. 


\subsection{Galvanic Corrosion}

\subsubsection{Mixed-Alloy Couples}

The coupling of dissimilar metals, as is the case with $\mathrm{Co}-\mathrm{Cr}$ on Ti-6Al-4V prostheses, presents the potential for an accelerated corrosion attack on the more noble member, amplified by the difference between their electrode potentials. In the case of titanium/cobalt-chrome couples, the standard EMF series potential for cobalt is $-.28 \mathrm{~V}$ and $-.33 \mathrm{~V}$ for titanium[58], an insufficient potential difference to drive the breakdown of the cobalt oxide layer, which requires a $400 \mathrm{mV}$ difference[44]. However, the potential difference between passivated cobalt and depassivated titanium has been reported by various groups to be between $600 \mathrm{mV}[44]$ and an astonishing $3.5 \mathrm{~V}[59]$, depending on the medium tested. A scenario where passivated cobalt exists alongside depassivated titanium is conceivable given the higher bulk hardness of $\mathrm{Co}-\mathrm{Cr}$ and the even harder carbides present in as-cast and $\mathrm{HC}$ wrought $\mathrm{Co}-\mathrm{Cr}[16]$. Through micromotion these carbide asperites are more than capable of disrupting the softer titanium oxide layer[60].

\subsubsection{Surface Area Effects}

Galvanic corrosion is amplified if the surface area of the cathodic metal is increased relative to the anodic metal's surface area[61]. This surface area effect on the anodic current density, $i_{a}$, is expressed as:

$$
i_{a}=\frac{S_{c}}{S_{a}} \times i_{c}
$$


where $\frac{S_{c}}{S_{a}}$ is the ratio of the cathodic surface area and the anodic surface area. In mixed couples, the cathodic titanium alloy is generally the femoral stem, which has a significantly larger surface area. The femoral stem surface area is significantly greater in the case of sintered porous coated stems where the surface area ratio can be as great as $13: 1[44]$.

\subsection{Sensitization Effect}

Inhomogeneities that result from material processing can create a state where different areas of the same metal surface acts as cathodes while nearby areas act as anodes[62]. As explained previously, during the solidification of cast $\mathrm{Co}-\mathrm{Cr}$, elements tend to segregate according to their melting points. The resulting carbides that form contain a higher weight percent of chromium and molybdenum than the surrounding matrix. These carbides have excellent corrosion resistance at the expense of the matrix which has been partially leached of its primary corrosion resistant additive, chromium[63]. This process, known as sensitization, causes the chromium deprived areas to become favorable sites for localized corrosion attack[32]. Although the primary purpose of $\mathrm{Co}-\mathrm{Cr}$ homogenizing solution treatments is to improve the poor mechanical properties seen in the as-cast state, the resulting microstructure homogenization has also been found by various groups to increase localized corrosion resistance.Ti-6Al-4V is not prone to sensitization-like effects as seen in $\mathrm{Co}-\mathrm{Cr}$. Unlike $\mathrm{Co}-\mathrm{Cr}$ where corrosion resistance is primarily provided by the oxide forming properties of chromium, the oxide in Ti-6Al-4V is provided by the base element titanium, which forms $\mathrm{TiO} 2$ [64]. 


\subsection{Pitting Corrosion}

Pitting corrosion is a highly localized form of corrosion that manifests itself as small pits on the surface of a metal and is often seen in retrieved metallic implants. Alloys which depend on passive oxide films for corrosive resistance are particularly vulnerable to pitting corrosion when in high chloride or sulfide containing environments. Ironically, pitting corrosion generally only occurs in areas that have chemical conditions favorable (high $\mathrm{pH}$ and oxygen) for oxide formation. Zones with depleted oxide films will generally undergo uniform corrosion attack, not pitting. Pitting corrosion is initiated by small surface defects such as scratches or inclusions that damage or restrict the formation of an otherwise intact protective oxide[62].

It's hypothesized that chloride is drawn by the positive metal ions that accumulate in nascent micropits. In the case of titanium, the immediate chemical product from this incursion is unstable titanium chloride, which then undergoes hydrolysis with water, forming metal hydroxide and hydrochloric acid[65]. The result is an extremely corrosive, oxygen-free micro-environment with a low $\mathrm{pH}$, which bears little resemblance to the bulk environment. The resulting runaway reaction is further encouraged by the large surface area ratio between the small anodic pit area and the vast cathodic area.

The susceptibility of $\mathrm{Co}-\mathrm{Cr}$ to pitting corrosion in-vivo is not clear. There are various reports of pitting in retrieved $\mathrm{Co}-\mathrm{Cr}[44]$ implants and during simulated electrochemical testing[66], although it does not seem to be the dominant mode of corrosion in-vivo[67]. Potentiostatic polarization tests indicate that reducing carbon content in as-cast ASTM F75 increases pitting corrosion resistance, due increased 
chemical and homogenity[68]. However, reducing carbon content in Co-Cr castings reduces their primary strengthening mechanism. Solution heat treatments might be a more favorable alternative to achieve homogenization at the carbon levels typically found in castings.

The pitting potentials seen for titanium alloys $(>10 \mathrm{~V})$ in chloride solutions indicate low pitting susceptibility in-vivo[67]. Nonetheless, as with Co-Cr there are mixed reports, with electrochemical studies in Ringers solution indicating susceptibility below the pitting potential in physiological conditions[69] and retrieval studies reporting pitting $[70,71]$.

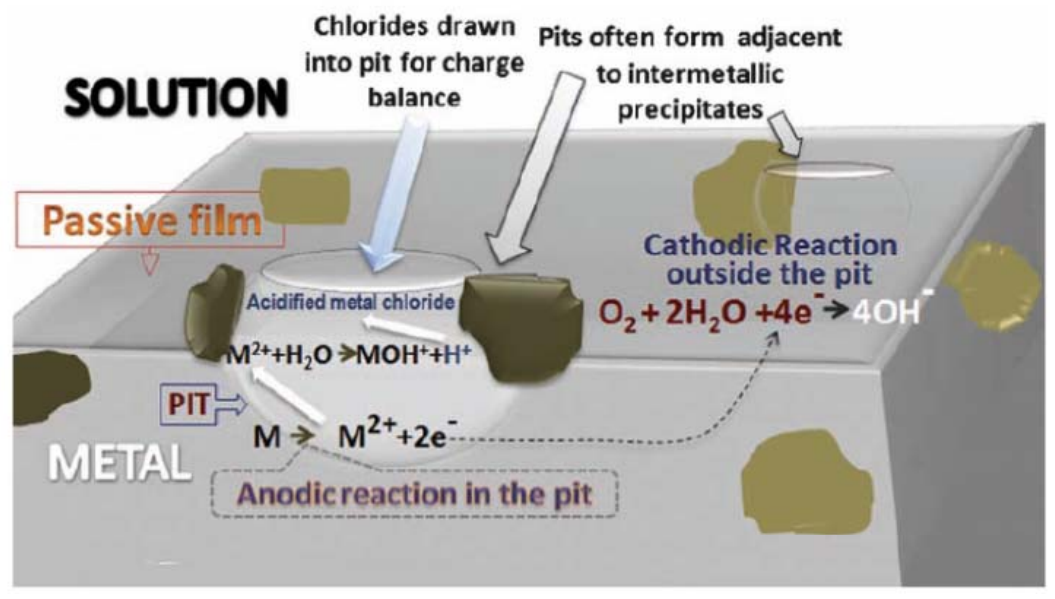

Figure 2.18. Pitting corrosion phenomena and associated reactions and surface features. [59]

\subsection{Crevice Corrosion}

The mechanisms underlying crevice corrosion are very similar to those in pitting corrosion, except that crevice corrosion is not nearly as localized. Unlike with pitting corrosion where the initiating factors are microscopic surface features and defects, crevice corrosion is generally caused by dimensional features and chemical conditions 
that affect broader areas. For crevice corrosion to occur, a crevice must exist of sufficient width to permit electrolyte entry, but must be sufficiently narrow to allow the electrolyte to stagnate. The process can be triggered by the variety of oxide break down processes discussed so far, particularly fretting[53]. As the original oxide layer is broken down and an increasing amount of abraded metal surface area and free metal ions are reoxidized, the fixed amount of oxygen available in the crevice decreases[72]. This depletion in oxygen reduces the $\mathrm{pH}$, exacerbating oxide film dissolution[12, 53]. As this phenomena tends to occur near the crevice opening, the complimentary half-cell reaction can occur in the electrically connected surface outside of the crevice, where a practically infinite amount of biologically based species are available for reduction. Titanium dioxide (TiO2) is thermodynamically stable in the $\mathrm{pH}$ range between 2 and 12[73] and Chromium(III) oxide $\left(\mathrm{Cr}_{2} \mathrm{O}_{3}\right)$ requires only a $\mathrm{pH}$ of 3 to become unstable below which active corrosion attack occurs, as in indicated in the chromium pourbaix diagram (Figure 2.19). While $\mathrm{pH}$ inside the human body is generally 7.4, infections can cause dramatic acidification in the area around the implant, where the $\mathrm{pH}$ may fall as low as 4.5[74]. One study found that upon implantation, the $\mathrm{pH}$ of the peri-prosthetic tissue may decrease to 5 and return to normal within weeks[75]. 


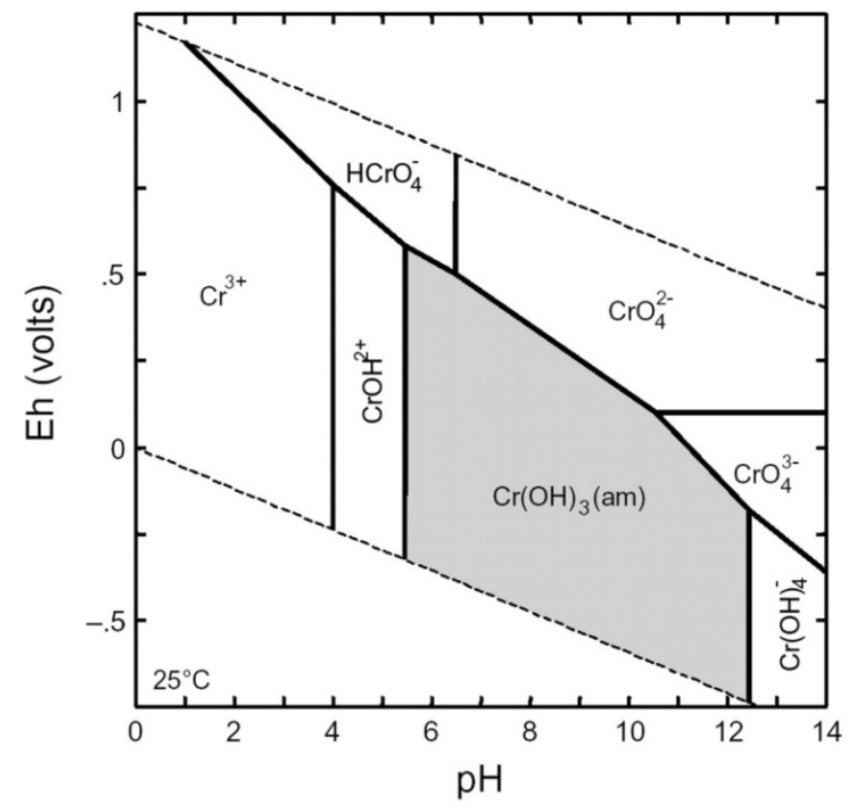

Figure 2.19. Pourbaix diagram illustrating $\mathrm{Eh} / \mathrm{pH}$ relationship for chromium.

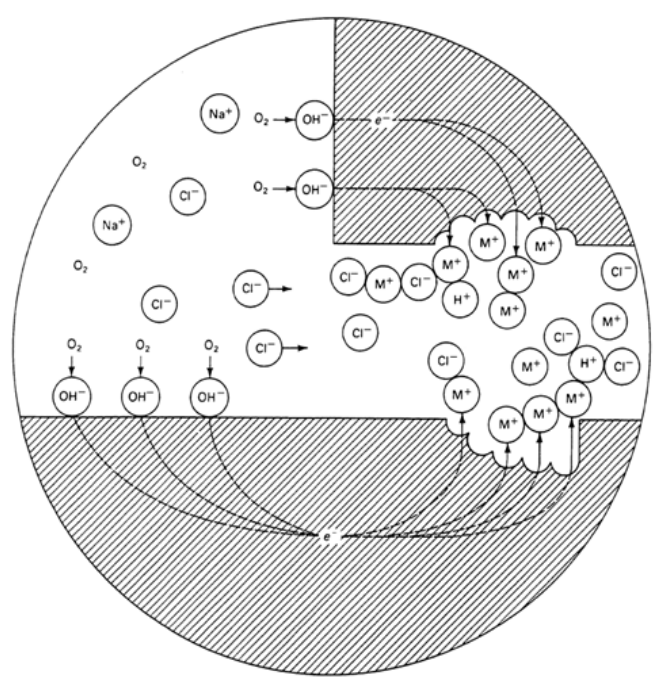

Figure 2.20. Schematic demonstrating corrosion half-cell reactions occurring outside the crevice [69]. 


\subsection{Mechanically Assisted Corrosion}

All of the corrosion mechanisms mentioned so far are either initiated or can be amplified by mechanical processes such as fretting. The role of wear versus electrochemical processes in many settings is difficult to compartmentalize due to their coupled and non-linear relationship[76]. Each has a synergistic effect on the other whereby wear accelerates corrosion, and corrosion causes structural changes that increases wear (i.e. micromotion/fretting), further accelerating corrosion, and so on. In many cases wear can be sufficient but not necessary for corrosion processes to occur i.e. wear can initiate corrosion but the subsequent corrosion can continue indefinitely in the absence of any further wear. This last point is particularly relevant when considering how isolated patient experiences, such as high impacts falls or accidents, can precipitate poor prosthesis performance.

In understanding mechanically assisted corrosion phenomena, such as fretting corrosion, it serves to investigate and compare the tribological nature of the protective oxides, which can differ from bulk properties. Retrieval studies consistently reportthat mixed-alloy couples show evidence of wear on the opposing surfaces of both alloys, [39], despite the lower bulk hardness of Ti-6Al-4V as compared to Co-Cr. Possibly pointing at the cause, sputter pit depth measurements demonstrate that the oxide thickness in titanium alloys is significantly greater $(150>\mathrm{nm})$ than the oxide layer formed on $\mathrm{Co}-\mathrm{Cr}$, which is only several nanometers thick. Furthermore, nanoindentation studies have found that the thicker titanium oxide is significantly harder than the unoxidized $\mathrm{Co}-\mathrm{Cr}$ 
surface[60].This interplay between oxidation and wear-altering material changes alludes to the coupled and complex relationship between wear and corrosion.
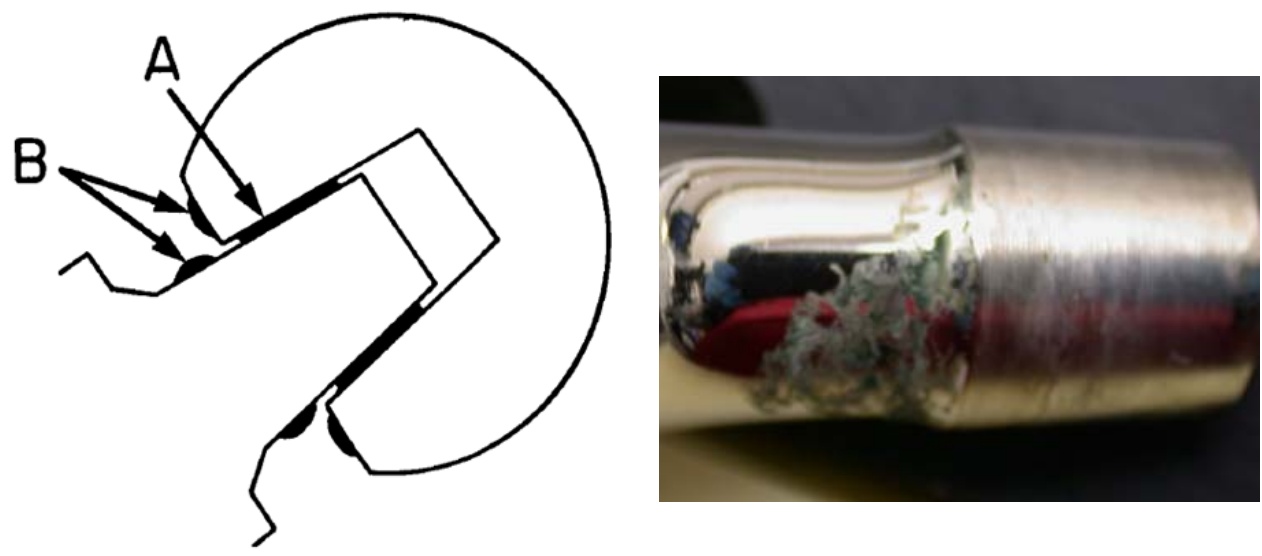

Figure 2.21. (Left) Drawing showing the location of corrosion products. A thin interfacial layer of mixed oxides and chlorides, $\mathrm{B}=$ thicker deposits of chromiumorthophospate hydrate-rich corrosion products around the opening of the crevice.[13]. (Right) Explanted Co-Cr prosthesis shown with green-white deposit outside the taper, identified by XPS analysis as a combination of chromium phosphate and chromium oxide with bone minerals and polypeptides and many other compounds of chromium, molybdenum, and cobalt. 


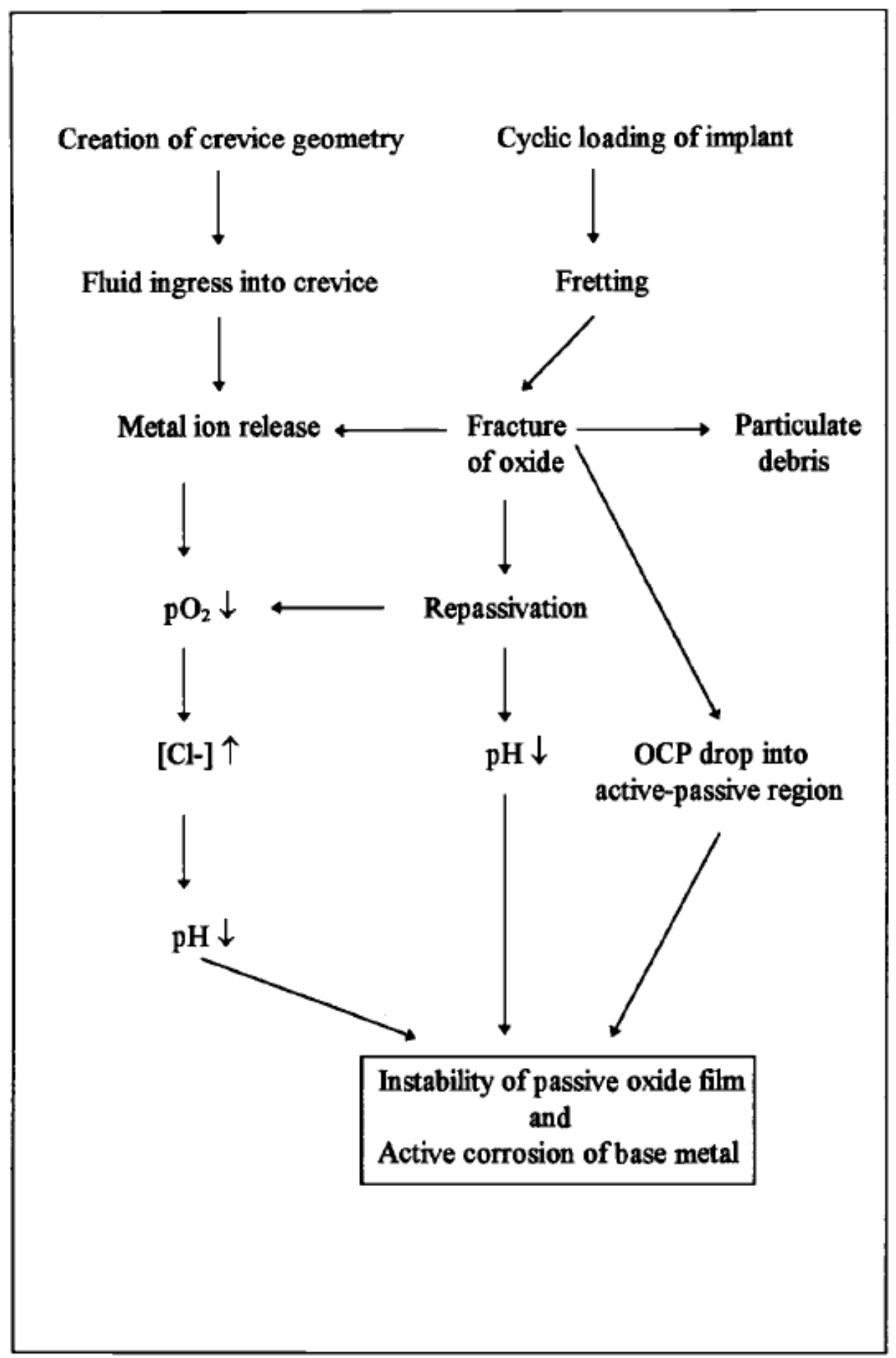

Figure 2.22. Synergistic relationship between fretting wear and corrosion processes. 


\section{Summary of Past Retrieval Studies}

Table 2.9. Summary of modular total hip prosthesis retrieval studies during the past 25 years.

\begin{tabular}{|c|c|c|c|c|c|c|c|c|c|c|c|}
\hline Ref & $\begin{array}{l}\text { Yr of } \\
\text { Study }\end{array}$ & $\begin{array}{l}\# \text { of } \\
\text { Samples }\end{array}$ & $\begin{array}{l}\text { Average } \\
\text { Patient } \\
\text { Age }\end{array}$ & Male/Female & $\begin{array}{l}\text { Avg } \\
\text { implantation } \\
\text { time }\end{array}$ & Sample set Summary & $\begin{array}{l}\text { Damage } \\
\text { Characterization } \\
\text { Method }\end{array}$ & $\begin{array}{l}\text { Dimensional } \\
\text { parameters } \\
\text { Evaluated }\end{array}$ & Summary of Findings & $\begin{array}{l}\text { Additional } \\
\text { Features }\end{array}$ & $\begin{array}{l}\text { Microstructural } \\
\text { Characterization }\end{array}$ \\
\hline [44] & 1992 & 139 & - & - & 34.5 months & $\begin{array}{l}\text { Different } \\
\text { Manufacturers. } \\
\text { Mostly Zimmer, } \\
\text { AML (DePuy), PCA } \\
\text { (Howmedica) } \\
\text { Mixed couples (91), } \\
\text { similar (48) }\end{array}$ & $\begin{array}{l}\text { Measurement of } \\
\text { wear volume by } \\
\text { profilometry. }\end{array}$ & - & $\begin{array}{l}52 \% \text { Mixed Ti/Co } \\
\text { showed corrosion } \\
\text { None of the Co/Co } \\
\text { or Ti/Ti couples } \\
\text { showed corrosion. } \\
\text { No corrosion seen } \\
\text { before } 9 \text { months. } \\
\text { after } 40 \text { months all } \\
\text { were corroded } \\
\text { Co-Cr head with } \\
\text { extensive pitting. }\end{array}$ & $\begin{array}{l}\text { Of the } 3 \\
\text { corroded, } \\
1 \text { was } \\
\text { smooth } \\
\text { taper, } 2 \\
\text { were } \\
\text { porous } \\
\text { coated }\end{array}$ & $\begin{array}{l}23 \text { As-cast Heads. } \\
1 \text { solution treated } \\
\text { head. } 1 \text { Forged } \\
\text { Head. }\end{array}$ \\
\hline [77] & 1994 & 108 & & $63: 55$ & $\begin{array}{l}20.1 \text { months } \\
(2 \text { to } 84)\end{array}$ & $\begin{array}{l}\text { Mixed couples(76), } \\
\text { similar (29) }\end{array}$ & $\begin{array}{l}\text { Visually scored } \\
\text { from 0-3. } \\
\text { Combined score } \\
\text { for wear and } \\
\text { corrosion. }\end{array}$ & - & $\begin{array}{l}\text { No cases of severe } \\
\text { corrosion. } \\
\text { Detectable } \\
\text { corrosion seen in } \\
34.5 \% \text { of mixed } \\
\text { alloy couples and } \\
9 \% \text { of similar alloy } \\
\text { couples after } 25 \\
\text { months. } \\
\\
\text { Implantation time } \\
\text { was not correlated } \\
\text { with corrosion. }\end{array}$ & - & None \\
\hline
\end{tabular}




\begin{tabular}{|c|c|c|c|c|c|c|c|c|c|c|}
\hline [39] & 2002 & 231 & $\begin{array}{l}61(25- \\
94)\end{array}$ & $102: 124$ & $\begin{array}{l}44.2 \text { months } \\
\text { (1 week to } \\
156 \text { months) }\end{array}$ & $\begin{array}{l}\text { Multiple } \\
\text { manufacturers } \\
\text { Mixed couples(89), } \\
\text { similar }(142)\end{array}$ & Goldberg criteria & $\begin{array}{l}\text { Head size, } \\
\text { Head offset, } \\
\text { Neck length }\end{array}$ & $\begin{array}{l}\text { Moderate } \\
\text { to severe corosion } \\
\text { was observed in } \\
28 \% \text { of the } \\
\text { heads of similar } \\
\text { alloy couples and } \\
\text { in } 42 \% \text { of heads of } \\
\text { mixed alloy } \\
\text { couples } \\
\text { severe corrosion in } \\
1 \% \text { of wrought } \\
\text { heads and } 17 \% \text { of } \\
\text { cast heads. } \\
\text { Implantation time } \\
\text { and neck diameter } \\
\text { correlated with } \\
\text { increased } \\
\text { corrosion/fretting. }\end{array}$ & $\begin{array}{l}\text { Scores } \\
\text { categorized by } \\
\text { wrought and cast } \\
\text { Co-Cr. } \\
\text { Method of } \\
\text { determination not } \\
\text { specified. }\end{array}$ \\
\hline [78] & 2009 & 16 & $\begin{array}{l}56(45- \\
67)\end{array}$ & $9: 7$ & 16 months & $\begin{array}{l}\text { Bimodular. Ceramic } \\
\text { head on ASTM } \\
\text { F799 stems. All } \\
\text { same model. }\end{array}$ & Goldberg criteria & $\begin{array}{l}\text { Not } \\
\text { specified. } \\
\text { All DTC } \\
\text { Margron } \\
\text { prosthesis. }\end{array}$ & $\begin{array}{l}\text { No fretting corrosion } \\
\text { before } 17 \text { months. } \\
38 \% \text { of neck-stem } \\
\text { tapers and } 19 \% \text { neck- } \\
\text { head tapers showed } \\
\text { significant } \\
\text { corrosion/fretting }\end{array}$ & $\begin{array}{l}\text { Microstructural } \\
\text { Characterization } \\
\text { on } 2 \text { Co-Cr stem } \\
\text { samples. } \\
\text { Revealed typical } \\
\text { forged } \\
\text { microstructure. }\end{array}$ \\
\hline [79] & 2012 & 110 & 62.7 & $63: 51$ & $\begin{array}{l}\text { Avg: } 46 \\
\text { Months }\end{array}$ & $\begin{array}{l}\text { Evaluated } \\
\text { cone/taper corrosion } \\
\text { in MoM large- } \\
\text { diameter head only } \\
\text { during revisions. } \\
\text { Evaluated } \\
\text { periprosthetic tissue } \\
\text { for metal content. } \\
\text { Patients selected }\end{array}$ & $\begin{array}{l}\text { Taper corrosion } \\
\text { was not scored. } \\
\text { Metal ion levels } \\
\text { in tissue were } \\
\text { quantified via } \\
\text { coupled plasma } \\
\text { spectroscopy. } \\
\text { Histological } \\
\text { sections graded }\end{array}$ & $\begin{array}{l}\text { Various } \\
\text { head sizes. }\end{array}$ & $\begin{array}{l}\text { No correlation } \\
\text { between head size } \\
\text { and metal ion } \\
\text { release. }\end{array}$ & None \\
\hline
\end{tabular}




\begin{tabular}{|c|c|c|c|c|c|c|c|c|c|c|c|}
\hline & & & & & & $\begin{array}{l}\text { presented early } \\
\text { clinical symptoms. }\end{array}$ & by particle count & & & & \\
\hline$[47]$ & 2013 & 74 & $\begin{array}{l}65 \cdot 5 \pm 12.3 \\
\text { years }\end{array}$ & $38: 36$ & $\begin{array}{l}\text { All: } \\
57 \cdot 7 \pm 42.5 \\
\text { months } \\
28 \mathrm{~mm} \\
\text { Heads: } \\
69.3 \pm 39 \cdot 5 \\
\text { months } \\
32 \mathrm{~mm}: \\
11.6 \pm 10.2 \\
\text { months }\end{array}$ & $\begin{array}{l}\text { All Metal-on- } \\
\text { Polyethylene } \\
59 \text { Heads: } 28 \mathrm{~mm} \\
15 \text { Head: } 36 \mathrm{~mm} \\
\text { Two manufacturers. }\end{array}$ & Goldberg & $\begin{array}{l}\text { Two head } \\
\text { sizes. }\end{array}$ & $\begin{array}{l}\text { Corrosion/Fretting } \\
\text { greater for larger } \\
36 \mathrm{~mm} \text { heads versus } \\
28 \mathrm{~mm} \text {. } \\
\text { Weak relationship } \\
\text { between implantation } \\
\text { time and damage. }\end{array}$ & & None \\
\hline [43] & 2013 & 5 & - & - & 51 Months & $\begin{array}{l}\text { All Large Heads } 36- \\
52 \mathrm{~mm} \text {. } \\
\text { All short } 10-12 \\
\text { tapers } \\
\text { All mixed Ti/Co } \\
\text { Couples. }\end{array}$ & $\begin{array}{l}\text { Measurement of } \\
\text { wear volume by } \\
\text { profilometry. }\end{array}$ & $\begin{array}{l}\text { Head size, } \\
\text { Head offset, } \\
\text { Taper angle } \\
\text { provided }\end{array}$ & $\begin{array}{l}2 \text { demonstrated } \\
\text { axisymmetric. } \\
3 \text { Asymmetric } \\
\text { demonstrated wear }\end{array}$ & $\begin{array}{l}\text { All Short- } \\
\text { tapers }\end{array}$ & None \\
\hline$[80]$ & 2013 & 52 & 75 & $28: 24$ & & $\begin{array}{l}\text { Evaluated Taper } \\
\text { Corrosion/Fretting } \\
\text { versus bearing } \\
\text { surface type. I.e. } \\
\text { MOM, COP, COC, } \\
\text { MOP. S-ROM } \\
\text { models only. }\end{array}$ & Goldberg & & $\begin{array}{l}\text { Hard-on-Hard } \\
\text { models, significantly } \\
\text { greater at stem/neck } \\
\text { as compared to hard- } \\
\text { on-soft }(\mathrm{p}<.05)\end{array}$ & & None \\
\hline
\end{tabular}




\section{CHAPTER III. EXPERIMENTAL METHODS}

This chapter details procedures for as-retrieved implant handling and preparation. After implant cleaning and sterilization, pre-destructive cataloging and testing procedures are detailed. After exhausting all possible pre-destructive testing and data acquisition, including but not limited to detailed dimensional measurements and macroimaging of all implant surfaces accessible without implant disassembly, destructive testing can commence as outlined. The aim of destructive testing is primarily to provide material samples for characterization and analysis, and to provide access to implant surfaces that might not have been accessible without sectioning or forceful disassembly. Detailed procedures for various material characterization methods are also provided.

In some cases, compromises must be made as to which imaging or material characterization method will be applied to a particular sample, as it might not be feasible to accommodate their conflicting sample preparation requirements. Likewise, future studies might find it necessary to modify aspects of this protocol, particularly as it pertains to the steps following destructive testing. For example, studies interested in characterizing the bearing surface of the femoral head or performing electrochemical testing might find it unnecessary and in all likelihood damaging to their purposes to section the femoral head as advised here.

The dimensional and feature categories outlined in this protocol might not be applicable to all future or even current implants models, as hip prosthesis designs evolve

and manufacturers develop significantly different product architectures that do not fit within this framework. 
This protocol has been developed in accordance with ASTM Standard F561 titled, Practice for Retrieval and Analysis of Implanted Medical Devices, and Associated Tissues and ISO standard 12891, Retrieval and Analysis of Surgical implants. Modifications and additions have been made as needed to accommodate the more focused goals of this study. Material characterization and analysis procedures have been individually designed in accordance with any respective ASTM or ISO standards that might apply. Such standards will be referenced in their respective sub section.

\section{$\underline{\text { 1. Retrieved Implant Cleaning and Sterilization }}$}

The 48 total hip prosthesis used as the basis for this study were acquired during revision surgeries to correct for a variety of implant failures including but not limited to aseptic loosening, acetabular liner degradation and dislocation. The implants were stored in a formaldehyde solution, as seen in Figure 3.1. Upon institutional review board approval, the implants were removed from formaldehyde and immersed in an industrial strength proteolytic enzyme detergent to soften and decompose any organic matter that remained. Until sterilization is complete, implants must be handled with extreme caution. It must be assumed that the implants contain infectious materials. 


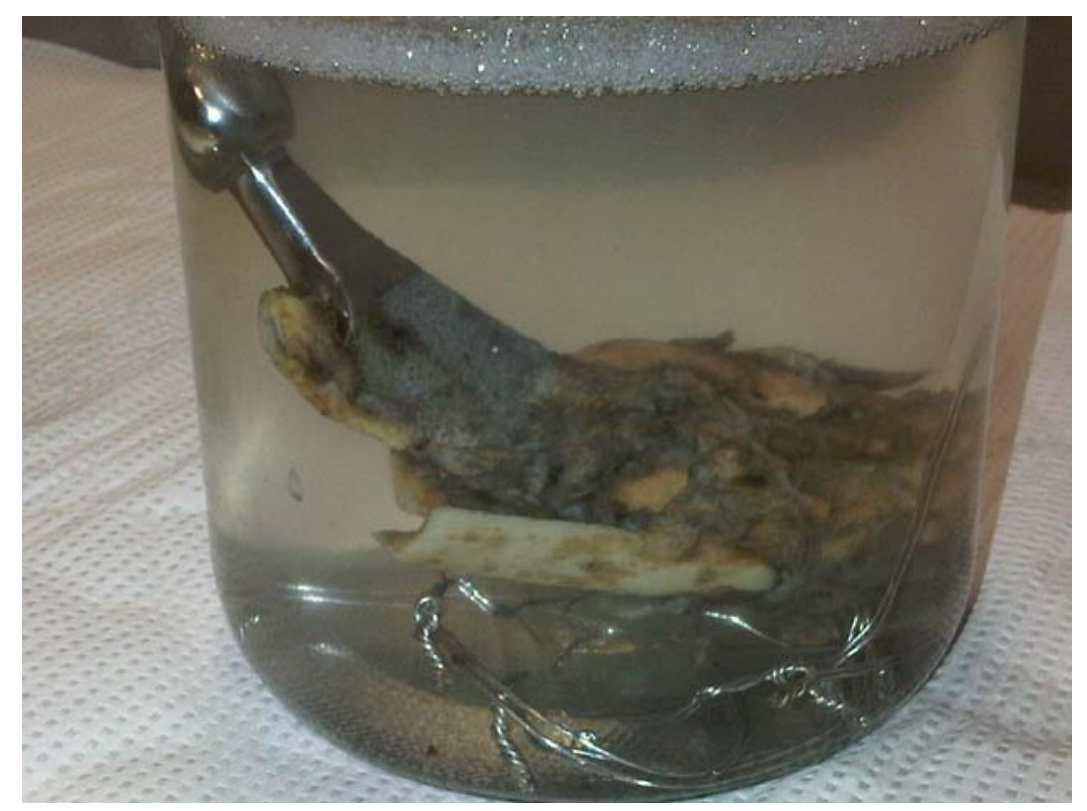

Figure 3.1. As-received retrieved total hip prosthesis with bone grafting and extensive osseointegration.

After a week of immersion in enzyme detergent, the implants were removed, rinsed, dried and individually placed in Crosstex Sterilization pouches with redundant steam and anproline indicators. Within their Crosstex pouches, the implants were then subjected to one 30 minute cycle of high pressure steam sterilization at $250^{\circ} \mathrm{F}$ in a Sterilemax Table Top Steam Sterilizer. Steam sterilization was proceeded by anproline (EtO) sterilization. At each step, sterilization validation was provided by the appropriate in-pouch indicator. At this point the implants are fully sterilized and ready to be handled freely. 


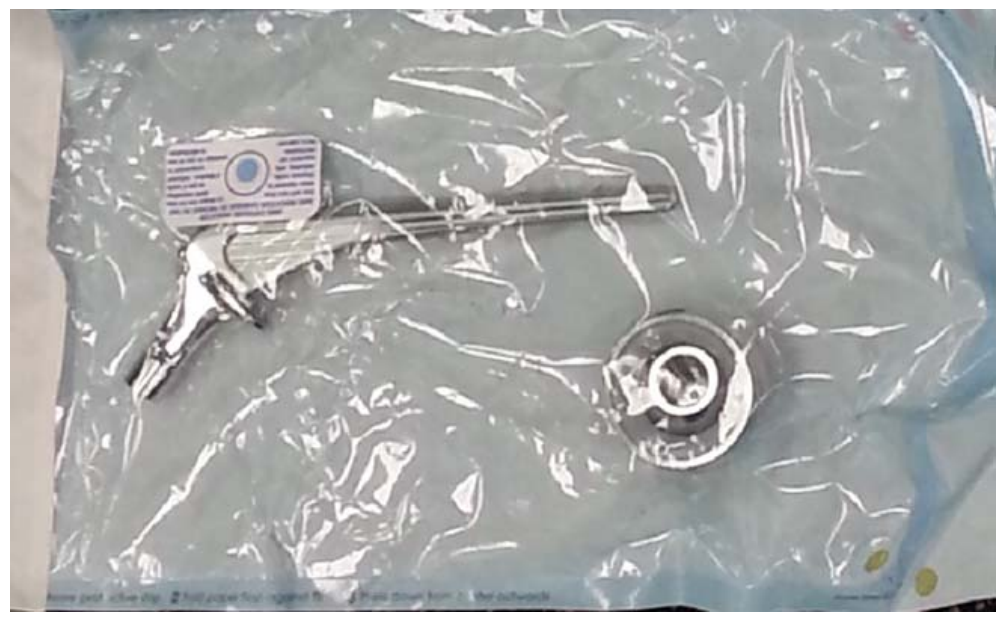

Figure 3.2. Sterilized retrieved prosthesis in CrosstTex pouch with indicators visible.

\section{$\underline{\text { 2. Non-Destructive Examination }}$}

\subsection{Cataloging and Initial Condition Assessment}

After sterilization, basic component inventory and cataloging was performed. It is important to extensively note the condition of the implant before destructive testing. Table 3.3 serves as a general guide when noting overall implant condition and any noteworthy surface anomalies. The ability to perform unanticipated studies in the future and the level of confidence in any resulting data, depends on extensive macro examination notes at this stage. For example, difficult to photograph swirl marks on the femoral head can indicate polyethylene liner wear-thru or significantly poor wear properties, however handling during material examination can itself add swirl marks or obfuscate existing marks, therefore determining their origin will depend on detailed notes.

All model numbers, serial numbers, and other markings should be recorded at this point, as future sectioning will likely damage any such markings. Component 
engagement should be noted as it will be crucial in determining if taper damage was due to fretting/corrosion or disengagement. If engaged, record orientation of the components.

Extensive macro photographs of the implants and any visible surfaces that can be imaged without forceful disassembly should be taken. Whenever possible, sample numbers should appear alongside the implants being photographed.

\subsection{Dimensional Measurements and Design Features}

Key dimensional measurements should be performed at this stage as noted in Tables 3.1-3.3. Several dimensions might not be accessible until after sectioning.

Table 3.1 As-received prostheses cataloging.

\begin{tabular}{lll}
\hline \multicolumn{1}{c}{ Description } & Notes \\
\hline 1 & Head Model and Serial \# \\
2 & Stem Model and Serial \# \\
3 & Sleeve Model and Seri al \# \\
4 & Head-Stem Engagement \\
5 & Evidence of \\
& Osseointegration \\
\hline 6 & Steam/EtO Batch \# \\
\hline
\end{tabular}

Table 3.2 General prostheses feature cataloging.

\begin{tabular}{lll}
\hline & Descrip tion & Example \\
\hline 1 & Bipolar & Y/N \\
2 & Sleeve/Two-Piece Taper & Y/N \\
3 & Bimodular & Y/N \\
4 & Collared & Y/N \\
5 & Skirted Head & Y/N \\
8 & Taper Roughness & \\
9 & Taper Type & Full/Hex/Other \\
\hline
\end{tabular}


Table 3.3. Macroscopic Examination. Overall implant examination, i.e. non-surface specific.

\begin{tabular}{|l|l|l|l|l|}
\hline & Damage & Location & Size/Area & Severity/Degree \\
\hline $\mathbf{2}$ & wear or burnishing & & & \\
\hline 3 & galling & & & \\
\hline 4 & change of shape & & & \\
\hline 5 & mechanical damage & & & \\
\hline 6 & macro porosity & & & \\
\hline 7 & pitting or crevice corrosion & & & \\
\hline $\mathbf{8}$ & fretting & & & \\
\hline 9 & embedded particles & & & \\
\hline 10 & discoloration or staining & & & \\
\hline 11 & calcification & & & \\
\hline 12 & degradation & & & \\
\hline 13 & stress cracking or crazing & & & \\
\hline 14 & loss of coating & mechanical failure & & \\
\hline 15 & cold flow & & \\
\hline 16 & & & & \\
\hline
\end{tabular}


Table 3.4. Porous Surface Coating Types.

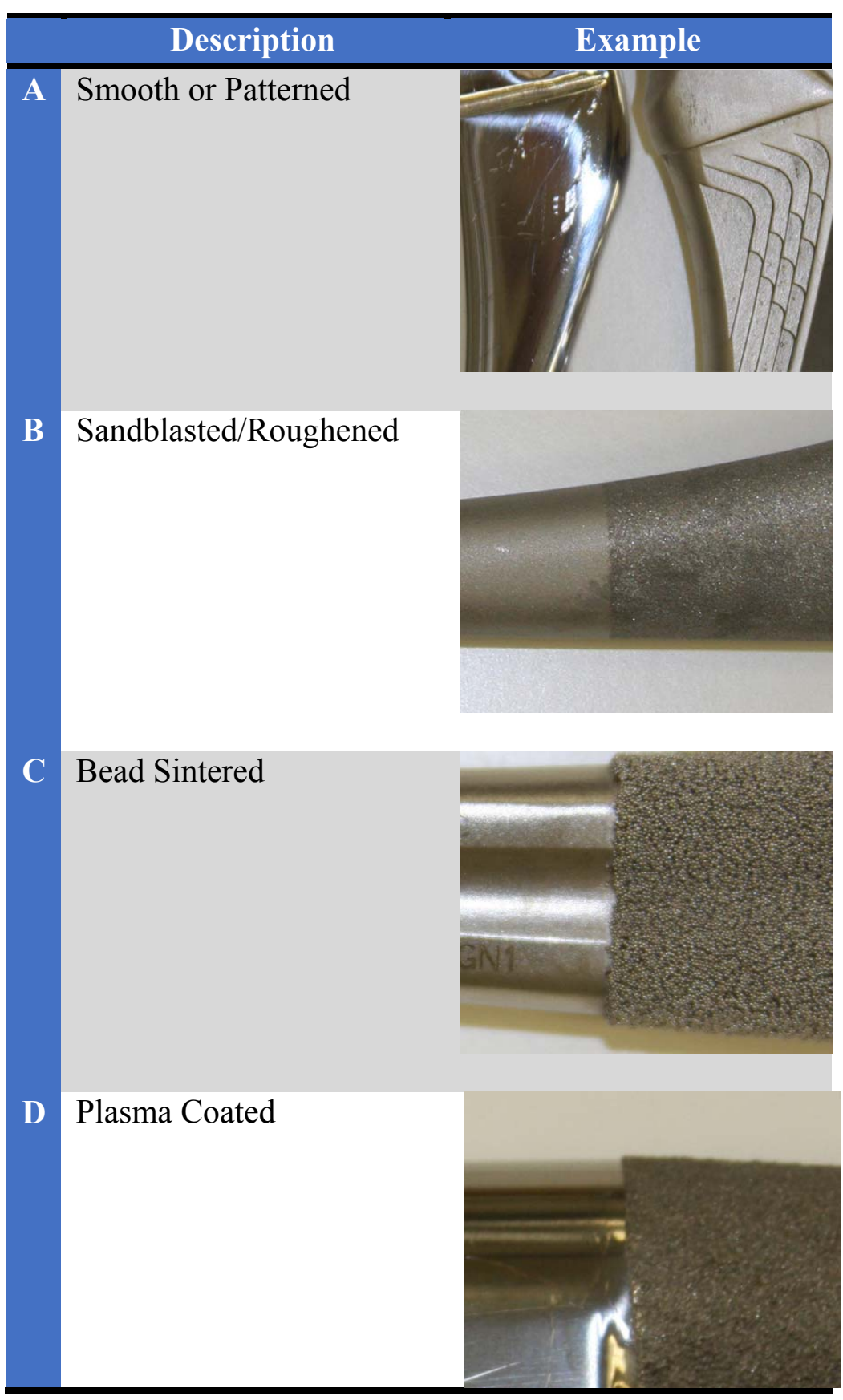



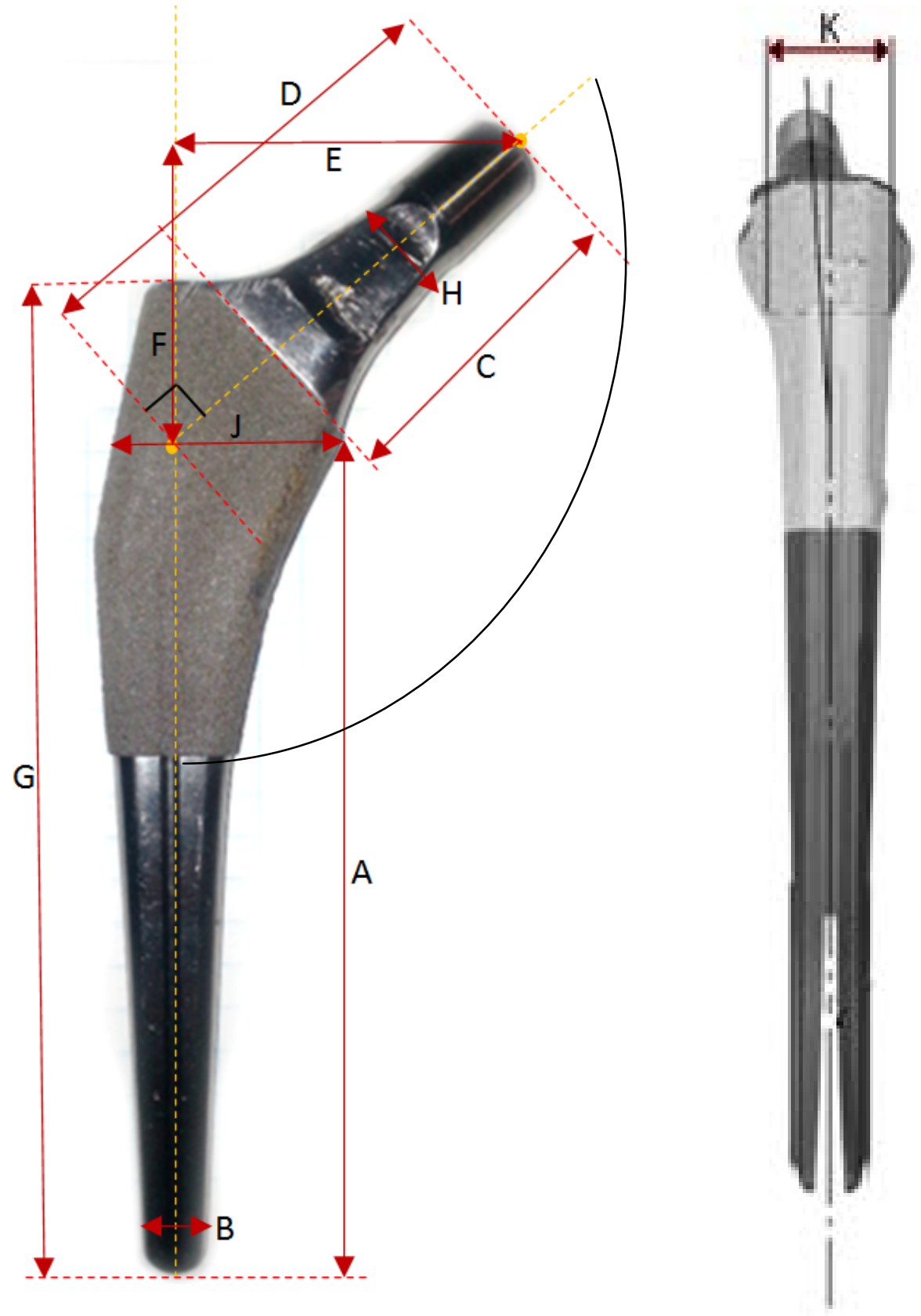

Figure 3.3. Dimensions for Typical Total Hip Prosthesis. (Left) Anterior/Posterior View. (Right) Mediolateral view 
Table 3.5 Femoral head and femoral stem dimensional variables

\begin{tabular}{|c|c|c|}
\hline A. & Stem Length & $\begin{array}{l}\text { Axis is determined using any available markers, lower stem symmetry, } \\
\text { and/or stem driver bore. }\end{array}$ \\
\hline B & Stem Width & Taken a one inch from the bottom of stem \\
\hline $\mathrm{C}$ & Neck length & $\begin{array}{l}\text { Taken from proximal end of taper to porous coating or below collar. Use } \\
\text { taper symmetry to find axis and extrapolate. }\end{array}$ \\
\hline $\mathrm{D}$ & Neck axis length & $\begin{array}{l}\text { Length of neck from proximal taper to stem axis intersection. Can be } \\
\text { calculated from } \operatorname{sqrt}\left(E^{2}+F^{2}\right)\end{array}$ \\
\hline $\mathrm{E}$ & Stem X-Offset & \\
\hline $\mathrm{F}$ & Stem Y-Offset & \\
\hline G & Full Stem Height & \\
\hline $\mathrm{H}$ & $\begin{array}{l}\text { Minimum Neck } \\
\text { thickness -A/P View }\end{array}$ & $\begin{array}{l}\text { Thickness at narrowest point along neck when viewed in } \\
\text { anterior/posterior view }\end{array}$ \\
\hline I & $\begin{array}{l}\text { Minimum Neck } \\
\text { thickness -Top view }\end{array}$ & Thickness at narrowest point along neck when viewed from top view. \\
\hline $\mathrm{J}$ & $\begin{array}{l}\text { Proximal Width A/P } \\
\text { View }\end{array}$ & \\
\hline $\mathrm{K}$ & $\begin{array}{l}\text { Proximal Width } \\
\text { M/L View }\end{array}$ & \\
\hline $\mathrm{L}$ & Neck Angle (deg) & As determined directly or by $\cdot \tan ^{-1} E / F$ \\
\hline $\mathrm{M}$ & Taper length & Length of in-contact taper surface \\
\hline $\mathrm{N}$ & Taper Axis Length & Length of taper axis length \\
\hline $\mathrm{O}$ & $\begin{array}{l}\text { Proximal Taper } \\
\text { Diameter }\end{array}$ & Diameter of proximal taper diameter \\
\hline $\mathrm{P}$ & $\begin{array}{l}\text { Distal Taper } \\
\text { Diameter }\end{array}$ & Diameter of distal taper diameter, ending in contact. \\
\hline Q & Taper Angle (deg) & $2 *\left(90-\propto_{\text {distal }}\right)$ \\
\hline $\mathrm{R}$ & Axial skirt Length & \\
\hline
\end{tabular}



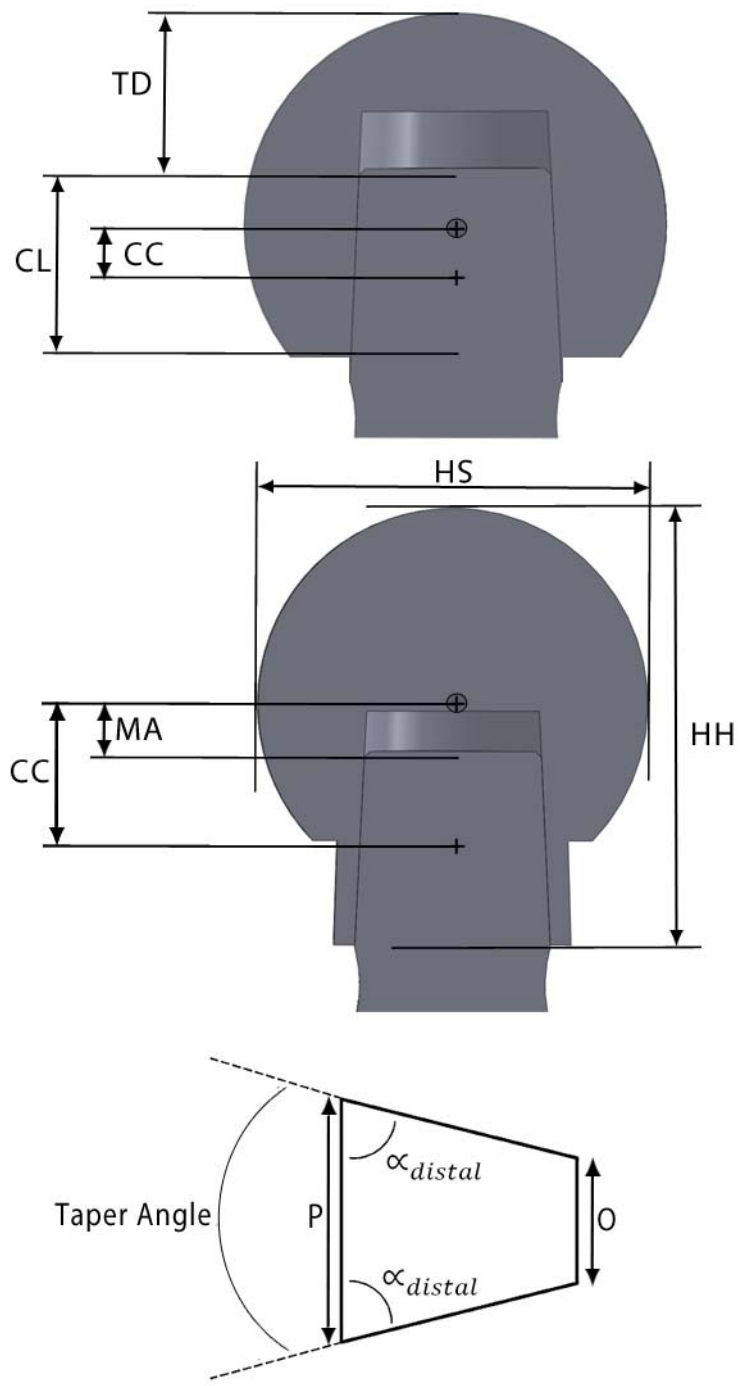

Figure 3.4. Key Dimensions for Femoral Head and Head-Trunnion Mating. (Top) Typical skirtless head with engaged taper. (Center) Skirted Head with engaged taper. (Bottom) Taper dimensions. 
Table 3.6 Modular junction dimensional variables.

\begin{tabular}{lll}
\hline \multicolumn{2}{c}{ Description } & \multicolumn{1}{c}{ Example } \\
\hline HS & Head Size & \\
HH & Head Height & \\
TD & Top-of-Head to Distal End of Taper & \\
CL & Taper Contact Length & Distance from the center of the in-contact \\
taper axis to the rotational center of the \\
CC & Center Coverage & head \\
MA & Trunnion-Head Moment Arm & HH-TD \\
PN & Penetration & \\
PR & Relative Penetration & \\
NL & Effective Neck Length & \\
SA & Taper in-contact surface area & \\
& &
\end{tabular}




\section{Destructive Examination and Materials Characterization}

\subsection{Sectioning}

Samples were all sectioned with a Buehler IsoMet 5000 Linear Precision Saw (IIllinois Tool Works, Inc, Road Lake Bluff, Illinois) with cobalt-boron-nitride wafering blades at 3000-4000 RPM and a feed rate of .15in/min for cobalt alloys and $.1 \mathrm{in} / \mathrm{min}$ for titanium alloys. Samples with engaged head-trunnions are first sectioned perpendicular to the neck axis as close to the head as possible without cutting into the male taper. Before sectioning, markings are made on the head and trunnion to record the as-received orientation. Next the head-trunnion are sectioned simultaneously thru the ML plane with a slight offset to keep one hemisphere engaged. Maintaining one half engaged simplifies the measurement of the mating interface and the imaging of possible taper head-trunnion angle mismatch. Unengaged heads and stems are sectioned separately but in a similar fashion. Heads larger than $32 \mathrm{~mm}$ generally require further sectioning for fitting in the SEM sample holder.

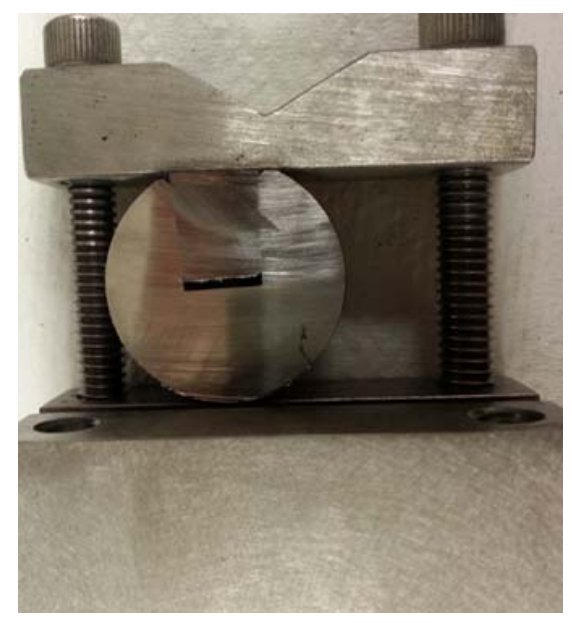

Figure 3.5. Cross-sectioned engaged head-trunnion couple in sectioning holder. 


\subsection{Corrosion and Fretting Imaging and Scoring}

After sectioning, the exposed tapers are gently wiped with water and/or alcohol soaked cleaning pads to remove any organic residue obscuring the corroded and worn surfaces. The degree of fretting and corrosion damage was quantified according to the criteria developed by Goldberg and commonly applied by retrieval studies thereafter [39].

Table 3.7 Goldberg criteria for corrosion and fretting of taper interface[39].

\begin{tabular}{|c|c|c|}
\hline Score & Corrosion Criteria & Fretting Criteria \\
\hline 1 (None) & No visible corrosion & No visible signs of fretting \\
\hline 2 (Mild) & $\begin{array}{l}<30 \% \text { surface } \\
\text { discoloured/dull }\end{array}$ & $\begin{array}{l}\text { Band(s) for fretting scars } \\
\text { across } \leq 3 \text { machine lines }\end{array}$ \\
\hline 3 (Moderate) & $\begin{array}{l}>30 \% \text { surface } \\
\text { discoloured/dull or }<10 \% \\
\text { containing black debris, } \\
\text { pits or etch marks }\end{array}$ & $\begin{array}{l}\text { Band(s) involving }>3 \\
\text { machine lines on taper } \\
\text { surface }\end{array}$ \\
\hline 4 (Severe) & $\begin{array}{l}>10 \% \text { of surface } \\
\text { containing black debris, } \\
\text { pits or etch marks }\end{array}$ & $\begin{array}{l}\text { Several bands of fretting } \\
\text { scars involving several } \\
\text { machine lines or flattened } \\
\text { areas with nearby fretting } \\
\text { scars }\end{array}$ \\
\hline
\end{tabular}

In determining the degree of fretting, comparisons between taper regions that were never in contact with opposing surfaces can be used to gauge fretting. Unworn surfaces can nearly always be found in the distal taper area of femoral heads. However, unworn regions are rare in trunnion tapers unless the taper extended beyond the bore of the femoral head. In cases where the entire trunnion taper was in contact, the asymmetrical nature of fretting wear along the circumference of the taper can be used as a reference point. In some taper designs, the circumferential machining lines are 
pronounced while in others they are barely visible to the naked eye and appear smooth and almost polished, in which case, optical profilometry, SEM imaging or 3D surface mapping are helpful aides. Figure 3.6 demonstrates the worn and corroded region of a trunnion taper (right) and unworn region (left).

Discoloration in the form of a tarnish film was considered to be a mild form of corrosion. Dullness can either be the result of a proteinaceous film or etching of the fine microstructure of wrought components. Homogenous dullness that covers the entire surface area might also be a surface finish particularly with titanium components. Splotchy dullness is indicative of mild corrosion. Black or green corrosion products are a form of severe corrosion and should be rated as moderate or severe depending on the size of the affected surface area. Even after cleaning, thin organic deposits can remain which appear similar to corrosion products. Determining their concavity might useful in determining their origin. In such cases the 3D surface profiling, as found in some SEM software package or in standalone 3D optical profilers are helpful. Pitting corrosion, as seen in Figure 3.8, is often microscopic and cannot be identified simply with a optical microscope.

Ascertaining the difference between fretting and corrosion can be difficult, particularly when there is extensive corrosion. In some cases damage is severe enough to warrant assigning the same score to both fretting and corrosion. Fretting damage caused by impaction or disengagement during retrieval should be disregarded. Such damage tends to manifest as single, off-angle, long narrow scratches over many machine lines. 
After imaging the exposed tapers with scanning electron microscope, stereomicroscope and/or optical camera, the least worn surface tapers halves are set aside for setting in epoxy.

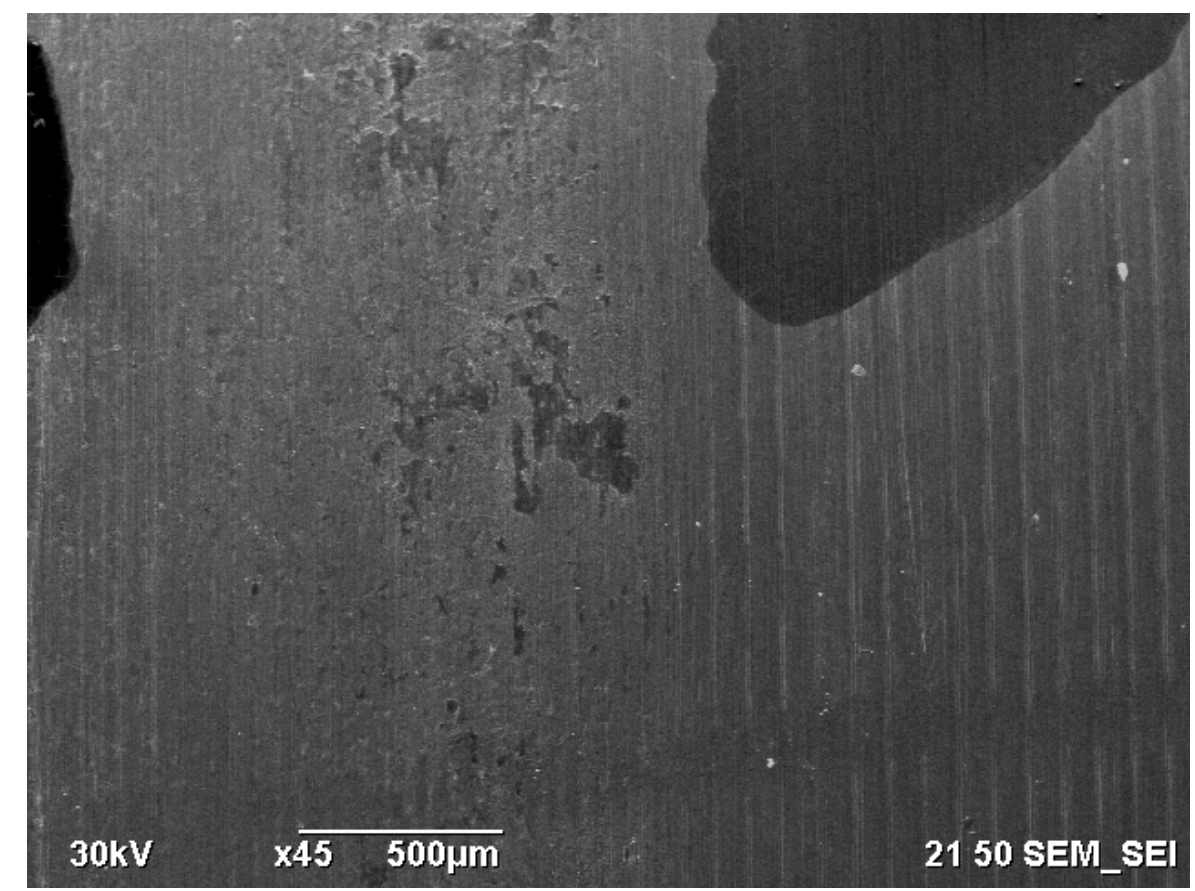

Figure 3.6. SEM image of worn and corroded trunnion taper (left half) and the unworn region that protruded from the femoral head (right half). 

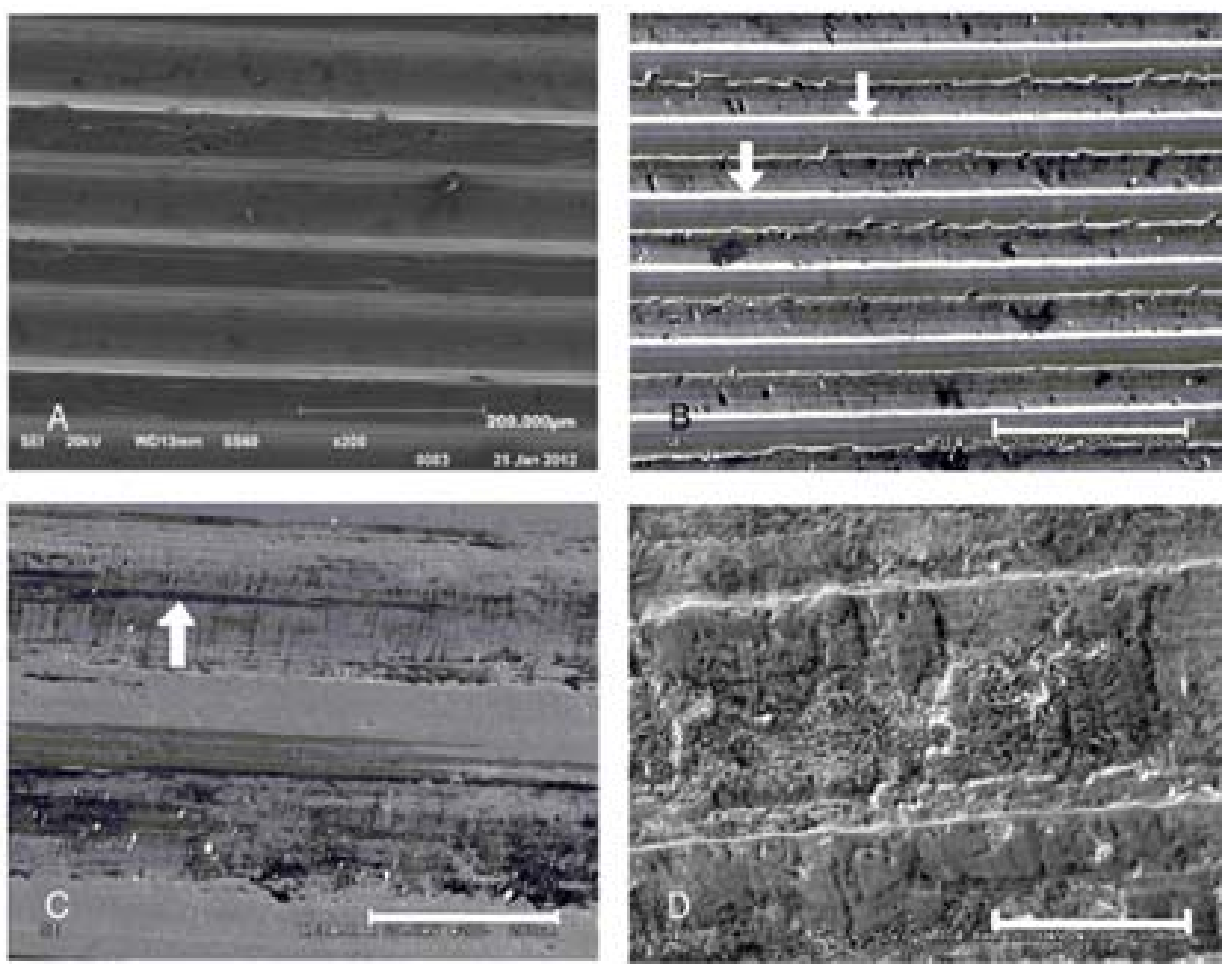

Figure 3.7. SEM images of machining groove fretting, highlighting the range of severity. a) no fretting. (b) mild fretting (c) moderate fretting (d) severe fretting.[47]

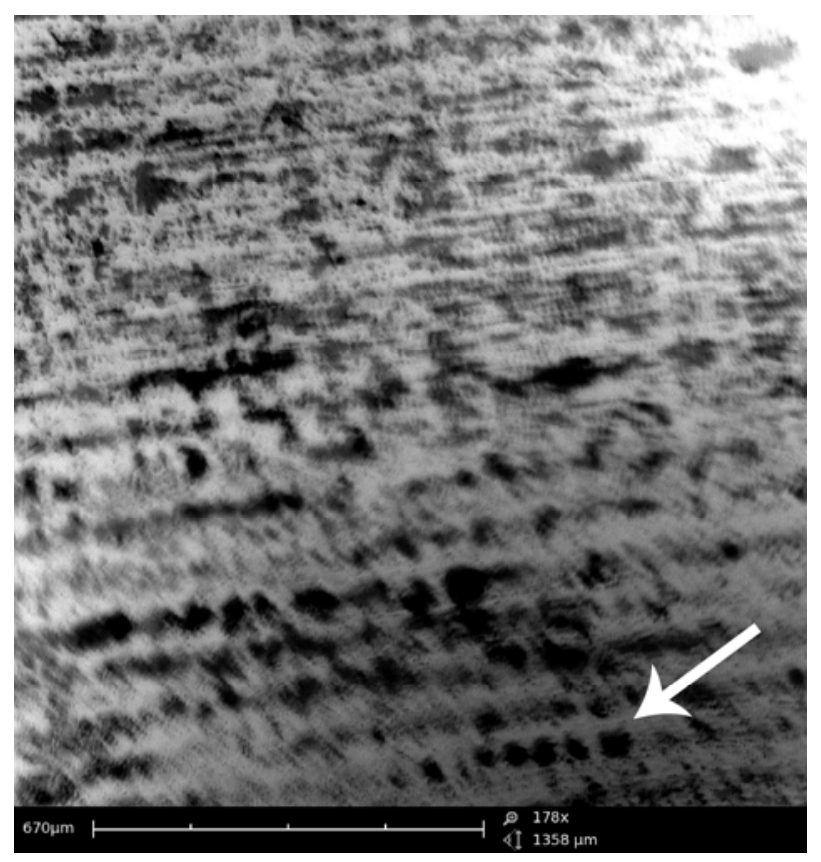

Figure 3.8. Backscattering Scanning Electron Microscope image of pitting corrosion seen in ascast Co-Cr-Mo femoral head tape. 


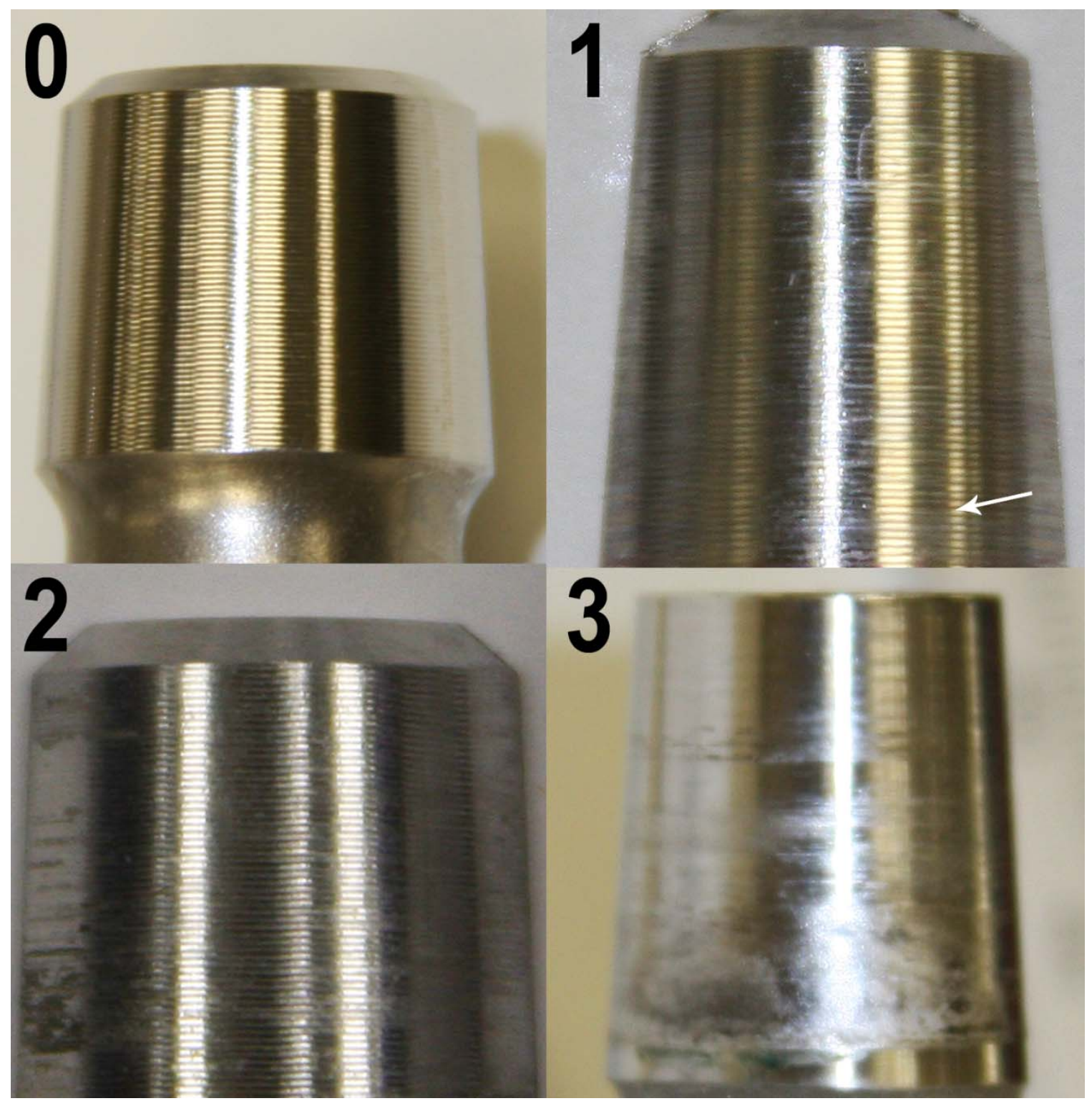

Figure 3.9. Femoral tapers demonstrating varying degrees of corrosion damage as determined by the Goldberg criteria. (0) None,(1) Mild, (2) Moderate (3) Severe. 


\subsection{Microstructural Characterization}

\subsubsection{Etching and Microscopic Examination of Grain Morphology}

The material samples were placed in a phenolic thermoset polymer or epoxy to provide for a stable and flat sample holder. The exposed sample surfaces were ground using progressively finer silicon carbide grinding papers (120, 240, 400, 600 grit size).

Grinding was followed by polishing using alumina or diamond slurries. Samples were thoroughly cleaned to remove any polishing residue.

Immediately after polishing microetching was performed according to ASTM standard E407. For cobalt base alloys the etchant consisted of $50 \mathrm{ml} \mathrm{HCL}+4 \mathrm{~g} \mathrm{~K} 2 \mathrm{~S} 2 \mathrm{O} 5$ (potassium metabisulfite) $+4 \mathrm{~g} \mathrm{NaOH}+50 \mathrm{ml}$ water. Most samples etched successfully within 30 seconds while solution-treated samples necessitated longer etching times. Ascast samples could be etched in less than 30 seconds and often required repolishing due

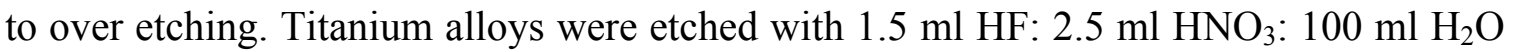
(Kroll's reagent).

Following etching, the revealed microstructures were imaged using a Buehler Versamet 3 Optical Microscope (Illinois, USA) at various magnifications to capture full grains and inclusions within and inside grain boundaries, as described in ASTM 561-97. ASTM standard E112 was followed for grain size determination. The darker color of the beta phase in Ti-6Al-4V allows for beta/alpha phase fraction to be approximated by contrast image analysis, yielding a field area percent that can be compared against the beta phase fraction percent determined by x-ray diffraction. This field area percent 
technique can be used to quantify carbide precipitation in $\mathrm{Co}-\mathrm{Cr}$ alloys but not $\mathrm{HCP} / \mathrm{FCC}$ phase fraction.

\subsubsection{Energy Dispersive Spectroscopy}

A JEOL JSM 5900LV SEM equipped with an EDAX EDS system is used to quantify the atomic composition of the various inclusions within and in grain boundaries, as well as any other surface features. EDS was used to characterize the subsurface composition within the sputtered trench formed during focused ion beam milling, in order to determine the depth from which selective leaching of any of the alloy components during corrosion occurs.

\subsubsection{Crystallography and X-ray Diffraction}

In order to approximate $\mathrm{HCP} / \mathrm{FCC}$ or $\mathrm{HCP} / \mathrm{BCC}$ phase fraction for $\mathrm{Co}-\mathrm{Cr}$ and titanium samples, X-ray diffraction experiments were carried out on the flat sectioned sample surfaces using a Siemens D-5000 X-ray diffractometer. The operating voltage and current were $40 \mathrm{kV}$ and $40 \mathrm{~mA}$ respectively, with $\mathrm{Cu} \mathrm{K} \alpha$ radiation at a wavelength of $1.542 \AA$. X-ray patterns were recorded at a scan rate of $0.02^{\circ} 2 \theta / \mathrm{s}$ throughout the entire $2 \theta$ angular scan range. Apart from phase fraction determination, the resulting diffraction patterns can aide in determining material processing and the presence of second and third phases such as carbides that appear as part of the optical microstructure examination.

Diffractogram based phase fraction calculations for cast cobalt-chrome samples must be interpreted with caution due to preferred orientations that arise during processing. The use of $\mathrm{Cu} \mathrm{K} \alpha$ radiation causes cobalt and chromium fluorescence leading 
to excessive background noise. In order to prevent fluorescence a chrome x-ray source or a monochromator would be needed, neither of which were available for this study.

Preliminary clues as to processing history can be inferred from features like significant Co-HCP fraction, which can be indicative of annealing. The appearance of two other peaks around $62^{\circ}$ and $84^{\circ}$ have also been reported after heat treatment. The volume percent of $\mathrm{HCP}$ phase also increases with $\mathrm{C}$ content as a result of $\mathrm{HCP}$ to $\mathrm{FCC}$ martensitic transformation suppression. Evidence of high carbon levels and/or $\mathrm{M}_{23} \mathrm{C}_{6}$ carbide precipitation might be indicated by small peaks at (420) and (422) as seen in Figure 3.10 [31].
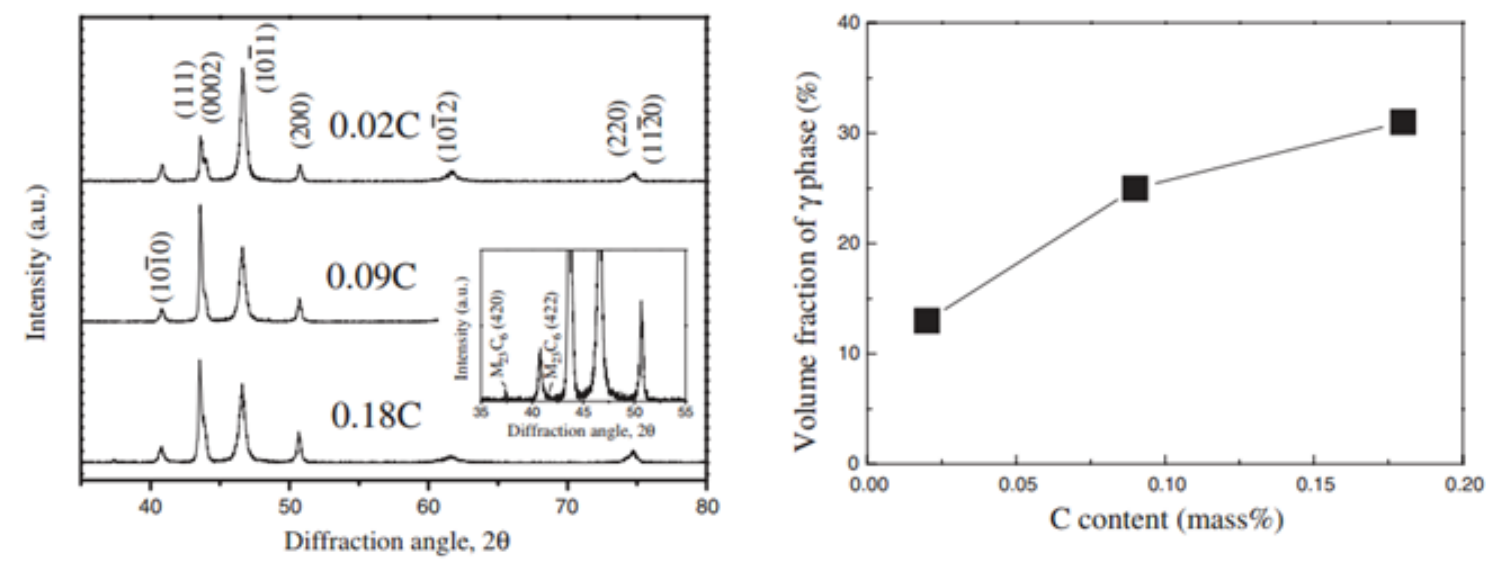

Figure 3.10. (top) XRD patterns of Co-Cr-Mo-C alloys with different $\mathrm{C}$ content. (bottom) Volume fraction of the HCP phase in Co-Cr-Mo-C alloys with different $\mathrm{C}$ content [31].

Sharp and intense (200) FCC peaks in wrought cobalt alloys can indicate the recrystallization of the FCC phase after high temperature annealing, while broad (200) FCC peaks can be the result of very high temperature and prolonged annealing resulting in coarse grain structures. 


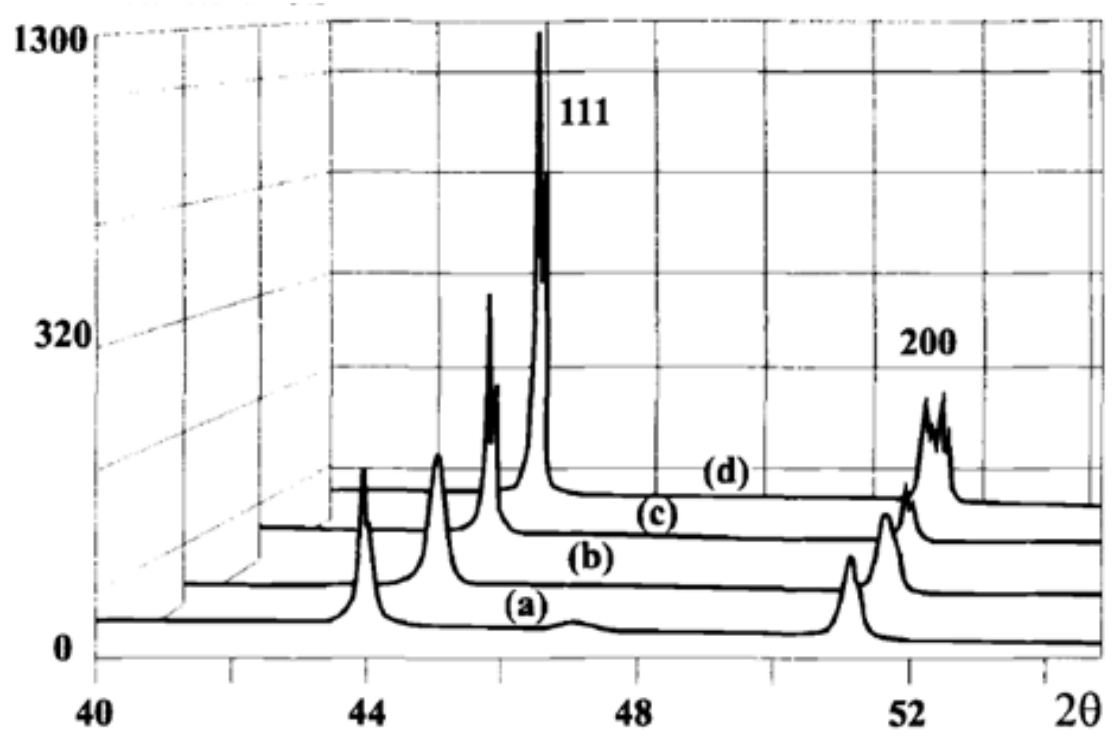

Figure 3.11. Effect of annealing temperature on the $\mathrm{X}$-ray diffraction patterns of low carbon Co-27Cr-5Mo-0.05C alloy (a) as-received, (b) $500{ }^{\circ} \mathrm{C}$, (c) $1100{ }^{\circ} \mathrm{C}$, and (d) $1250{ }^{\circ} \mathrm{C}[21]$.

The relative amounts of FCC and HCP phases in cobalt-alloys were estimated from the integrated intensities of the strong and isolated FCC (200) and HCP (10-11) diffraction peaks, as detailed by Sage and Gillaud [81].

$$
f^{\mathrm{hcp}}=\frac{I_{10 \overline{1} 1}^{\mathrm{hcp}}}{I_{10 \overline{1} 1}^{\mathrm{hcp}}+1.5 I_{200}^{\mathrm{fcc}}} \quad(\text { Sage and Gillaud Method })
$$

An alternative method for estimating phase fraction involves the summing of all the intensity peaks associated with a particular phase, $I_{\text {Peaks }}$, divided by the intensity summation for the peaks of every phase, $I_{\text {PeaksTotal }}$. 


$$
\left.f^{\text {phaseA }}=\frac{\sum I_{\text {PeaksA }}}{\sum I_{\text {PeaksTotal }}} \text { (total peak method }\right)
$$

$\mathrm{BCC} / \mathrm{HCP}$ phase fraction determination for titanium alloys is based on a similar principle as the Sage and Gillaud method for cobalt alloys, namely as a ratio of the area of the alpha $(10 \overline{1})$ peaks to the sum of the alpha $(10 \overline{1})$ and beta (110) peak areas as in equation $2 \mathrm{a}$.

$$
f^{\mathrm{bcc}}=\frac{I_{110}^{\mathrm{bcc}}}{I_{10 \overline{1}}^{\mathrm{hcp}}+I_{110}^{\mathrm{bcc}}}
$$

A corrected phase fraction is calculated using the method detailed in reference [4], whereby the relative intensity for a given diffraction peak is given by:

$$
R=F^{2} \times p \times \frac{1}{v^{2}} \times\left(\frac{1+\cos ^{2}(2 \Theta)}{\sin ^{2}(\Theta) \times \cos (\Theta)}\right) \times e^{-2 M}
$$

Where:

- $\mathrm{F}^{2}$ is the structure factor that describes the effect of the crystal structure on the intensity of the diffracted beam. For alpha $(10 \overline{1}), F$ is $3 f^{2} \cos ^{2}(5 \pi / 6)$ and for beta (110), $\mathrm{F}$ is $4 \mathrm{f}^{2} . f$ is an atomic scattering taken from [6], in this case the value for pure titanium.

- $\mathrm{p}$ is the number of family of planes contributing to the reflection.

- $\mathrm{v}$ is the volume of the unit in nanometers.

- $\mathrm{e}^{-2 \mathrm{M}}$ is the temperature factor and disregarded as data on the effect of temperature on intensity is not readily available. 
Table 3.8. Table of structure factor parameters for Ti-6Al-4V alpha and beta phase fraction calculation.

\begin{tabular}{|c|c|c|}
\hline & Alpha $(\mathbf{1 0} \overline{1})$ & Beta (110) \\
\hline $2 \Theta$ & 40.339 & 39.9348 \\
\hline Lattice Parameter, a, (nm) & .292 & .319 \\
\hline Lattice Parameter, c, (nm) & .467 & \\
\hline Volume of unit cell, $\mathrm{v}\left(\mathrm{nm}^{3}\right)$ & .03407 & .03246 \\
\hline$\frac{\sin (\theta)}{\lambda}(\lambda=1.54056 \AA)$ & $0.22485 \times 10^{10}$ & $0.22166 \times 10^{10}$ \\
\hline Atomic scattering factor, $f$ & 15.3 & 15.43 \\
\hline Structure factor, $\mathrm{F}^{2}$ & 701.537 & 952.710 \\
\hline Multiplicity factor, $p$ & 12 & 12 \\
\hline $\begin{array}{l}\text { Lorentz-polarization factor } \\
\left(\frac{1+\cos ^{2}(2 \theta)}{\sin ^{2}(\theta) \times \cos (\theta)}\right)\end{array}$ & 14.02 & 14.49 \\
\hline Relative integrated intensity, $\mathbf{R}$ & $1.0168 \times 10^{8}$ & $1.5722 \times 10^{8}$ \\
\hline $\boldsymbol{R}_{\beta} / \boldsymbol{R}_{\alpha}$ & 1.546 & \\
\hline
\end{tabular}

The ratio $R_{\beta} / R_{\alpha}$ provides the correction factor for the corrected beta intensity, $I_{\beta c o r}$.

$I_{\beta c o r}=\frac{I_{\beta}}{R_{\beta} / R_{\alpha}}$. The corrected beta phase fraction is calculated by replacing $I_{\beta}$ with $I_{\beta c o r}$ in equation 2a. 


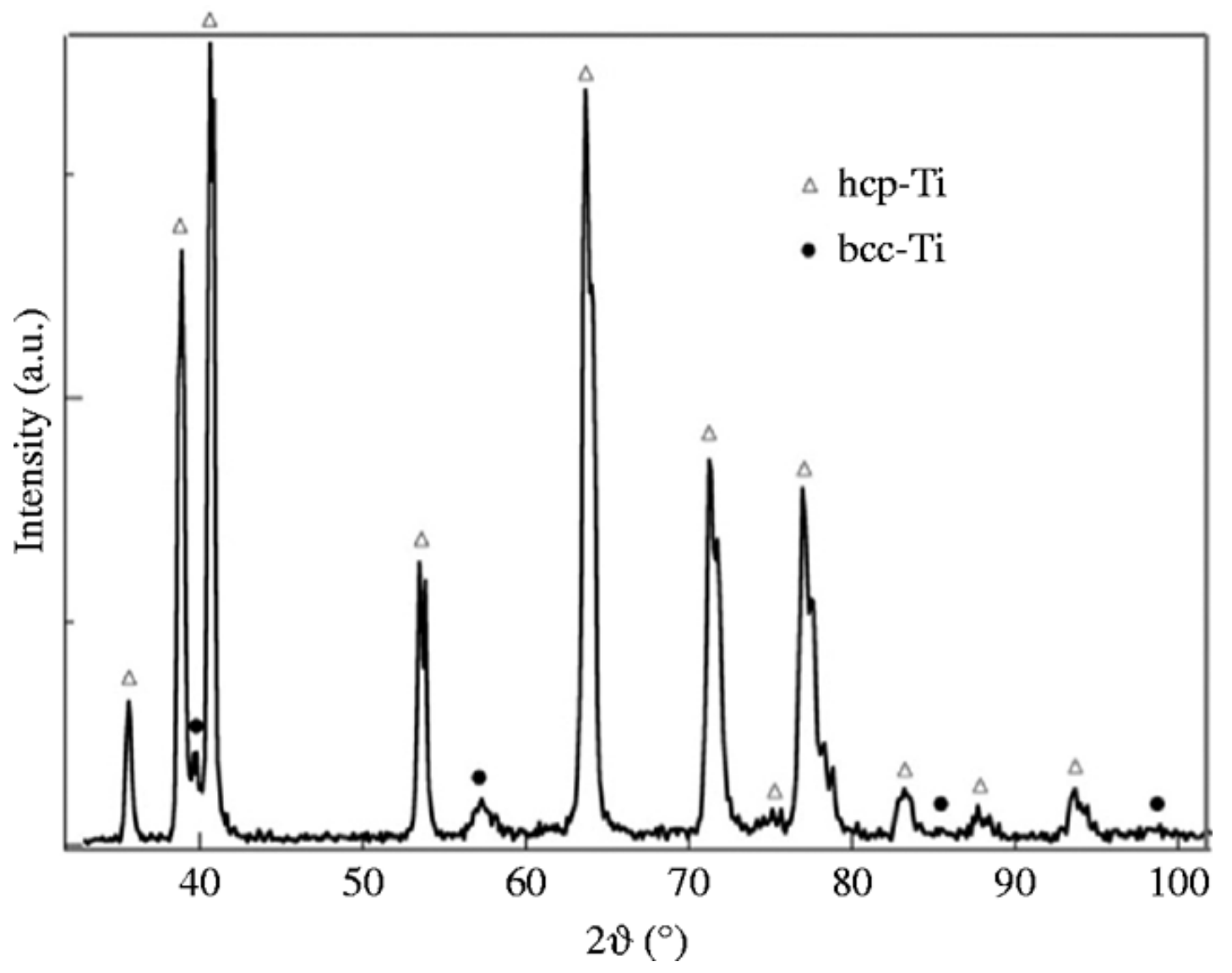

Figure 3.12. Typical diffraction pattern for Ti-6Al-4V with corresponding beta and alpha peaks.

\subsubsection{Microhardness Testing}

Microhardness was measured using a microhardness tester with a Vickers tip (Shanghai Taiming Optical Instrument Co. Ltd., model HXD-1000 TMC, Shanghai). The measurements were performed on the polished surfaces of select head and stem samples of each microstructural category. Measurements were taken at various points on the surface at $100 \mathrm{lbs}$ of loading. Vickers hardness is calculated from the following equation, where $\mathrm{P}$ is the applied load, $\theta$ is the angle between the opposite faces of the diamond tip, 
and $\mathrm{L}$ is the length of the diagonal of the square indentation. The length of the diagonal is taken by optical microscope inspection after indentation, as seen in Figure 3.13(b).

$$
\text { Hardness }=\frac{2 P \sin \frac{\theta}{2}}{L^{2}}
$$

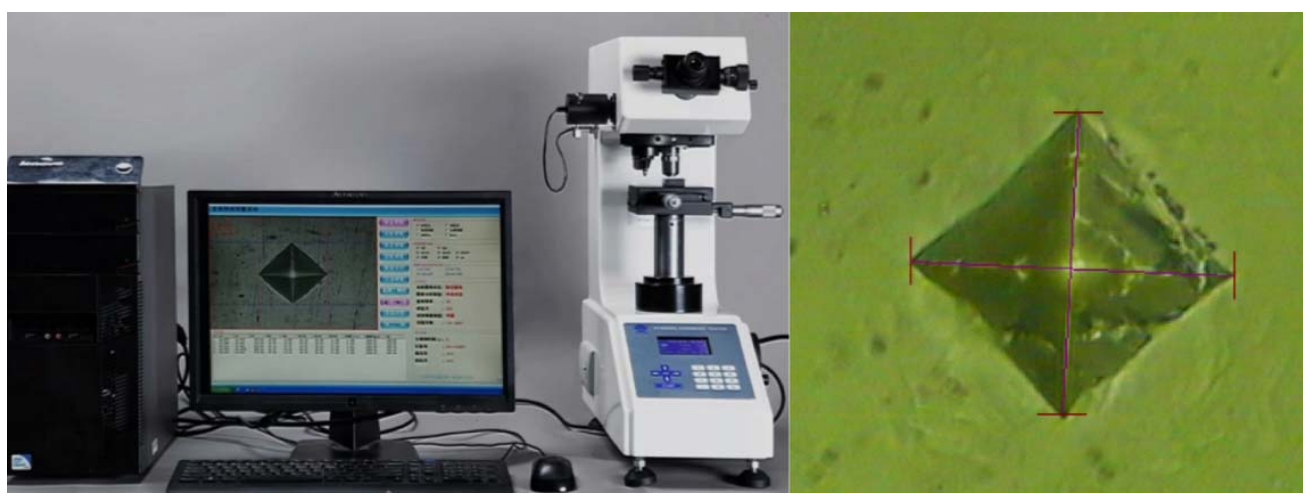

Figure 3.13. (a) HXD-1000 TMC micro-hardness instrument. (b). Sample indentation as imaged by optical microscope showing diagonal length (L).

\subsubsection{Focused Ion Beam and Transmission Electron Microscopy}

A JEOL dual beam focused ion beam (JEOL, JIB 4500 Dual-Beam FIB-SEM) with a $25-50 \mathrm{kV}$ gallium liquid metal ion source (LMIS) was employed for preparing $1 \mu \mathrm{m}$ thick TEM samples from a select as-cast femoral stem. Two samples were taken from oxidized and unoxidized areas of the taper, the former containing a carbide. A third sample was taken from an oxidized area without a carbide and imaged with ion channeling contrast for detecting subsurface wear/deformation. TEM investigations were carried out using a Phillips CM-200 200 kV Transmission Electron Microscope (TEM). 


\section{CHAPTER IV: RESULTS AND ANALYSIS}

\subsection{Statistical Summary of Retrieval Sample Set}

Table 4.1. Summary of samples by microstructure and design features.

\begin{tabular}{|c|c|c|c|}
\hline Stems/Trunnions & $\begin{array}{l}\text { \# of } \\
\text { Samples }\end{array}$ & Heads & $\begin{array}{l}\text { \# of } \\
\text { Samples }\end{array}$ \\
\hline$\underline{\text { Co-Cr-Mo }}$ & & Co-Cr-Mo & \\
\hline As-Cast & $3 \%(1)$ & As-Cast & $2 \%(1)$ \\
\hline Cast + ST/HIP'ed & $32 \%(12)$ & Cast + ST/HIP'ed & $15 \%(6)$ \\
\hline Wrought Low Carbon & $24 \%(9)$ & Wrought Low Carbon & $15 \%(7)$ \\
\hline Other/Unexamined & $40 \%(15)$ & Wrought High Carbon & $24 \%(12)$ \\
\hline Total Co-Cr-Mo & $100 \%$ & Other/Unexamined & $43 \%(20)$ \\
\hline & $(3 /)$ & Total Co-Cr-Mo & $100 \%(46)$ \\
\hline$\underline{\text { Ti-6Al-4V }}$ & & $\underline{\text { Ti-6Al-4V }}$ & \\
\hline Total & 11 & Total & 2 \\
\hline Porous Coated Stem & 19 & Bipolar Head & $10 \%(5)$ \\
\hline$\%$ of Ti-6Al-4V Coated & $91 \%(10)$ & & \\
\hline$\%$ of Co-Cr-Mo Coated & $24 \%(9)$ & & \\
\hline Total & & & \\
\hline Bimodular & $8 \%(4)$ & Heads with Skirt & $20 \%(10)$ \\
\hline With Sleeve Adapter & $13 \%(6)$ & & \\
\hline
\end{tabular}




\subsection{Statistical Summary of Basic Patient Data}

Table 4.2. Summary of samples by patient age and weight and in-vivo time.

\begin{tabular}{|lc|lc|}
\hline $\begin{array}{l}\text { Total samples with } \\
\text { Clinical Data }\end{array}$ & 23 & & \\
\hline $\begin{array}{l}\text { Average Patient Age (At } \\
\text { retrieval) }\end{array}$ & $\mathbf{6 8 . 5}$ & Average Weight (Lbs) & $\mathbf{1 7 3 . 4}$ \\
\hline $\begin{array}{l}\text { Patient Age Range } \\
\text { Patient Age Standard }\end{array}$ & $\mathbf{3 8 ~ - 8 8}$ & $\begin{array}{l}\text { Weight Standard } \\
\text { Deviation } \\
\text { Weight Range }\end{array}$ & $\mathbf{4 2 . 6}$ \\
\begin{tabular}{|l} 
Deviation \\
\hline $\begin{array}{l}\text { Average Time in-vivo } \\
\text { (years) }\end{array}$
\end{tabular} & $\mathbf{1 1 . 0}$ & & $\mathbf{1 0 5 - 2 5 3}$ \\
\hline $\begin{array}{l}\text { In-vivo Time Range } \\
\text { (years) }\end{array}$ & $\mathbf{6 - 2 8}$ & & \\
\hline $\begin{array}{l}\text { In-vivo Time Standard } \\
\text { Deviation (years) }\end{array}$ & $\mathbf{6 . 4}$ & \\
\hline
\end{tabular}




\subsection{Statistical Summary of Corrosion/Fretting by Alloy Couple Type}

Table 4.3. Corrosion/Fretting score distribution by alloy couple type (all, similar, and mixed).

\begin{tabular}{|c|c|c|c|c|}
\hline \multicolumn{5}{|c|}{ All Alloy Corrosion/Fretting Score Distribution } \\
\hline Corrosion Score & $\mathbf{0}$ & 1 & 2 & 3 \\
\hline Head & $32 \%(15)$ & $45 \%(21)$ & $9 \%(4)$ & $15 \%(7)$ \\
\hline Stem/Trunnion & $45 \%(21)$ & $36 \%(17)$ & $2 \%(1)$ & $17 \%(8)$ \\
\hline Fretting Score & $\mathbf{0}$ & 1 & 2 & 3 \\
\hline Head & $11 \%(5)$ & $64 \%(30)$ & $11 \%(5)$ & $15 \%(7)$ \\
\hline Stem/Trunnion & $34 \%(16)$ & $45 \%(21)$ & $6 \%(3)$ & $15 \%(7)$ \\
\hline \multicolumn{5}{|c|}{ Co/Co Alloy Couples Corrosion/Fretting Score Distribution } \\
\hline Corrosion Score & $\mathbf{0}$ & 1 & 2 & 3 \\
\hline Head & $42 \%(15)$ & $44 \%(16)$ & $3 \%(1)$ & $11 \%(4)$ \\
\hline Stem/Trunnion & $56 \%(20)$ & $33 \%(12)$ & $0 \%(0)$ & $11 \%(4)$ \\
\hline Fretting Score & $\mathbf{0}$ & 1 & 2 & 3 \\
\hline Head & $14 \%(5)$ & $70 \%(25)$ & $6 \%(2)$ & $11 \%(4)$ \\
\hline Stem/Trunnion & $42 \%(15)$ & $47 \%(17)$ & $0 \%(0)$ & $11 \%(0)$ \\
\hline \multicolumn{5}{|c|}{ Ti/Co Alloy Couples Corrosion/Fretting Score Distribution } \\
\hline Corrosion Score & $\mathbf{0}$ & 1 & 2 & 3 \\
\hline Head & $0 \%(0)$ & $40 \%(4)$ & $20 \%(2)$ & $40 \%(4)$ \\
\hline Stem/Trunnion & $10 \%(1)$ & $40 \%(4)$ & $0 \%(0)$ & $50 \%(5)$ \\
\hline Fretting Score & $\mathbf{0}$ & 1 & 2 & 3 \\
\hline Head & $0 \%(0)$ & $40 \%(4)$ & $20 \%(2)$ & $40 \%(4)$ \\
\hline Stem/Trunnion & $10 \%(1)$ & $30 \%(3)$ & $20 \%(2)$ & $40 \%(4)$ \\
\hline
\end{tabular}




\subsection{Summary of Corrosion/Fretting Scores by Microstructure}

Table 4.4. Microstructure, phase fraction, grain size, couple type and fretting/corrosion score for all 48 samples scored. W LC $=$ Wrought Low Carbon, W HC $=$ Wrought High Carbon, Cast ST = Cast Solution Treated, $\mathrm{U}=$ Microstructure unexamined.

\begin{tabular}{|c|c|c|c|c|c|c|c|c|}
\hline $\begin{array}{l}\text { Sample } \\
\text { Pair \# }\end{array}$ & Similar/Mixed & Trunnion/Head & Alloy & $\begin{array}{l}\text { Grain } \\
\text { Size } \\
(\mu \mathrm{m}) \\
\end{array}$ & Microstructure & $\begin{array}{c}\text { XRD } \\
\text { BCC or } \\
\text { HCP } \\
\text { Phase } \% \\
\end{array}$ & $\begin{array}{l}\text { Fretting } \\
\text { Score } \\
\end{array}$ & $\begin{array}{c}\text { Corrosion } \\
\text { Score } \\
\end{array}$ \\
\hline 36 & SIMILAR & TRUNNION & Co & & AS-CAST & $25 \%$ & 3 & 3 \\
\hline 15 & MIXED & HEAD & Co & & AS-CAST & $32 \%$ & 3 & 3 \\
\hline 5 & SIMILAR & TRUNNION & Co & & CAST ST & & 1 & 1 \\
\hline 8 & SIMILAR & TRUNNION & Co & 135 & CAST ST & $20 \%$ & 1 & 1 \\
\hline 12 & SIMILAR & TRUNNION & Co & & CAST ST & & 0 & 0 \\
\hline 13 & SIMILAR & TRUNNION & Co & & CAST ST & $11 \%$ & 0 & 1 \\
\hline 22 & SIMILAR & TRUNNION & Co & 500 & CAST ST & & 0 & 0 \\
\hline 24 & SIMILAR & TRUNNION & Co & & CAST ST & & 1 & 1 \\
\hline 25 & SIMILAR & TRUNNION & Co & 500 & CAST ST & $23 \%$ & 0 & 0 \\
\hline 28 & SIMILAR & TRUNNION & Co & 500 & CAST ST & $25 \%$ & 1 & 1 \\
\hline 29 & SIMILAR & TRUNNION & Co & 500 & CAST ST & & 0 & 1 \\
\hline 32 & SIMILAR & TRUNNION & $\mathrm{Co}$ & 10 & CAST ST & & 0 & 0 \\
\hline 44 & SIMILAR & TRUNNION & Co & 200 & CAST ST & $13 \%$ & 3 & 3 \\
\hline 48 & SIMILAR & TRUNNION & Co & 250 & CAST ST & & 0 & 0 \\
\hline 3 & SIMILAR & HEAD & Co & & CAST ST & & 0 & 1 \\
\hline 5 & SIMILAR & HEAD & Co & & CAST ST & & 1 & 1 \\
\hline 7 & SIMILAR & HEAD & Co & & CAST ST & & 1 & 1 \\
\hline 21 & SIMILAR & HEAD & Co & & CAST ST & & 0 & 0 \\
\hline 22 & SIMILAR & HEAD & Co & & CAST ST & & 0 & 1 \\
\hline 25 & SIMILAR & HEAD & Co & 500 & CAST ST & $24 \%$ & 0 & 0 \\
\hline 1 & SIMILAR & HEAD & Co & 10 & W HC & & 0 & 1 \\
\hline 8 & SIMILAR & HEAD & Co & 8 & W HC & & 1 & 1 \\
\hline 9 & SIMILAR & HEAD & Co & 13 & W HC & & 0 & 0 \\
\hline 14 & SIMILAR & HEAD & Co & 40 & W HC & & 0 & 0 \\
\hline 17 & MIXED & HEAD & Co & 5 & W HC & $18 \%$ & 2 & 2 \\
\hline 20 & SIMILAR & HEAD & Co & 20 & W HC & & 0 & 1 \\
\hline 23 & SIMILAR & HEAD & Co & 10 & W HC & & 0 & 1 \\
\hline 28 & SIMILAR & HEAD & Co & 5 & W HC & $19 \%$ & 1 & 1 \\
\hline 32 & SIMILAR & HEAD & Co & 10 & W HC & & 0 & 1 \\
\hline 38 & SIMILAR & HEAD & Co & 10 & W HC & & 1 & 1 \\
\hline 42 & SIMILAR & HEAD & Co & 8 & W HC & $31 \%$ & 1 & 1 \\
\hline 46 & SIMILAR & HEAD & Co & 7 & W HC & & 1 & 1 \\
\hline
\end{tabular}




\begin{tabular}{|c|c|c|c|c|c|c|c|c|}
\hline 10 & SIMILAR & TRUNNION & $\mathrm{Co}$ & 10 & W LC & $28 \%$ & 1 & 1 \\
\hline 1 & SIMILAR & TRUNNION & $\mathrm{Co}$ & 10 & W LC & & 1 & 1 \\
\hline 3 & SIMILAR & TRUNNION & Co & 50 & W LC & & 0 & 1 \\
\hline 7 & SIMILAR & TRUNNION & Co & 50 & W LC & & 0 & 0 \\
\hline 9 & SIMILAR & TRUNNION & Co & 10 & W LC & & 0 & 0 \\
\hline 14 & SIMILAR & TRUNNION & $\mathrm{Co}$ & 75 & W LC & $22 \%$ & 0 & 0 \\
\hline 20 & SIMILAR & TRUNNION & $\mathrm{Co}$ & 50 & W LC & & 1 & 1 \\
\hline 21 & SIMILAR & TRUNNION & $\mathrm{Co}$ & 50 & W LC & & 0 & 0 \\
\hline 23 & SIMILAR & TRUNNION & Co & 10 & W LC & & 0 & 1 \\
\hline 35 & SIMILAR & TRUNNION & $\mathrm{Co}$ & 25 & W LC & & 0 & 0 \\
\hline 38 & SIMILAR & TRUNNION & $\mathrm{Co}$ & 10 & W LC & & 1 & 1 \\
\hline 40 & SIMILAR & TRUNNION & $\mathrm{Co}$ & 50 & W LC & & 3 & 3 \\
\hline 42 & SIMILAR & TRUNNION & $\mathrm{Co}$ & 50 & W LC & $26 \%$ & 0 & 1 \\
\hline 46 & SIMILAR & TRUNNION & Co & 10 & W LC & & 0 & 0 \\
\hline 2 & MIXED & HEAD & $\mathrm{Co}$ & 8 & W LC & & 2 & 2 \\
\hline 4 & MIXED & HEAD & $\mathrm{Co}$ & 8 & W LC & $25 \%$ & 3 & 3 \\
\hline 26 & MIXED & HEAD & $\mathrm{Co}$ & 8 & W LC & & 1 & 1 \\
\hline 36 & SIMILAR & HEAD & $\mathrm{Co}$ & 10 & W LC & $27 \%$ & 3 & 3 \\
\hline 39 & MIXED & HEAD & $\mathrm{Co}$ & & W LC & & 1 & 1 \\
\hline 44 & SIMILAR & HEAD & $\mathrm{Co}$ & 8 & W LC & $21 \%$ & 3 & 3 \\
\hline 48 & SIMILAR & HEAD & $\mathrm{Co}$ & 8 & W LC & & 0 & 0 \\
\hline 2 & MIXED & TRUNNION & $\mathrm{Ti}$ & & $\mathrm{Ti}$ & & 3 & 3 \\
\hline 4 & MIXED & TRUNNION & $\mathrm{Ti}$ & 5 & $\mathrm{Ti}$ & $14 \%$ & 3 & 3 \\
\hline 11 & MIXED & TRUNNION & $\mathrm{Ti}$ & & $\mathrm{Ti}$ & & 3 & 3 \\
\hline 15 & MIXED & TRUNNION & $\mathrm{Ti}$ & 20 & $\mathrm{Ti}$ & $15 \%$ & 3 & 2 \\
\hline 16 & SIMILAR & TRUNNION & $\mathrm{Ti}$ & & $\mathrm{Ti}$ & $27 \%$ & 2 & 2 \\
\hline 17 & MIXED & TRUNNION & $\mathrm{Ti}$ & & $\mathrm{Ti}$ & & 1 & 2 \\
\hline 26 & MIXED & TRUNNION & $\mathrm{Ti}$ & & $\mathrm{Ti}$ & $13 \%$ & 1 & 1 \\
\hline 31 & SIMILAR & TRUNNION & $\mathrm{Ti}$ & & $\mathrm{Ti}$ & $20 \%$ & 1 & 1 \\
\hline 33 & MIXED & TRUNNION & $\mathrm{Ti}$ & & $\mathrm{Ti}$ & & 1 & 1 \\
\hline 37 & MIXED & TRUNNION & $\mathrm{Ti}$ & & $\mathrm{Ti}$ & & 3 & 3 \\
\hline 39 & MIXED & TRUNNION & $\mathrm{Ti}$ & & $\mathrm{Ti}$ & $18 \%$ & 0 & 0 \\
\hline 47 & MIXED & TRUNNION & $\mathrm{Ti}$ & & $\mathrm{Ti}$ & $19 \%$ & 1 & 1 \\
\hline 16 & SIMILAR & HEAD & $\mathrm{Ti}$ & & $\mathrm{Ti}$ & $15 \%$ & 2 & 2 \\
\hline 31 & SIMILAR & HEAD & $\mathrm{Ti}$ & & $\mathrm{Ti}$ & & 1 & 1 \\
\hline 6 & SIMILAR & TRUNNION & $\mathrm{Co}$ & & $\mathrm{U}$ & & 0 & 0 \\
\hline 18 & SIMILAR & TRUNNION & $\mathrm{Co}$ & & $\mathrm{U}$ & & 1 & 1 \\
\hline 19 & SIMILAR & TRUNNION & $\mathrm{Co}$ & & $\mathrm{U}$ & & 0 & 0 \\
\hline 27 & SIMILAR & TRUNNION & $\mathrm{Co}$ & & $\mathrm{U}$ & & 0 & 0 \\
\hline 30 & SIMILAR & TRUNNION & Co & & $\mathrm{U}$ & & 0 & 0 \\
\hline
\end{tabular}




\begin{tabular}{|c|c|c|c|c|c|c|c|}
\hline 34 & SIMILAR & TRUNNION & $\mathrm{Co}$ & $\mathrm{U}$ & & 1 & 1 \\
\hline 41 & SIMILAR & TRUNNION & $\mathrm{Co}$ & $\mathrm{U}$ & $24 \%$ & 1 & 1 \\
\hline 43 & SIMILAR & TRUNNION & $\mathrm{Co}$ & $\mathrm{U}$ & & 1 & 0 \\
\hline 45 & SIMILAR & TRUNNION & Co & $\mathrm{U}$ & & 0 & 1 \\
\hline 6 & SIMILAR & HEAD & $\mathrm{Co}$ & $\mathrm{U}$ & & 1 & 1 \\
\hline 10 & SIMILAR & HEAD & $\mathrm{Co}$ & $\mathrm{U}$ & & 1 & 1 \\
\hline 11 & MIXED & HEAD & Co & $\mathrm{U}$ & & 3 & 3 \\
\hline 12 & SIMILAR & HEAD & Co & $\mathrm{U}$ & & 0 & 1 \\
\hline 13 & SIMILAR & HEAD & Co & $\mathrm{U}$ & & 0 & 1 \\
\hline 18 & SIMILAR & HEAD & $\mathrm{Co}$ & $\mathrm{U}$ & & 1 & 1 \\
\hline 19 & SIMILAR & HEAD & $\mathrm{Co}$ & $\mathrm{U}$ & & 1 & 1 \\
\hline 24 & SIMILAR & HEAD & $\mathrm{Co}$ & $\mathrm{U}$ & & 1 & 1 \\
\hline 27 & SIMILAR & HEAD & Co & $\mathrm{U}$ & & 1 & 1 \\
\hline 29 & SIMILAR & HEAD & $\mathrm{Co}$ & $\mathrm{U}$ & & 0 & 1 \\
\hline 30 & SIMILAR & HEAD & Co & $\mathrm{U}$ & & 1 & 1 \\
\hline 33 & MIXED & HEAD & $\mathrm{Co}$ & $\mathrm{U}$ & & 1 & 1 \\
\hline 34 & SIMILAR & HEAD & Co & $\mathrm{U}$ & & 1 & 2 \\
\hline 35 & SIMILAR & HEAD & $\mathrm{Co}$ & $\mathrm{U}$ & & 1 & 1 \\
\hline 37 & MIXED & HEAD & $\mathrm{Co}$ & $\mathrm{U}$ & & 3 & 3 \\
\hline 40 & SIMILAR & HEAD & $\mathrm{Co}$ & $\mathrm{U}$ & & 3 & 3 \\
\hline 41 & SIMILAR & HEAD & $\mathrm{Co}$ & $\mathrm{U}$ & & 2 & 2 \\
\hline 43 & SIMILAR & HEAD & $\mathrm{Co}$ & $\mathrm{U}$ & & 0 & 1 \\
\hline 45 & SIMILAR & HEAD & $\mathrm{Co}$ & $\mathrm{U}$ & & 0 & 0 \\
\hline 47 & MIXED & HEAD & $\mathrm{Co}$ & $\mathrm{U}$ & & 1 & 1 \\
\hline
\end{tabular}




\subsection{Typical Microstructure Morphology}

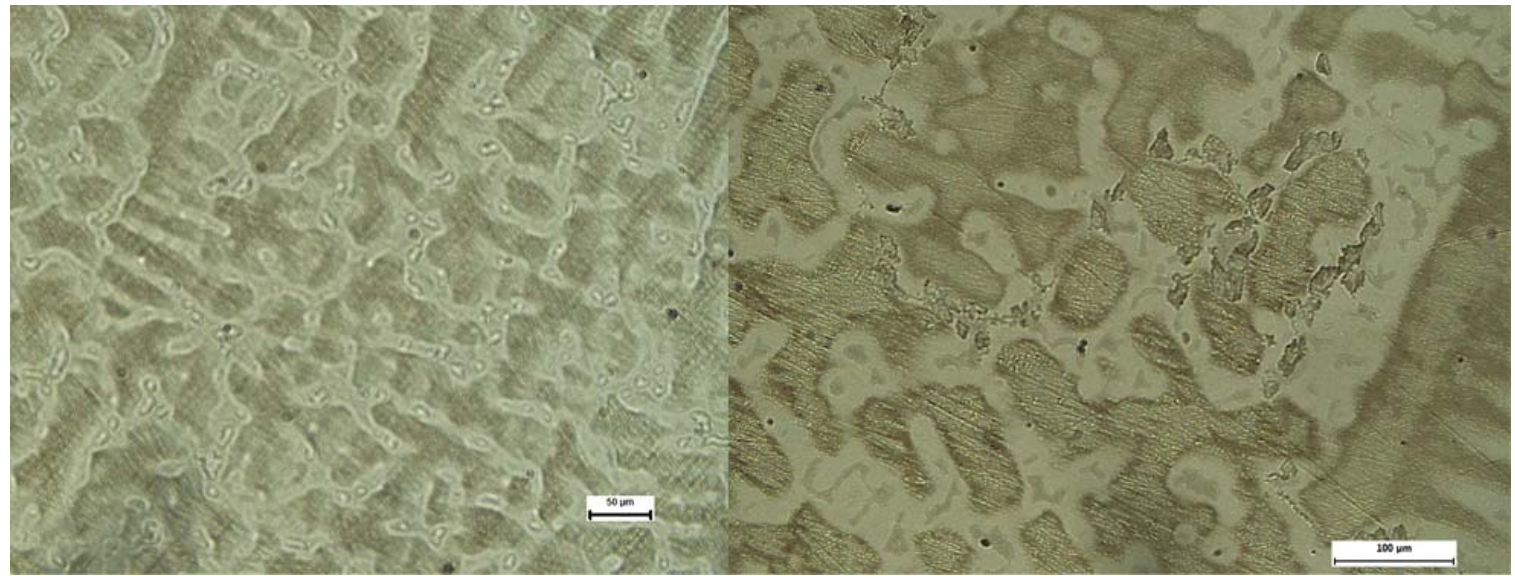

Figure 4.1. As-cast Co-Cr microstructure revealed after 50ml HCL + 4g K2S2O5 (Potassium Metabisulfite) $+4 \mathrm{~g} \mathrm{NaOH}+50 \mathrm{ml}$ water a) 50x magnification (b) Different as-cast sample at 100x magnification with larger dendritic arm spacing.

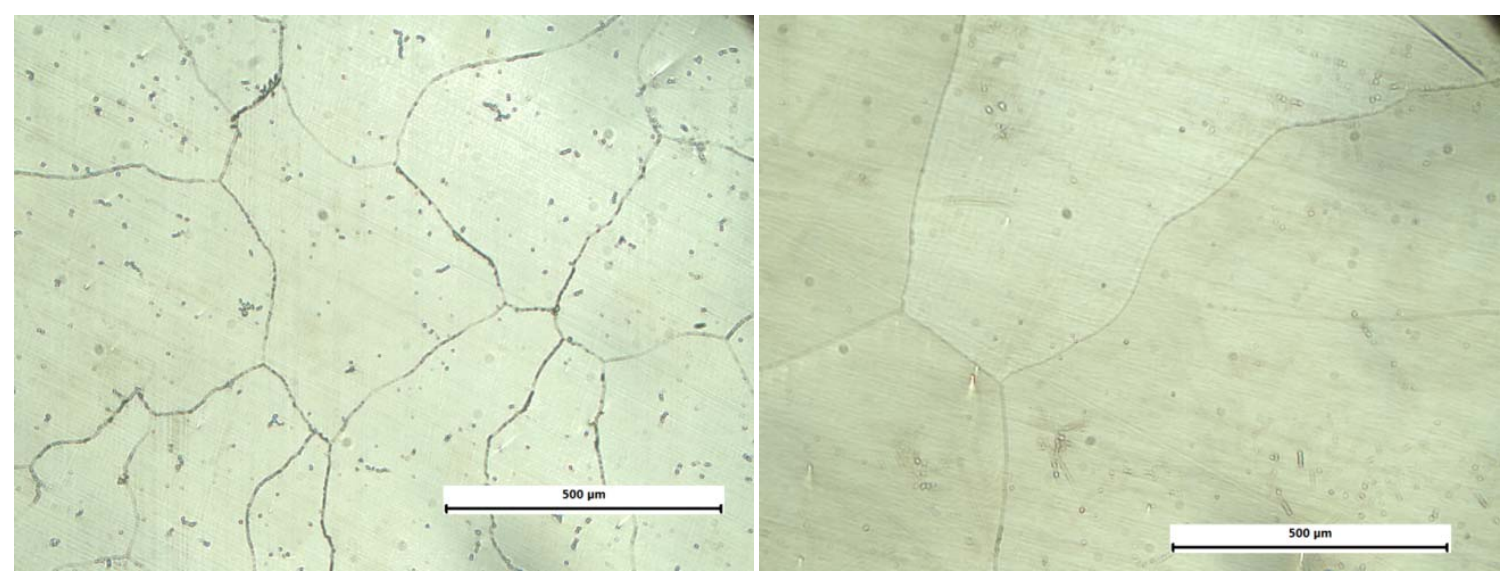

Figure 4.2. Solution Treated (ST) Co-Cr microstructure revealed after 50ml HCL $+4 \mathrm{~g}$ K2S2O5 (Potassium Metabisulfite) $+4 \mathrm{~g} \mathrm{NaOH}+50 \mathrm{ml}$ water (a) Nearly $100 \% \mathrm{ST}$ sample at 50x magnification showing small amounts of secondary phases within the grain boundaries. (b) Different ST sample at 50x magnification showing large $>500 \mu \mathrm{m}$ grains and miniscule amounts of secondary phases visible likely due to double ST and/or annealing. 


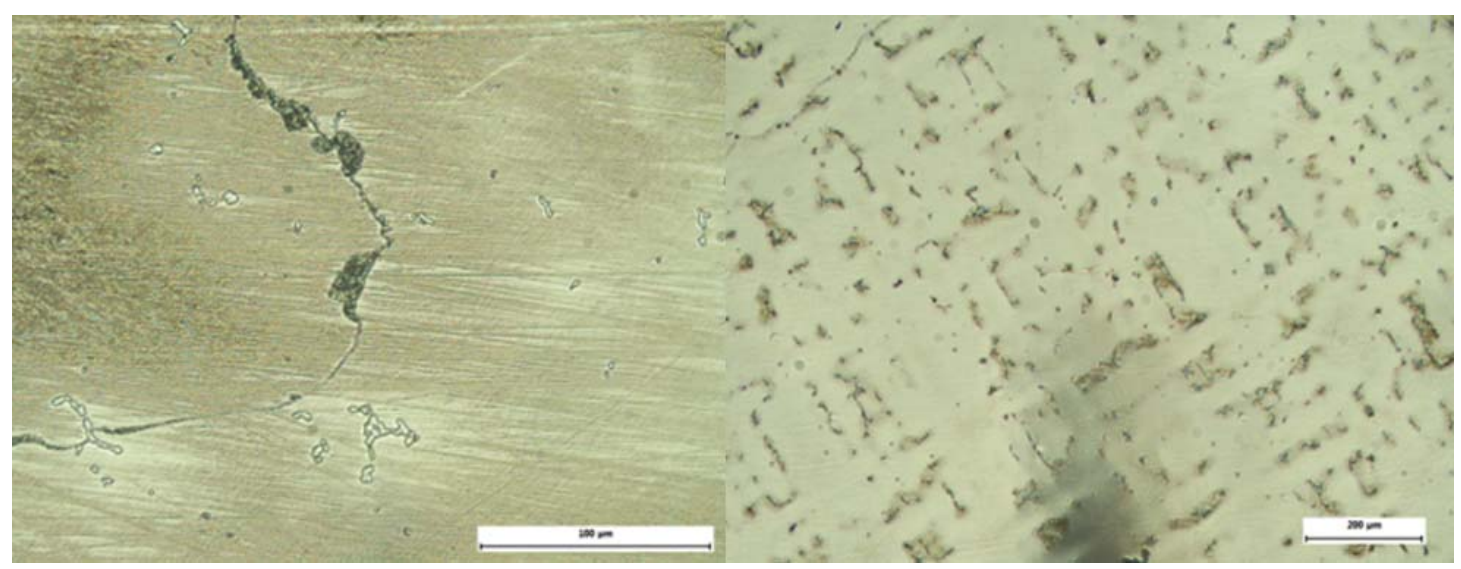

Figure 4.3. Solution Treated Co-Cr microstructure revealed after 50ml HCL + 4g K2S2O5 (Potassium Metabisulfite) $+4 \mathrm{~g} \mathrm{NaOH}+50 \mathrm{ml}$ water (a) ST sample at 200x magnification after slow cooling (b) Partially ST sample at 50x magnification.

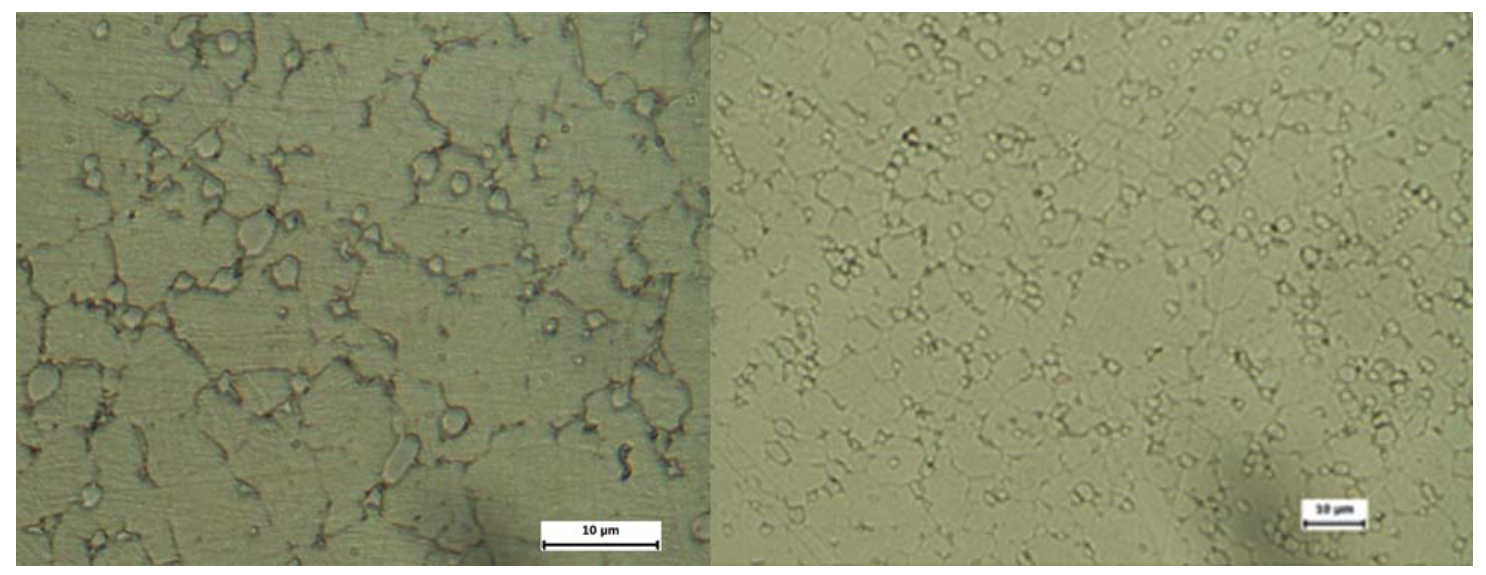

Figure 4.4. Wrought High Carbon Co-Cr microstructure revealed after 50ml HCL $+4 \mathrm{~g}$ $\mathrm{K} 2 \mathrm{~S} 2 \mathrm{O} 5$ (Potassium Metabisulfite) $+4 \mathrm{~g} \mathrm{NaOH}+50 \mathrm{ml}$ water (a) 1000x magnification (b) 100x magnification. 


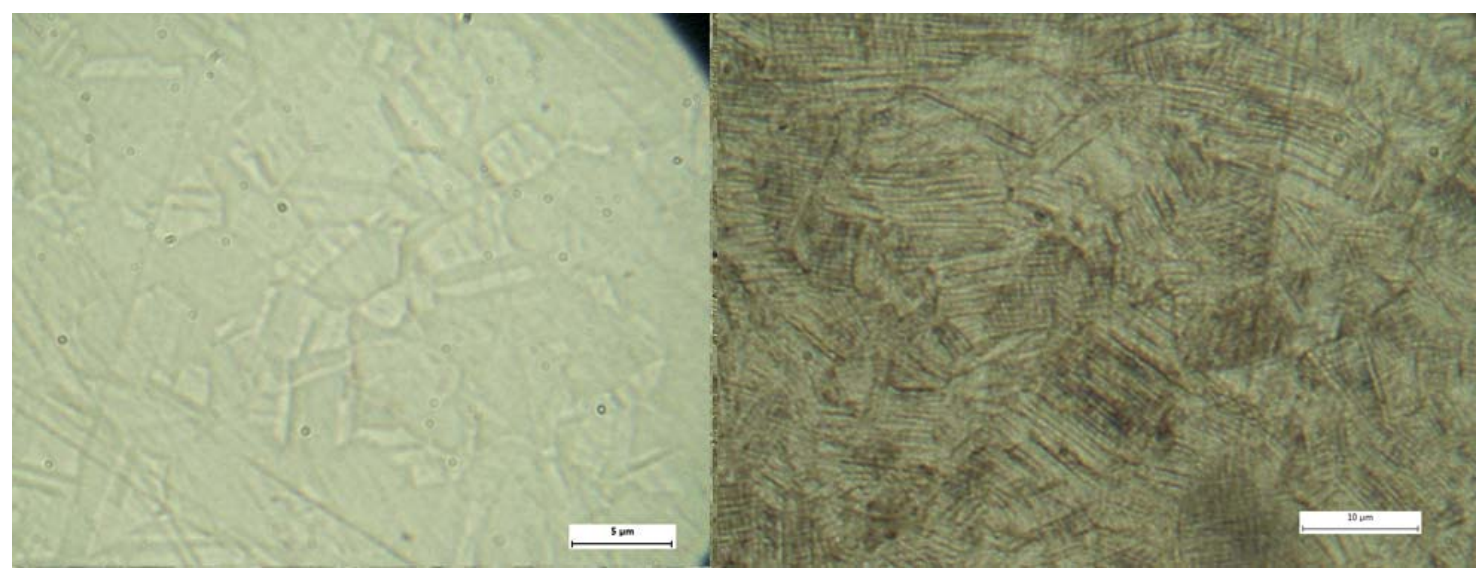

Figure 4.5. Wrought Low Carbon Co-Cr microstructure revealed after 50ml HCL $+4 \mathrm{~g}$ K2S2O5 (Potassium Metabisulfite) $+4 \mathrm{~g} \mathrm{NaOH}+50 \mathrm{ml}$ water (a) 1000x magnification (b) 500x magnification. Dark striations indicative of highly strained wrought $\mathrm{Co}-\mathrm{Cr}$ [21].

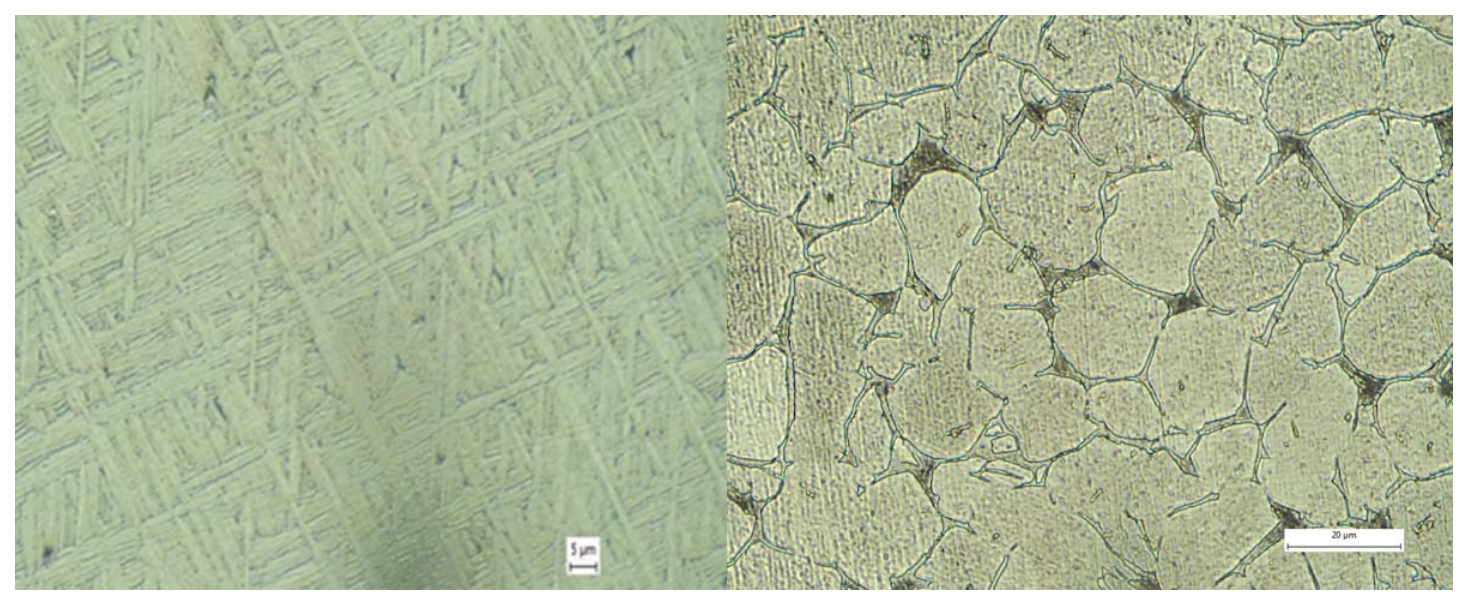

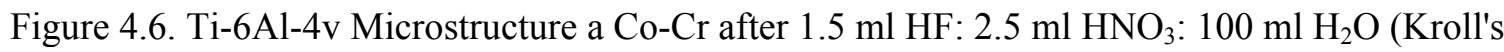
reagent) (a) Acicular microstructure at 1000x magnification (b) Equiaxed microstructure at 500x magnification . 


\subsection{Summary of Corrosion/Fretting Scores By Microstructure}

Co-Cr as-cast microstructures all demonstrated severe corrosion/fretting $(\mathrm{n}=2)$. Cast solution treated samples performed excellent with $95 \%$ having a maximum score of 0 or 1. Of the wrought LC and $\mathrm{HC}$ alloys, the high carbon variant performed best with $91 \%$ demonstrating a max score of 0 or 1 . Low carbon wrought performed slightly worse than the high carbon version with $76 \%$ with a max score of 0 or 1 and $19 \%$ with the most severe score of 3 . Among titanium alloys, $59 \%$ demonstrated a max score of 2-3, worse than all other categories except 'as-cast'.

Table 4.5. Worst fretting or corrosion score distribution by microstructure for all couple types.

\begin{tabular}{|lrrrrrr|}
\hline \multicolumn{5}{|c|}{ Worst Score by Microstructure for All Couples } \\
\hline \multicolumn{1}{|c}{ Microstructure lWorst Score } & 0 & $\mathbf{1}$ & $\mathbf{2}$ & $\mathbf{3}$ & Total \\
CO-CR As-Cast & 0 & 0 & 0 & 2 & 1 \\
\hline & $\mathbf{0 \%}$ & $\mathbf{0 \%}$ & $\mathbf{0 \%}$ & $\mathbf{1 0 0 \%}$ & \\
\hline $\begin{array}{l}\text { CO-CR Cast Solution } \\
\text { Treated }\end{array}$ & 7 & 10 & 0 & 1 & 18 \\
\hline CO-CR Wrought LC & $\mathbf{3 9 \%}$ & $\mathbf{5 6 \%}$ & $\mathbf{0 \%}$ & $\mathbf{5 \%}$ & \\
\hline & $\mathbf{3 3 \%}$ & 9 & 1 & 4 & 21 \\
\hline CO-CR Wrought HC & 2 & 8 & $\mathbf{5 \%}$ & $\mathbf{1 9 \%}$ & \\
\hline & $\mathbf{1 8 \%}$ & $\mathbf{7 3 \%}$ & $\mathbf{9 \%}$ & $\mathbf{0 \%}$ & \\
\hline Any Ti & 0 & 5 & 2 & 5 & 12 \\
\hline & $\mathbf{8 \%}$ & $\mathbf{4 2 \%}$ & $\mathbf{1 7 \%}$ & $\mathbf{4 2 \%}$ & \\
\hline
\end{tabular}

When excluding mixed couples, severe corrosion of low carbon wrought $\mathrm{Co}-\mathrm{Cr}$ decreases. The percentage of high carbon wrought demonstrating a maximum score of 2 or 3 is now $0 \%$, down from $9 \%$. There were no mixed-alloy couples with a solutiontreated Co-Cr component, therefore no changes were seen for ST. 
Table 4.6. Worst fretting or corrosion score distribution by microstructure for similar alloy couple types only.

\begin{tabular}{|lrrrrr|}
\hline \multicolumn{6}{|c|}{ Worst Scores by Microstructure For Similar-Alloy Couples Only } \\
\hline \multicolumn{1}{|c}{ Microstructure WWorst Score } & $\mathbf{0}$ & $\mathbf{1}$ & $\mathbf{2}$ & $\mathbf{3}$ & Total \\
CO-CR As-Cast & 0 & 0 & 0 & 1 & 1 \\
\hline & $\mathbf{0 \%}$ & $\mathbf{0 \%}$ & $\mathbf{0 \%}$ & $\mathbf{1 0 0 \%}$ & \\
\hline $\begin{array}{l}\text { CO-CR Cast Solution } \\
\text { Treated }\end{array}$ & 7 & 10 & 0 & 1 & 18 \\
\hline CO-CR Wrought LC & $\mathbf{3 9 \%}$ & $\mathbf{5 6 \%}$ & $\mathbf{0 \%}$ & $\mathbf{5 \%}$ & \\
\hline & 7 & 7 & 0 & 3 & 17 \\
\hline CO-CR Wrought HC & $\mathbf{4 1 \%}$ & $\mathbf{4 1 \%}$ & $\mathbf{0 \%}$ & $\mathbf{1 8 \%}$ & \\
\hline & 2 & 8 & 0 & 0 & 11 \\
\hline Ti/Ti & $\mathbf{1 8 \%}$ & $\mathbf{8 2 \%}$ & $\mathbf{0 \%}$ & $\mathbf{0 \%}$ & \\
\hline & 0 & 2 & 2 & 0 & 4 \\
\hline
\end{tabular}

Although solution treated and wrought $\mathrm{HC} / \mathrm{LC} \mathrm{Co}-\mathrm{Cr}$ samples clearly demonstrate excellent corrosion and fretting resistance, a closer examination of the 7 standout samples amongst this group, provide clues as to other important factors driving in-vivo damage. 


\subsection{High Moment Arms and Skirted Heads}

Of $18 \mathrm{Co}-\mathrm{Cr}$ cast and solution treated samples, sample 44-STEM was 1 of 4 in whose microstructure revealed large $300>\mu \mathrm{m}$, non-equiaxed grains containing significant secondary phases at the grain boundaries. This was the only $\mathrm{Co}-\mathrm{Cr}$ ST sample demonstrating severe or moderate corrosion/fretting. HCP phase fraction was calculated using the Sage and Guillaud method to be $33 \%$. The sample did not have a porous coating, which rules out a coating application as the cause of second phase precipitation. The $32 \mathrm{~mm}$, skirted femoral head was low carbon wrought with fine $5 \mu \mathrm{m}$ grains and a morphology typical of ASTM F1537. The femoral head hardness was measured at 400 Vickers at a 100lb loading. No clinical data was available for this implant, therefore the corrosion scores could not be normalized by in-vivo time. This skirted sample had a moment arm of $5.2 \mathrm{~mm}$, the 5th longest moment arm of the 32 implants that were measured. In-contact surface area was the fourth largest, $117 \mathrm{~mm}^{2}$ more than the median. Observed corrosion and fretting was uniformly distributed throughout the head and trunnion tapers, unlike the localized damage indicative of taper angle mismatch. It seems plausible, given the relationship between offset and corrosion/fretting seen in the remaining samples, that the high offset coupled with the $32 \mathrm{~mm}$ head size might be the key precipitating factor for sample 44 . 


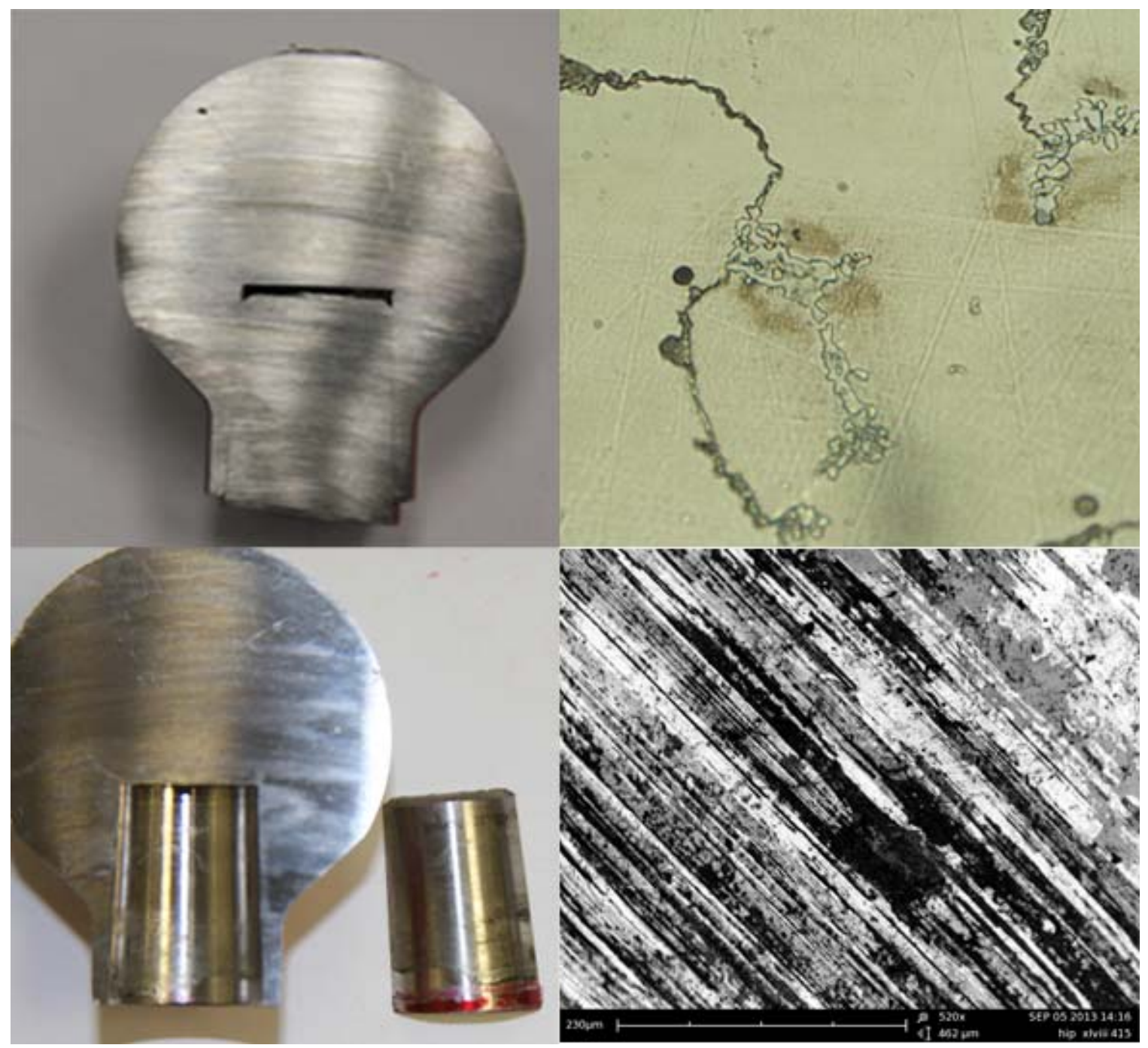

Figure 4.7. Sample \#44. (Top-left) trunnion-head assembly. Note very high offset. (Top-right) Etched ST Co-Cr microstructure at 500X magnification revealing secondary phases at grain boundaries. (Bottom-Left) Disengaged trunnion revealing uniformly distributed corrosion black corrosion products on both tapers. (Bottom-Right) SEM image of machine lines demonstrating extensive fretting and corrosion. 


\subsection{Variable Contact Length Tapers and Crevice Corrosion}

Mixed-alloy couple samples \#2 and \#4 demonstrated the most extensive corrosion of any sample examined, with wide and deep areas of titanium alloy completely corroded away. Likewise, the cobaltheads showedsevere corrosion concentrated in the areas immediately opposed to the largest pit seen on the titanium taper, in what was the most severe corrosion attack on any cobalt alloy examined. Although samples \#2 and \#4 were different models, they both incorporated the same two taper features which were not seen in any other sample, namely, flattened neck notches (intended for increasing range of motion) that extended far into the femoral head, and a taper contact area of only 2-fold symmetry, leading to variable taper contact length. The variable contact length creates a tortuous taper edge that extend deep into the femoral head. Together these features result in a crevice large enough to allow fluids to enter but small enough to allow for stagnation, creating ripe conditions for crevice corrosion. 


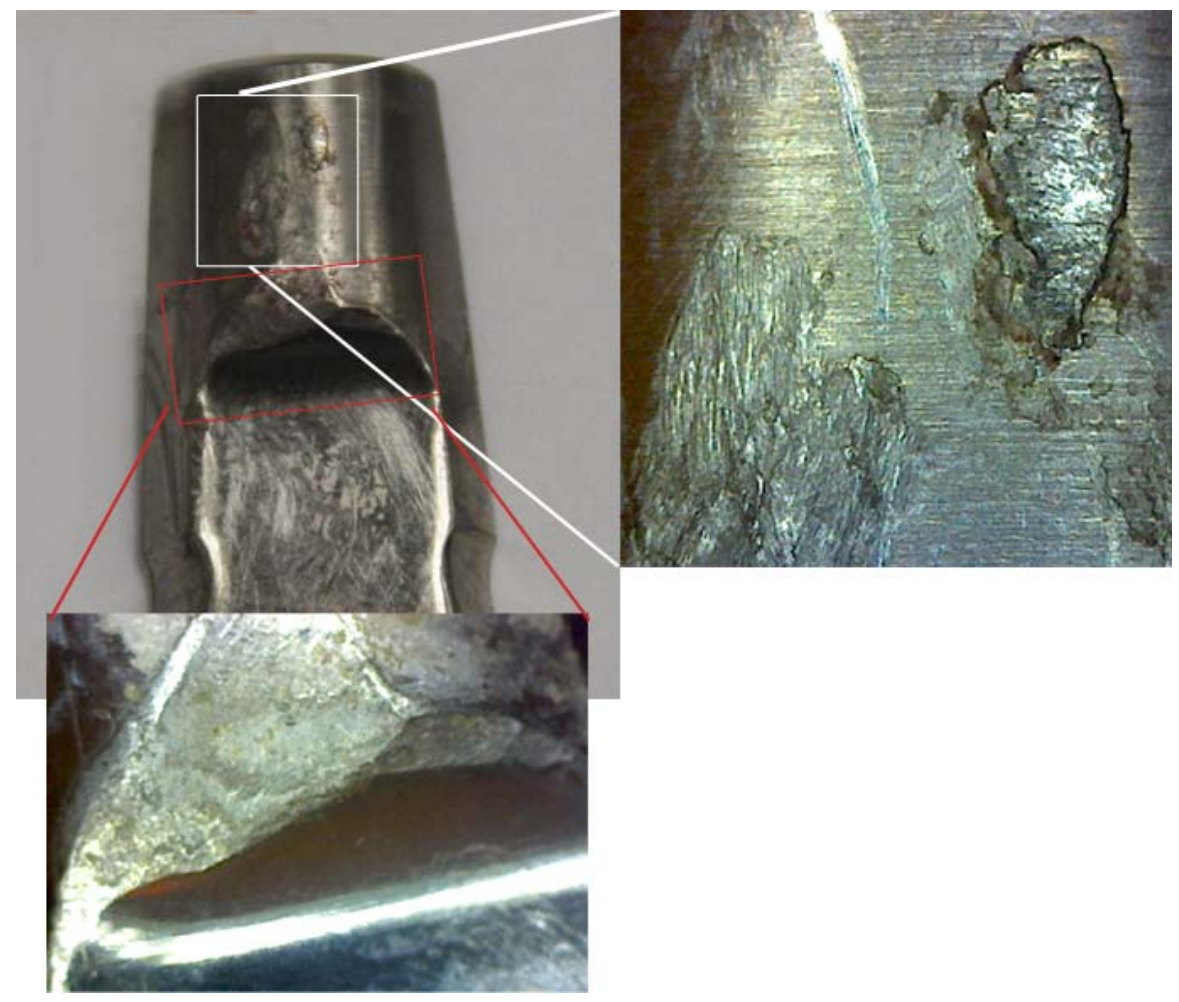

Figure 4.8. Extensive Corrosion seen in Titanium Sample with a Variable Taper Contact Length. (Lower-Left inset) Taper showing significant loss of material at the taper edge, indicative of crevice corrosion. (Upper-Right inset) Large and deep corrosion pit approximately $2 \mathrm{~mm}$ in length and $1 \mathrm{~mm}$ in width.

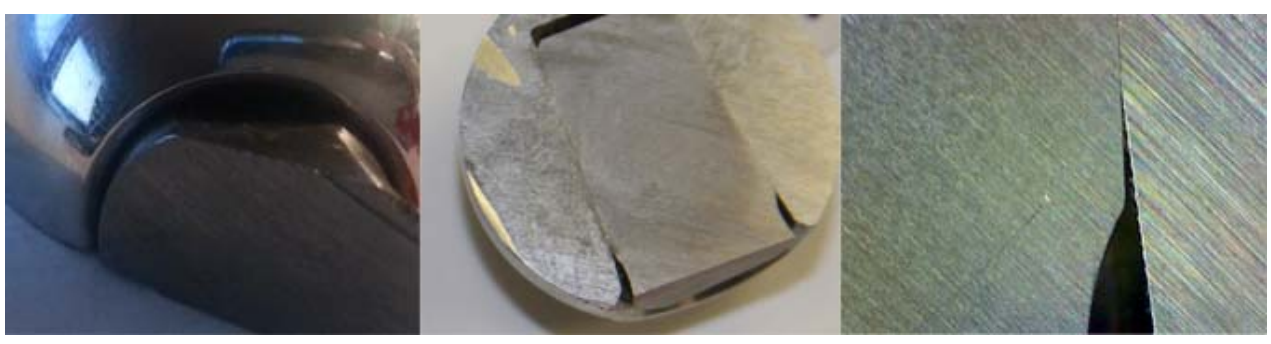

Figure 4.9. (Left) Notch extending deep into femoral head. (Center and Right) Crevice at the trunnion-head interface.

Despite different Ti-6Al-4V stem microstructures, both samples demonstrated the same corrosion pattern and on both sides of the trunnion. The moment arm for both 
samples was the most negative of any other sample. Both samples were received with engaged trunnions and were only separated after sectioning, ruling out disengagement damage. Clinical data was only available for one of the two samples and the diagnosis at the time of retrieval was determined to be periprosthetic osteolysis, in agreement with what theory dictates should occur with significant amount of metal ion release.

\subsection{As-Cast/Dendritic Microstructure: Sensitization and Intergranular Corrosion}

All samples with a dendritic $\mathrm{Co}-\mathrm{Cr}$ microstructure, otherwise referred to as-cast due to its formation during the initial investment casting, exhibit severe corrosion and fretting. While there are only two samples with the as-cast microstructure, there is strong evidence that the same results can be expected with larger sample sizes. The small number of as-cast samples is likely not due to their discontinuance, but rather because they are predominately used in metal-on-metal prostheses, which were excluded from this sample set. 


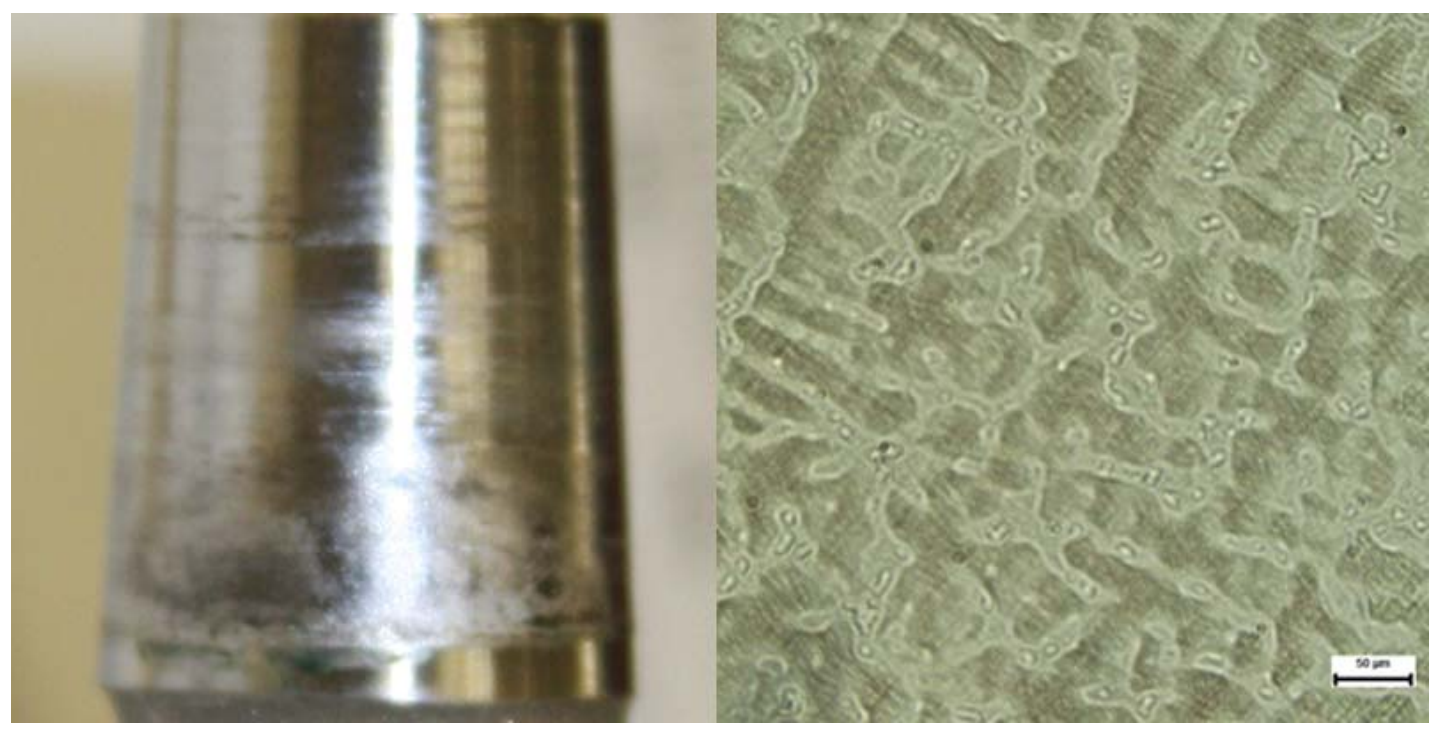

Figure 4.10. (Left) As-Cast Co-Cr trunnion taper exhibiting severe corrosion and fretting. (Right) Revealed dendriticmicrostructure at 100X magnification after etching with 50ml HCL $+4 \mathrm{~g}$ $\mathrm{K} 2 \mathrm{~S} 2 \mathrm{O} 5+4 \mathrm{~g} \mathrm{NaOH}+50 \mathrm{ml}$ water.

The first sample consists of an as-cast, porous coated stem, with a skirted, LC wrought Co-Cr head. Bulk hardness was measured at 450 vickers for the as-cast stem versus 480 vickers for the LC wrought head. SEM image of the distal taper region shows how the as-retrieved taper has corroded sufficiently to reveal the dendritic microstructure and carbides with great detail (compare to the purposely etched microstructure during metallography). The white strip is a tungsten coating added for subsurface protection during focused ion beam milling. Figure 4.6 shows ion channeling contrast enhanced image of the subsurface after focused ion beam milling, revealing different subsurface morphology below $\sim 10 \mu \mathrm{m}$. These features might be caused by subsurface wear or corrosive processes. 


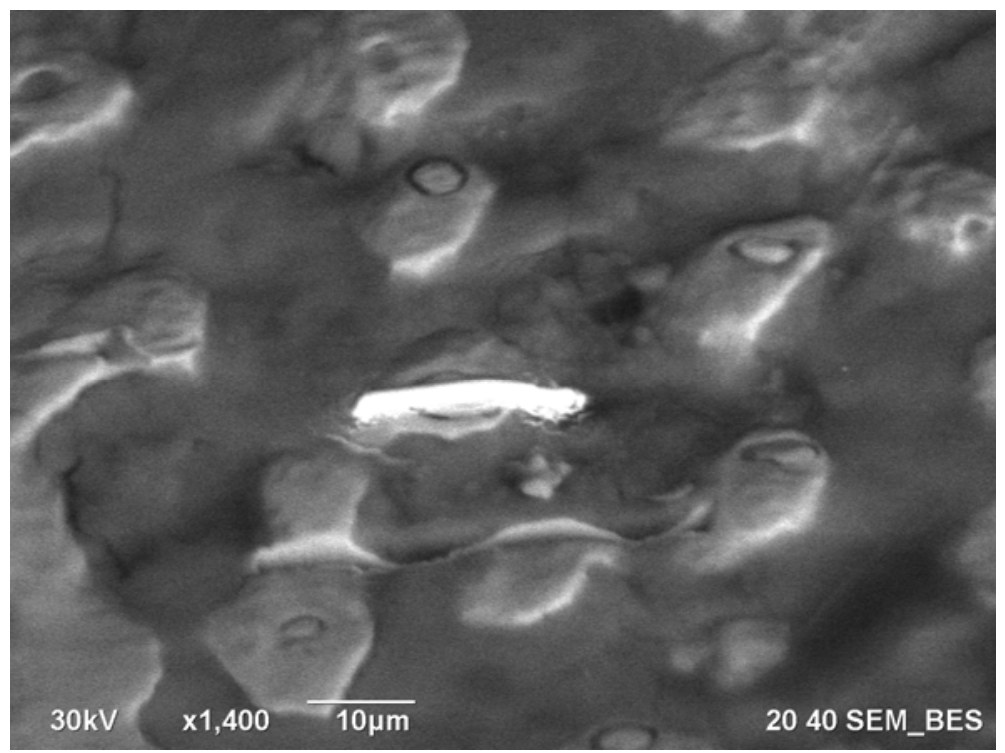

Figure 4.11. 1,400X magnification SEM image of as-retrieved as-cast Co-Cr trunnion taper, revealing the dendritic microstructure etched in-vivo. Note absence of machining lines.

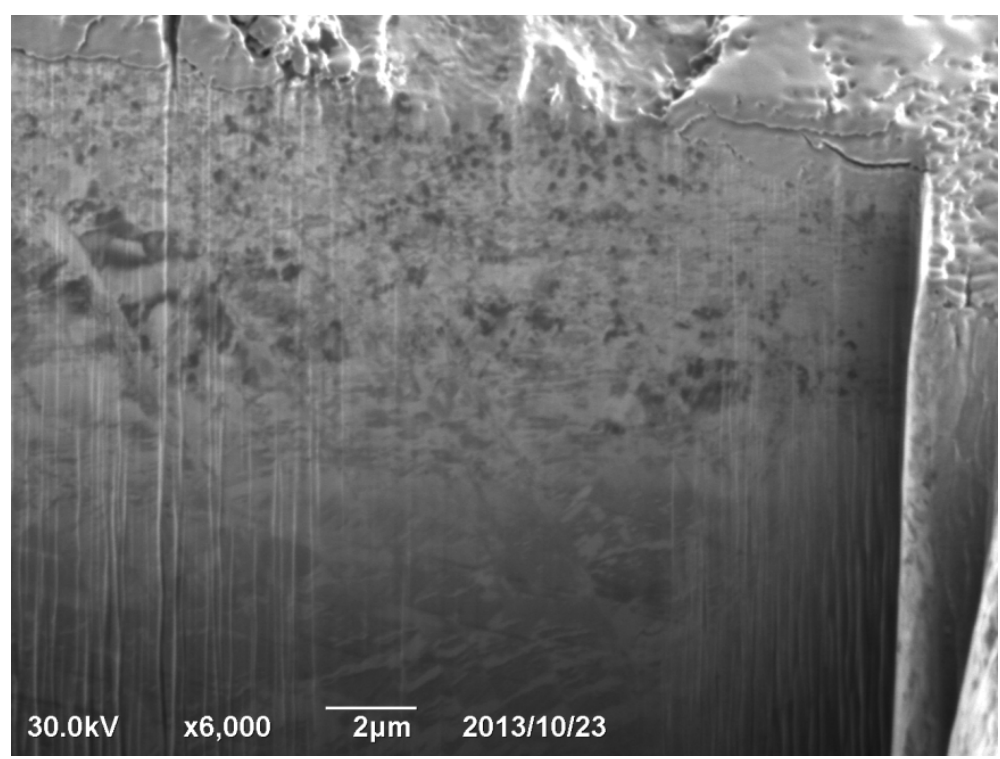

Figure 4.12. Ion channeling contrast enhanced image of taper subsurface at 6,000X magnification, revealing differences in morphology near the surface. 
Energy dispersive spectroscopy of the subsurface regions indicates that the weight percent of the primary corrosion resistant elements, chromium and molybdenum, decrease towards the surface. This finding agrees with finding of several authors who indicate that the corrosion products formed at $\mathrm{Co}-\mathrm{Cr}$ modular interfaces mostly consist of chromium orthophosphates. Note the SEM image as compared to the ion contrast channeling enhanced image and the lack of subsurface features.

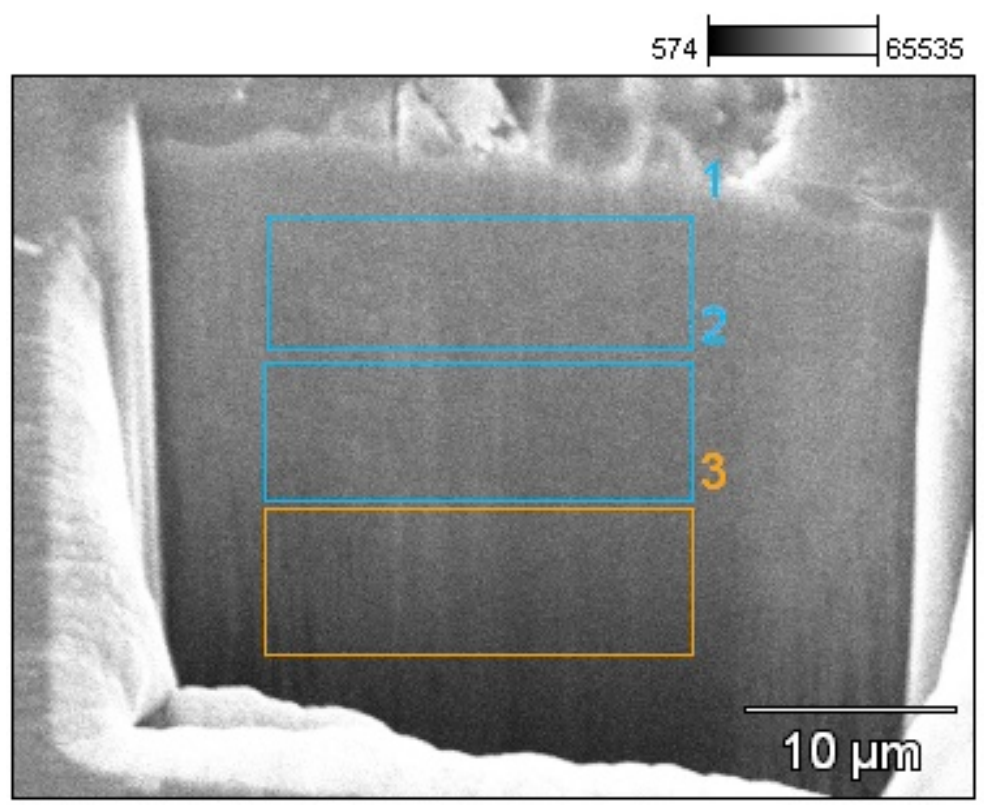

Figure 4.13. FIB trench subsurface regions selected for energy dispersive spectroscopy analysis. 


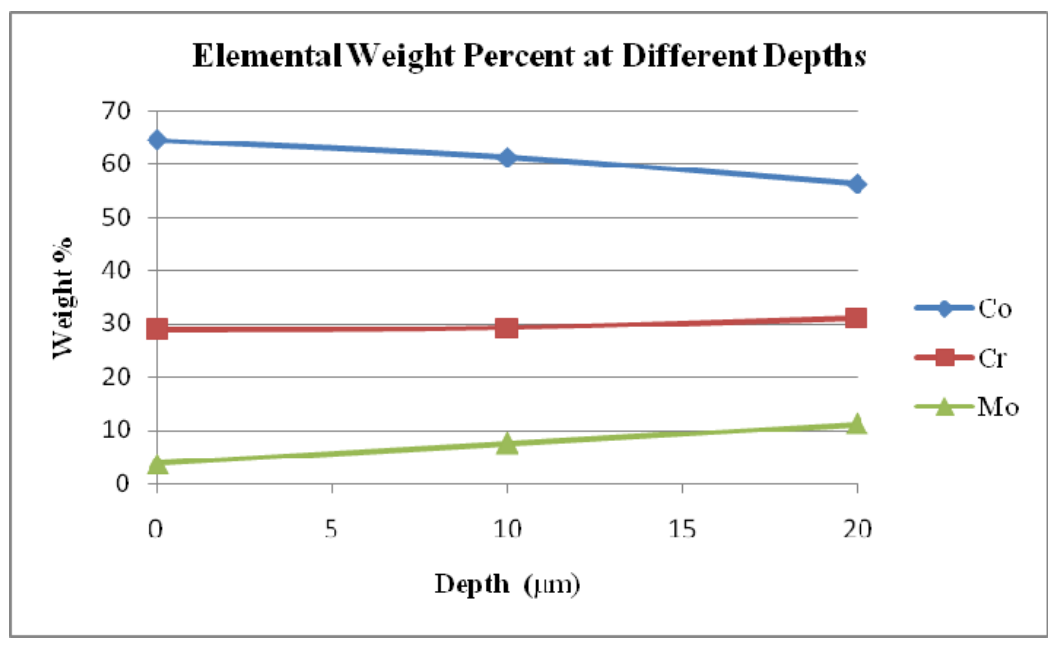

Figure 4.14. Cobalt, chromium, and molybdenum elemental weight percent at different depths as determined by EDS.

Energy dispersive spectroscopy of the dendritic microstructure confirmed increased molybdenum and chromium in the areas surrounding the spherical features likely to be M23C6 carbides, as analyzed by selected area electron diffraction (SAED). This confirms the microstructural features which form during slow cooling from the liquidus phase during investment casting. The preferential attack of the matrix is consistent with the sensitization effect expected due to the segregation of higher melting point elements, particularly the corrosion resistance imparting additive, chromium. 


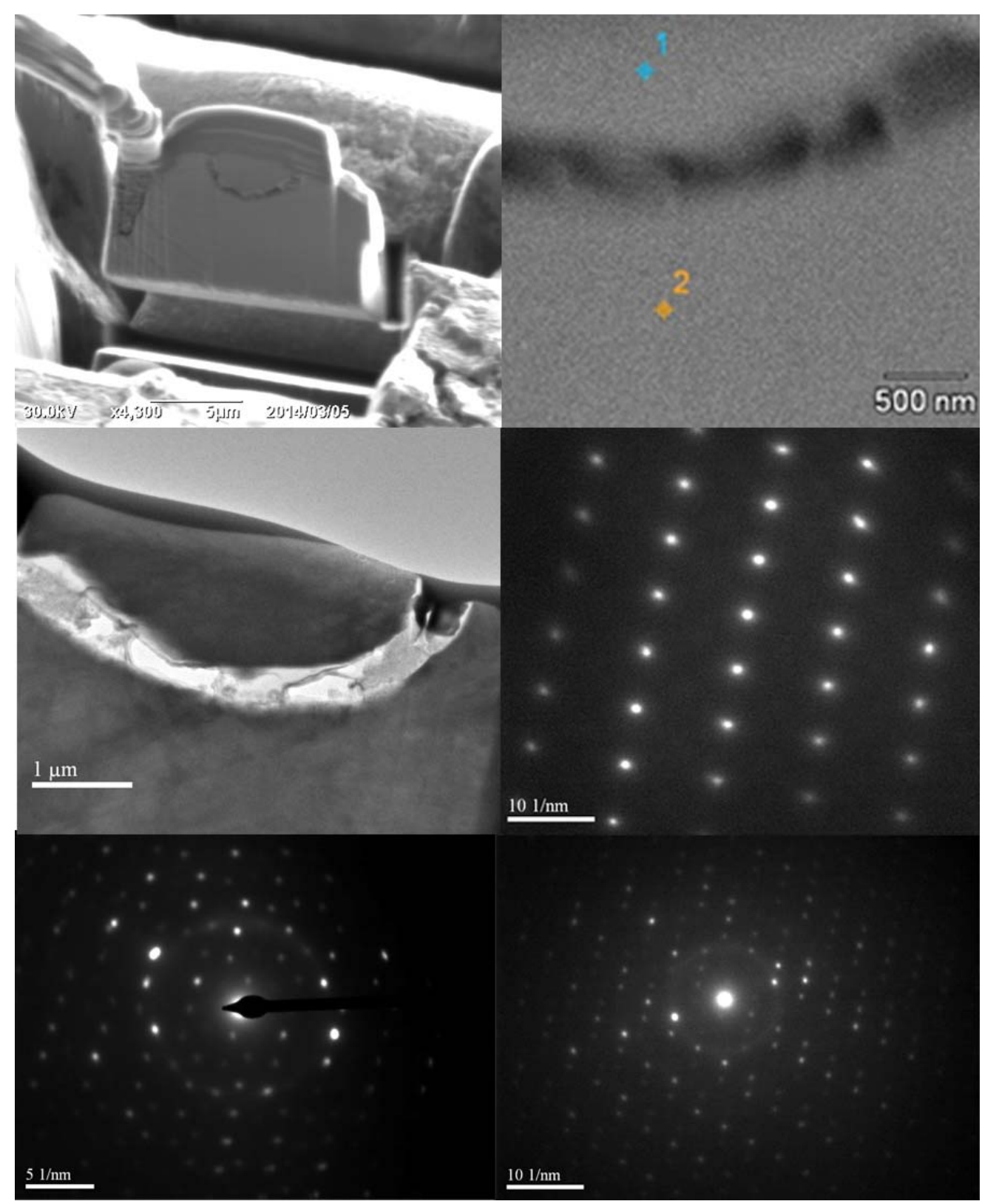

Figure 4.15. (Left to right) 1. FIB sample pull out of as-cast carbide in matrix. 2. Areas from which EDS and TEM diffraction patterns were taken. 3. TEM image of carbide and matrix. 4. SAED pattern of matrix. 5. SAED of region between second phase and matrix 6. SAED of second phase particle. 
The second Co-Cr as-cast sample was coupled to a titanium trunnion with a globular microstructure, showed severe corrosion throughout the entire taper, but was most severe near the bore opening. There were signs of micropitting towards the middle of head taper where the machine lines were still visible. Corrosion on the titanium trunnion was most severe near the bottom facing side of the stem taper, although corrosion was visible all throughout the circumference of the taper. This wear pattern might be indicative of a taper angle mismatch. Unlike the as-cast head, corrosion on the titanium taper was exclusive to the area the circumference on the distal end of the taper, demarcating the inside and exposed areas of the junction. Bulk hardness was measured at 340 Vickers for the as-cast head, softer than the previous as-cast sample, versus 280 Vickers for the titanium stem.

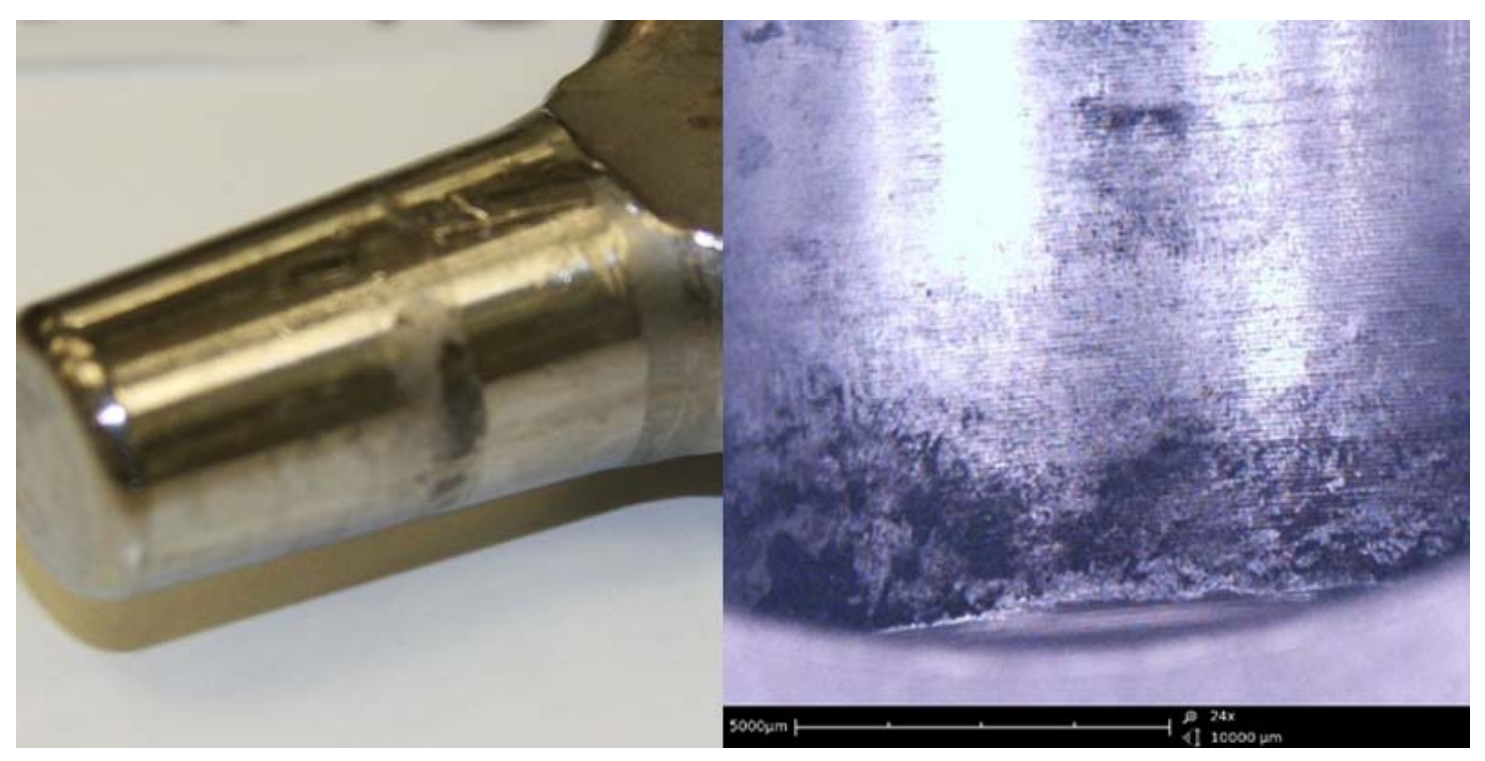

Figure 4.16 Extensive corrosion seen in mixed-alloy couple. (Left) Titanium trunnion showing severe corrosion near bore opening. (Right) As-cast Co-Cr femoral head exhibiting severe corrosion attack. 


\subsection{Titanium on Titanium Couples: Discerning The role of Galvanic Corrosion in Ti/Co Mixed Alloy Couples}

Two samples consisted of the rare combination of a titanium head on a titanium trunnion. The use of titanium heads is rarely seen or offered by manufacturers due to poor wear resistance and a tendency to gall, likely explaining why they are rarely discussed in the literature. Nevertheless, there is value to be had in their analysis, as they shed light on whether the higher corrosion/fretting scores seen for mixed Ti/Co couples as compared to $\mathrm{Co} / \mathrm{Co}$ couples is due to galvanic effects, differences in tribological behavior or perhaps simply due to a unique susceptibility of titanium to the physiological electrochemical environment.

Notably, one $\mathrm{Ti} / \mathrm{Ti}$ couple exhibited only mild/moderate corrosion and fretting after an impressive 21 years in-vivo, despite one of the lowest taper contact surface areas of any sample. The corrosion/fretting observed predominantly manifested itself as a hazy dullness throughout the taper and a small amount dark corrosion debris on the trunnion tapers, similar in appearance to titanium galling. Overall the corrosion and fretting observed was underwhelming. Of note was the severely worn and brown bearing surface which was the likely cause of the clinically reported massive osteolysis and metallosis. This last observation is in agreement with the generally accepted reason why titanium should not and is not, for the most part, used as a bearing material. The second Ti/Tialso exhibited only mild corrosion and fretting, and similar bearing surface issues after 9 years in-vivo. 


\subsection{Influence of Moment Arm Length}

Table 4.7. Worst fretting or corrosion score distribution by moment arm length.

\begin{tabular}{|c|c|c|c|c|c|}
\hline \multicolumn{6}{|c|}{ Worst Trunnion/Head Score by Moment Arm Length } \\
\hline Moment-Arm IWorst Score & $\mathbf{0}$ & 1 & 2 & 3 & Total \\
\hline \multirow[t]{2}{*}{$<4.78 \mathrm{~mm}$} & 0 & 4 & 0 & 0 & 4 \\
\hline & $0 \%$ & $100 \%$ & $0 \%$ & $0 \%$ & \\
\hline \multirow[t]{2}{*}{$-4.78 \mathrm{~mm} \geq$ and $<-1.82 \mathrm{~mm}$} & 0 & 8 & 1 & 1 & 10 \\
\hline & $0 \%$ & $80 \%$ & $10 \%$ & $10 \%$ & \\
\hline \multirow[t]{2}{*}{$--1.82 \mathrm{~mm} \geq$ and $<1.14 \mathrm{~mm}$} & 1 & 5 & 2 & 2 & 10 \\
\hline & $10 \%$ & $50 \%$ & $20 \%$ & $20 \%$ & \\
\hline \multirow[t]{2}{*}{$1.14 \mathrm{~mm} \geq$ and $<4.11 \mathrm{~mm}$} & 0 & 3 & 0 & 0 & 3 \\
\hline & $0 \%$ & $100 \%$ & $\mathbf{0 \%}$ & $\mathbf{0 \%}$ & \\
\hline \multirow[t]{2}{*}{$\geq 4.11 \mathrm{~mm}$} & 0 & 1 & 0 & 3 & 4 \\
\hline & $0 \%$ & $10 \%$ & $0 \%$ & $75 \%$ & \\
\hline
\end{tabular}

The moment arm or more precisely, the distance from the center of pressure of the femoral head to the proximal taper contact, appears to have varying degrees of influence on fretting and corrosion. At lower moment arm (MA) values, particularly negative values where the taper extends beyond the center of the femoral head, corrosion and fretting scores is non-existent or mild in $100 \%$ of the lowest MA values and $80 \%$ for MA values between $-4.78 \mathrm{~mm}$ and $-1.82 \mathrm{~mm}$. For MA values near $0 \mathrm{~mm}$, this pattern persists for $60 \%$ of prostheses. At the highest MA values, $75 \%$ of samples exhibit severe corrosion and fretting. Between $1.14 \mathrm{~mm}$ and $4.11 \mathrm{~mm}$, there is a break in the pattern with $100 \%$ of prostheses exhibiting mild fretting/corrosion.

The few poorly performing prostheses with MA values of zero or below include a mixed alloy as-cast sample, a rare $\mathrm{Ti} / \mathrm{Ti}$ with 21 years in-vivo, a 3rd year in-vivo 
fractured $\mathrm{Ti} / \mathrm{Co}$, and a wrought low carbon sample with 12 years in-vivo implanted on a 47 year old female. Amongst the high performing samples in the same negative MA group, there are various samples with 7 to 16 years in-vivo only exhibiting mild corrosion and fretting.

Samples with the longest moment arms $(\geq 4.11 \mathrm{~mm})$ all require a skirted femoral head to maintain high contact surface area at such low head penetrations. Nevertheless, contact surface area alone does not seem to be correlated with corrosion/fretting . While at these high offsets some of the worst performing prosthesis can be found, there are also excellent performers, particularly of high carbon wrought heads on low carbon wrought femoral stems.

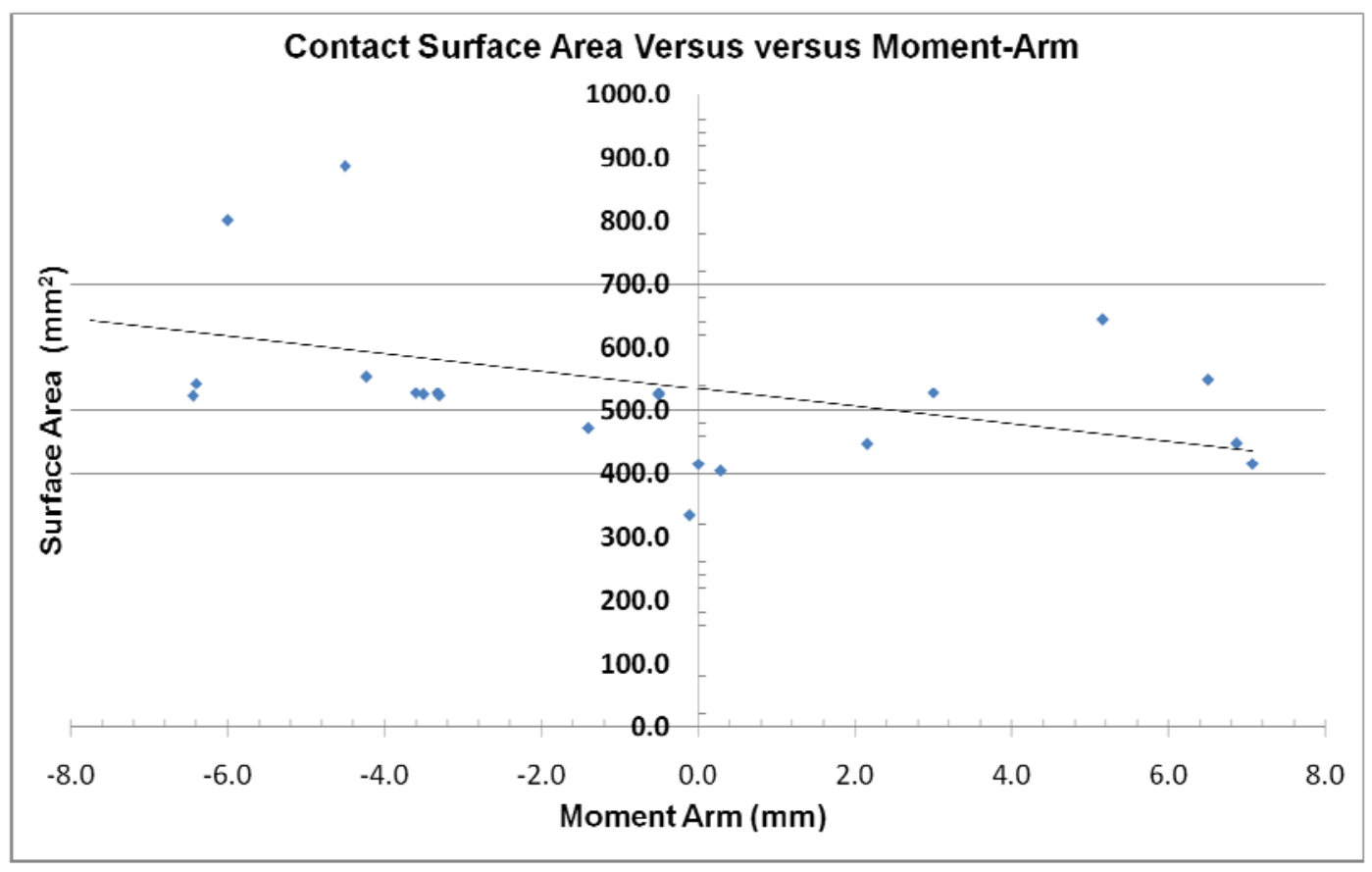

Figure 4.17. Scatter plot of taper contact surface area versus head-trunnion moment arm length. 


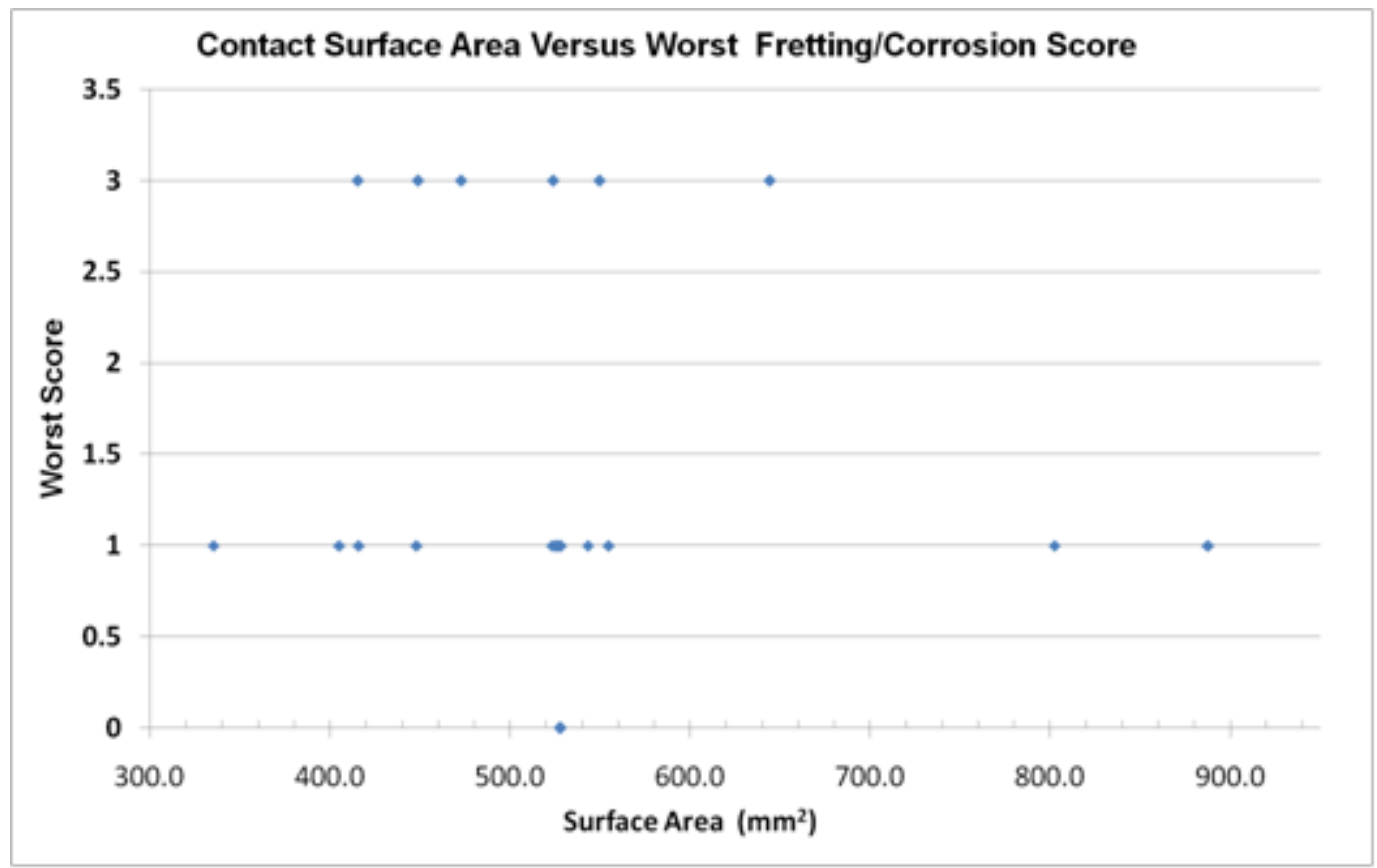

Figure 4.18. Scatter plot of contact surface area versus worse fretting or corrosion score.

\subsection{Influence of Femoral Head Size}

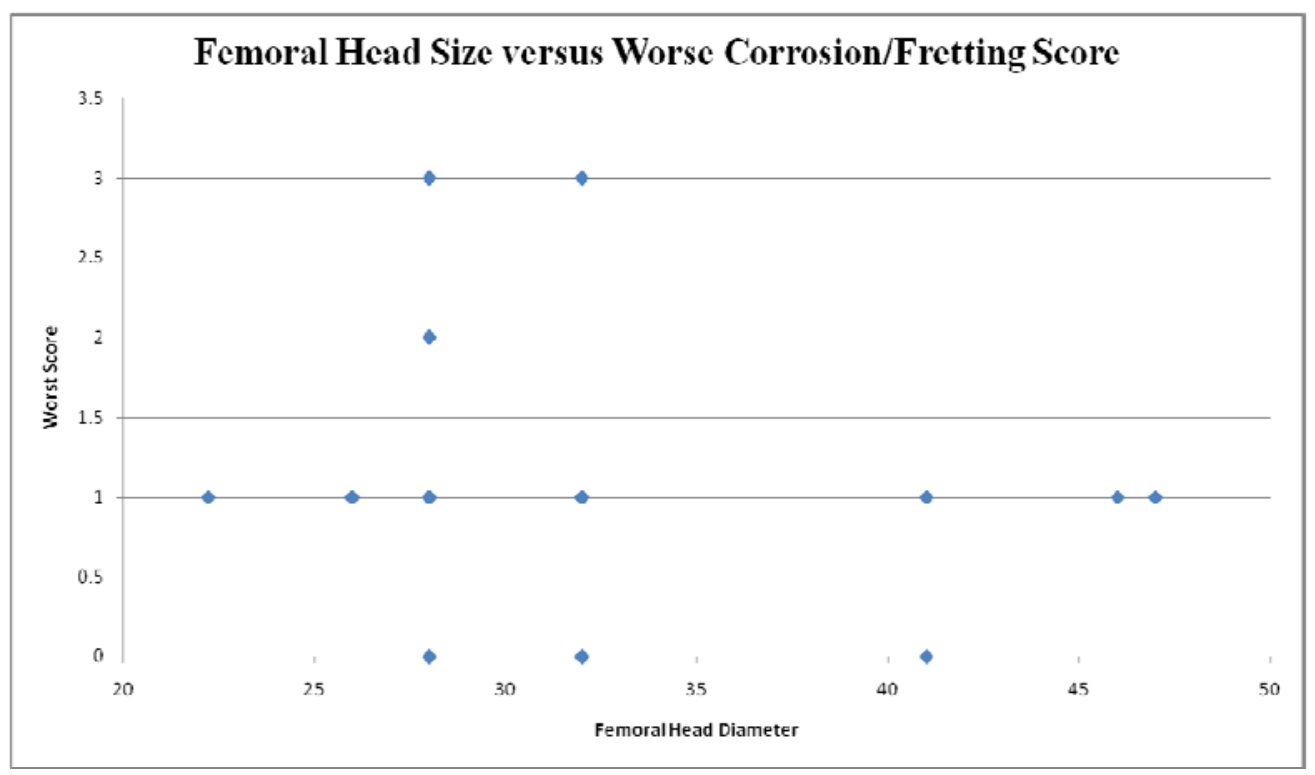

Figure 4.19. Scatter plot of femoral head size versus worse fretting or corrosion score. 
Of 6 samples with a femoral head size greater than $32 \mathrm{~mm}$, neither demonstrated a score greater than 1 for corrosion or fretting. Femoral head sizes in this grouped ranged from $41 \mathrm{~mm}$ to $46 \mathrm{~mm}$ in diameter. Two of 8 , or $25 \%$ of samples with a femoral head size of $32 \mathrm{~mm}$ exhibited fretting/corrosion score of 2 or greater. Possibly contributing to the excellent scores seen with the large diameter heads is the zero or negative moment arm values seen for all large diameter heads. Large diameter prostheses can achieve the same overall neck lengths at lower moment arms, as compared to smaller heads. This appears to be a factor that has not been considered in most studies indicating greater wear for larger heads. The role of increased torque at the bearing surface translating to greater micromotion at the taper might be reduced by the increased trunnion/neck diameters seen in the large femoral head samples included in our sample set. All of the larger $>32 \mathrm{~mm}$ heads were cast and solution treated. ST Co-Cr has been associated with higher bearing surface wear as compared to as-cast or wrought alloys and might be a more likely cause of failure with these prostheses. However, the bearing surface was not examined as a part of this study. 


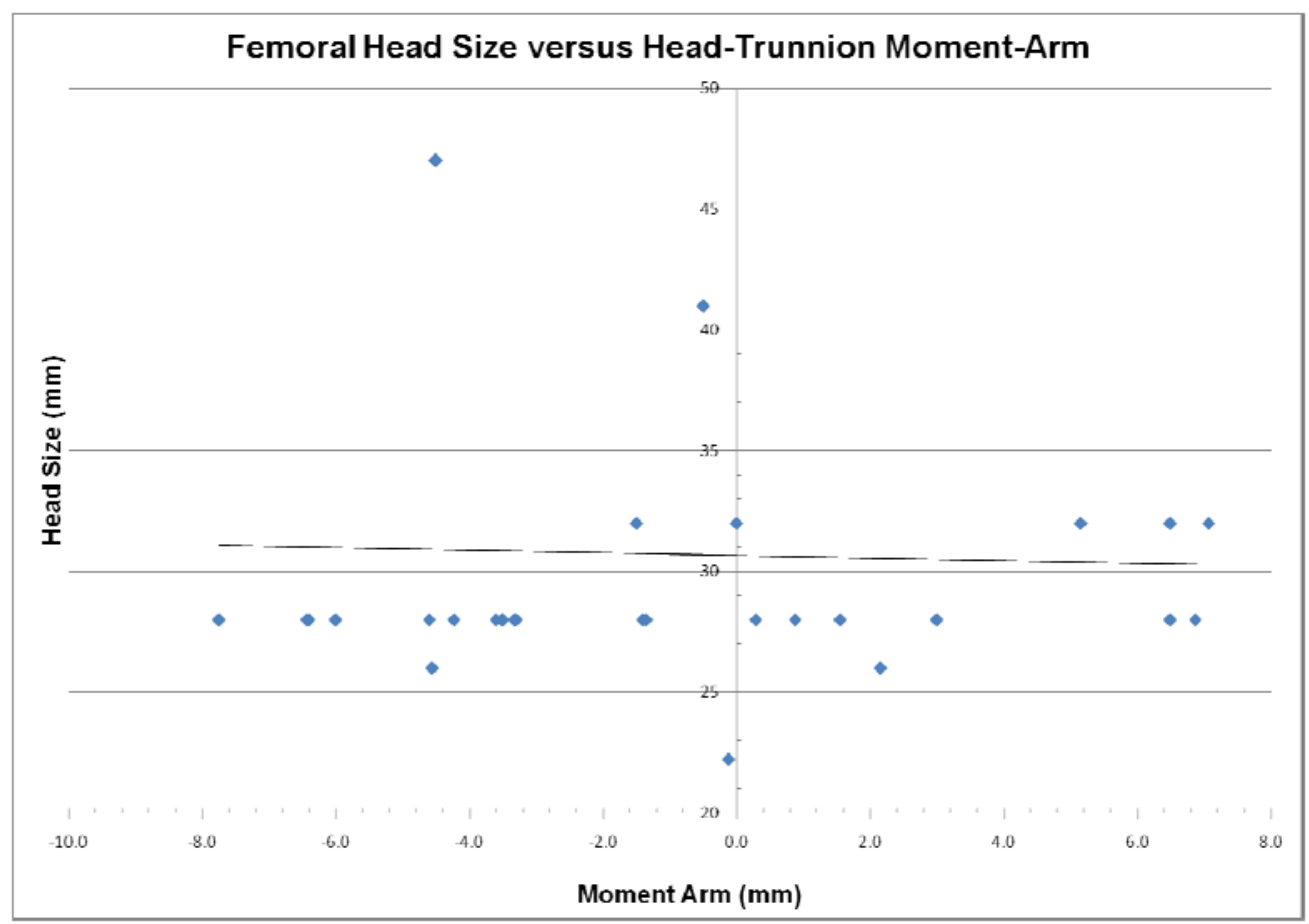

Figure 4.20. Scatter plot of femoral head size versus head-trunnion moment-arm length.

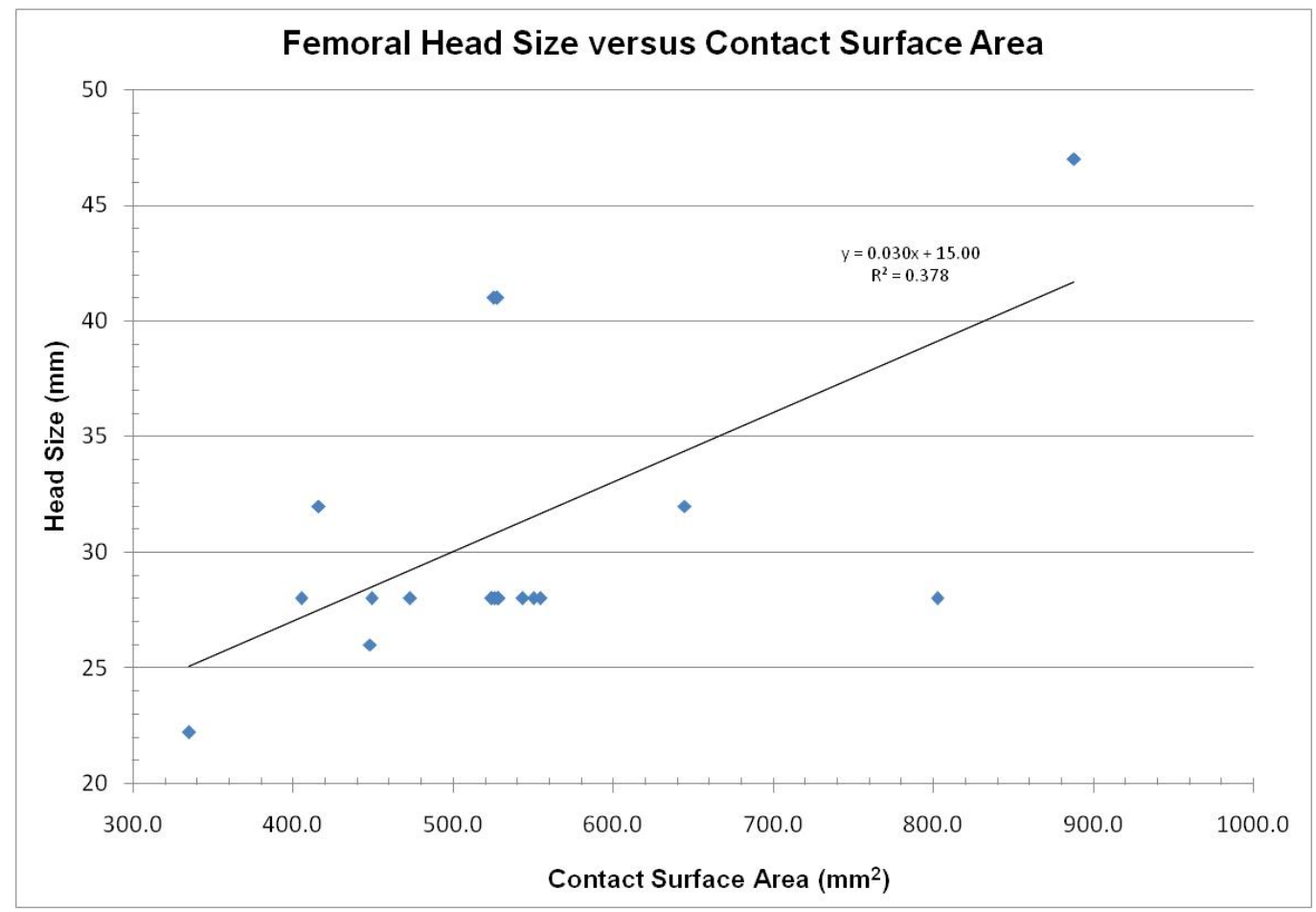

Figure 4.21. Scatter plot of femoral head size versus contact surface area. 


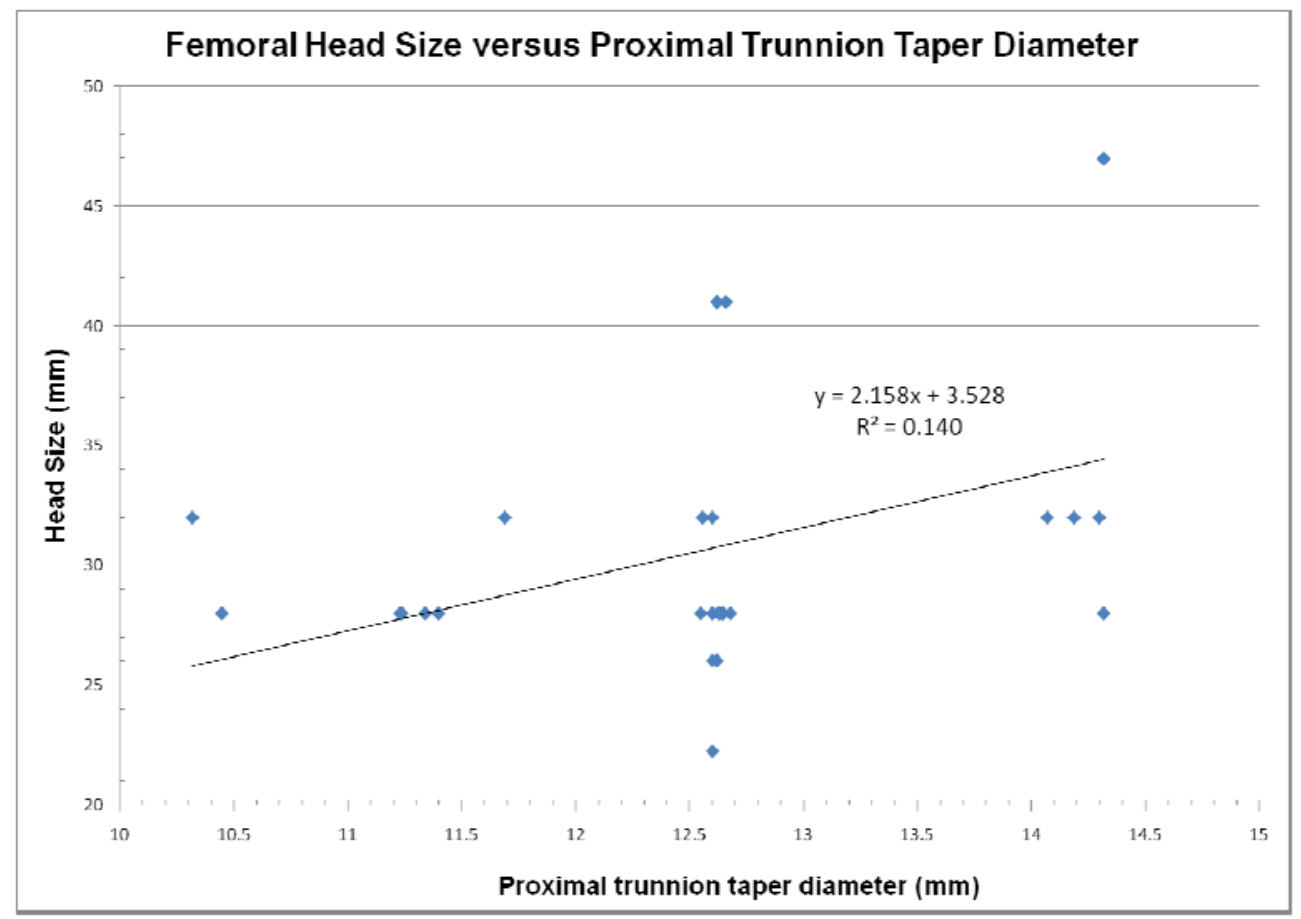

Figure 4.22. Scatter plot of femoral head size proximal trunnion taper diameter.

\section{Influence of Clinical Variables}

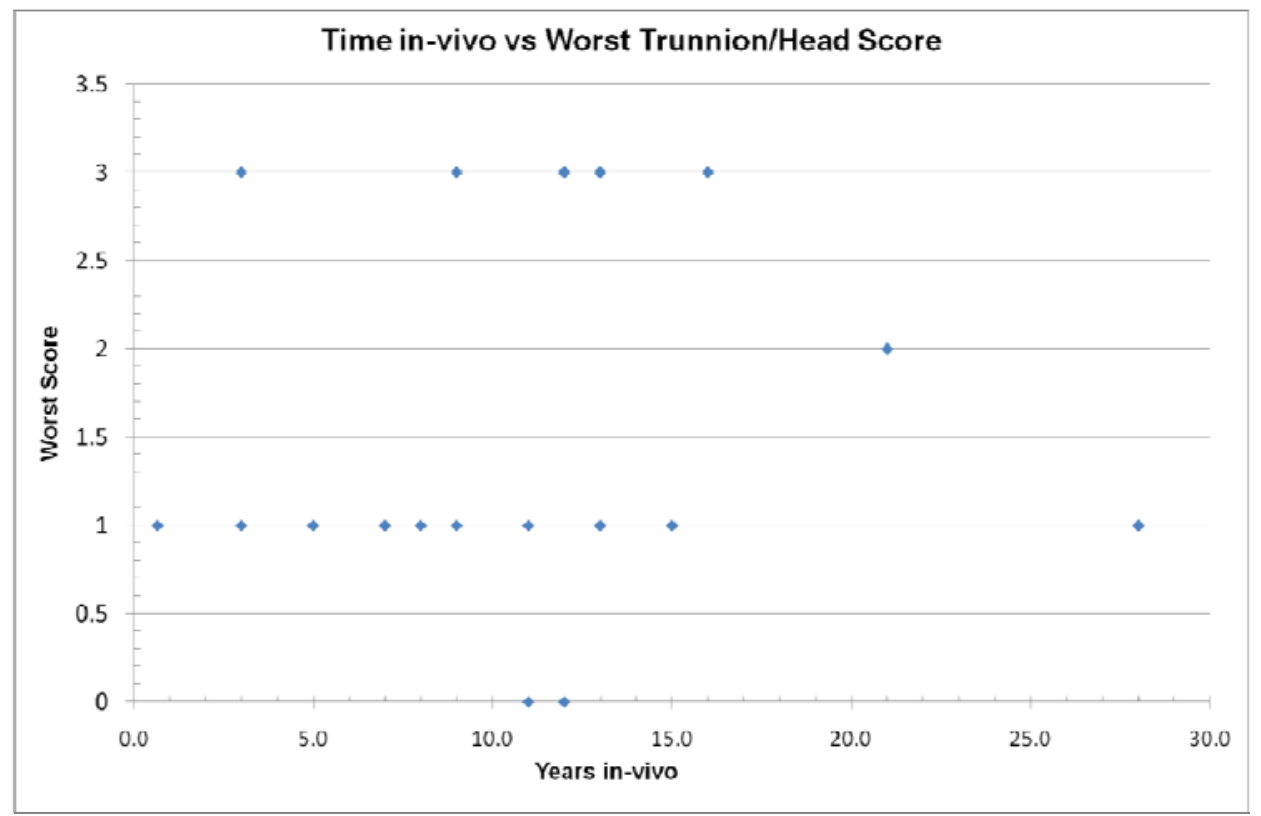

Figure 4.23. Scatter plot of time in-vivo versus worst fretting/corrosion score for either coupled component. 
Table 4.8. Worst fretting/corrosion score distribution for either head or trunnion by implantation time in-vivo.

\begin{tabular}{|l|r|r|r|r|}
\hline \multicolumn{5}{|c|}{ Worst Trunnion/Head Score by Implantation Time In-Vivo } \\
\hline Years In-vivo $\backslash$ Worst Score & 0 & 1 & 2 & 3 \\
\hline $0 \geq$ and $<-5$ years & $0 \%$ & $67 \%$ & $0 \%$ & $33 \%$ \\
\hline $5 \geq$ and $<10$ years & $0 \%$ & $80 \%$ & $0 \%$ & $20 \%$ \\
\hline $10+$ years & $18 \%$ & $36 \%$ & $9 \%$ & $36 \%$ \\
\hline
\end{tabular}

From the limited clinical data available, time in-vivo does not seem to be strongly correlated with fretting or corrosion damage, nor does it seem to be sufficient to cause it. A sizeable $18 \%$ of samples within-vivo time exceeding 10 years, show no corrosion or fretting (scores $=0$ ). While in as little as 3 to 5 years several prostheses have demonstrated severe corrosion (score $=3$ ). There is nonetheless, a slight increasing occurrence of severe corrosion/fretting damage as in-vivo time increases, but clearly other factors play a more important role in determining outcomes.

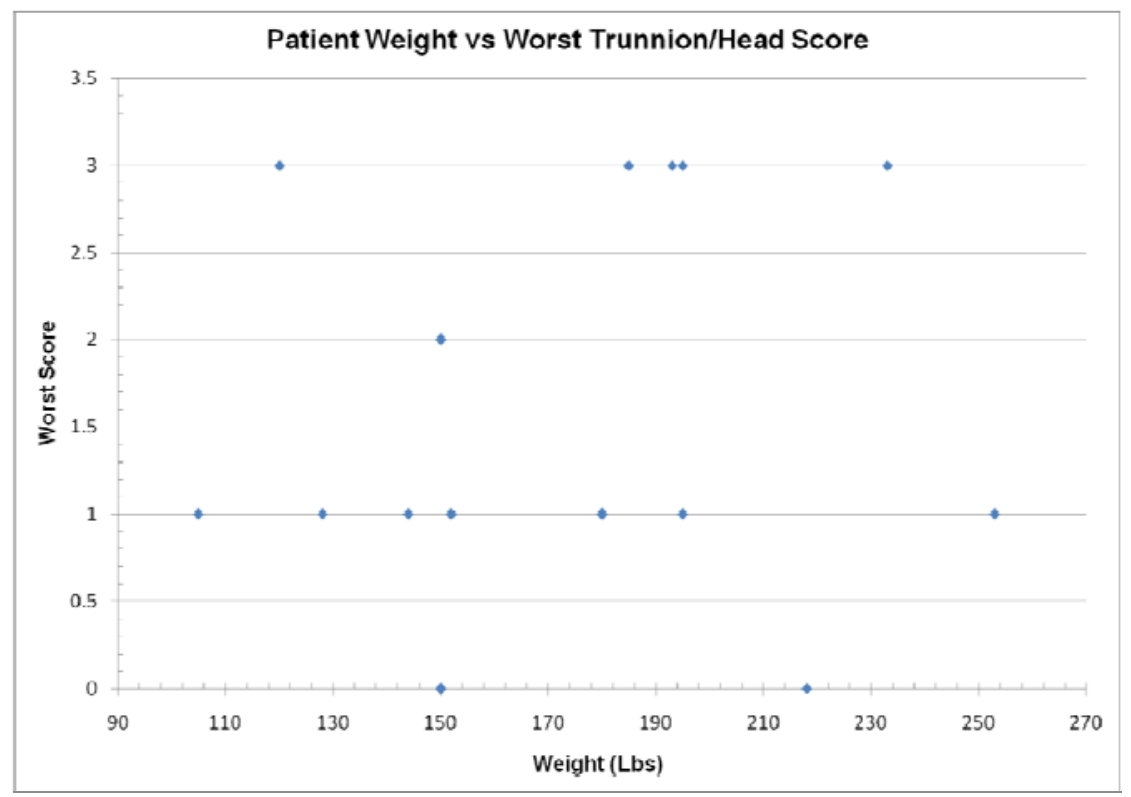

Figure 4.25. Scatter plot of patient weight versus worst fretting/corrosion score for either coupled component. 


\section{Damage Co-Occurrence in Coupled Heads and Trunnions}

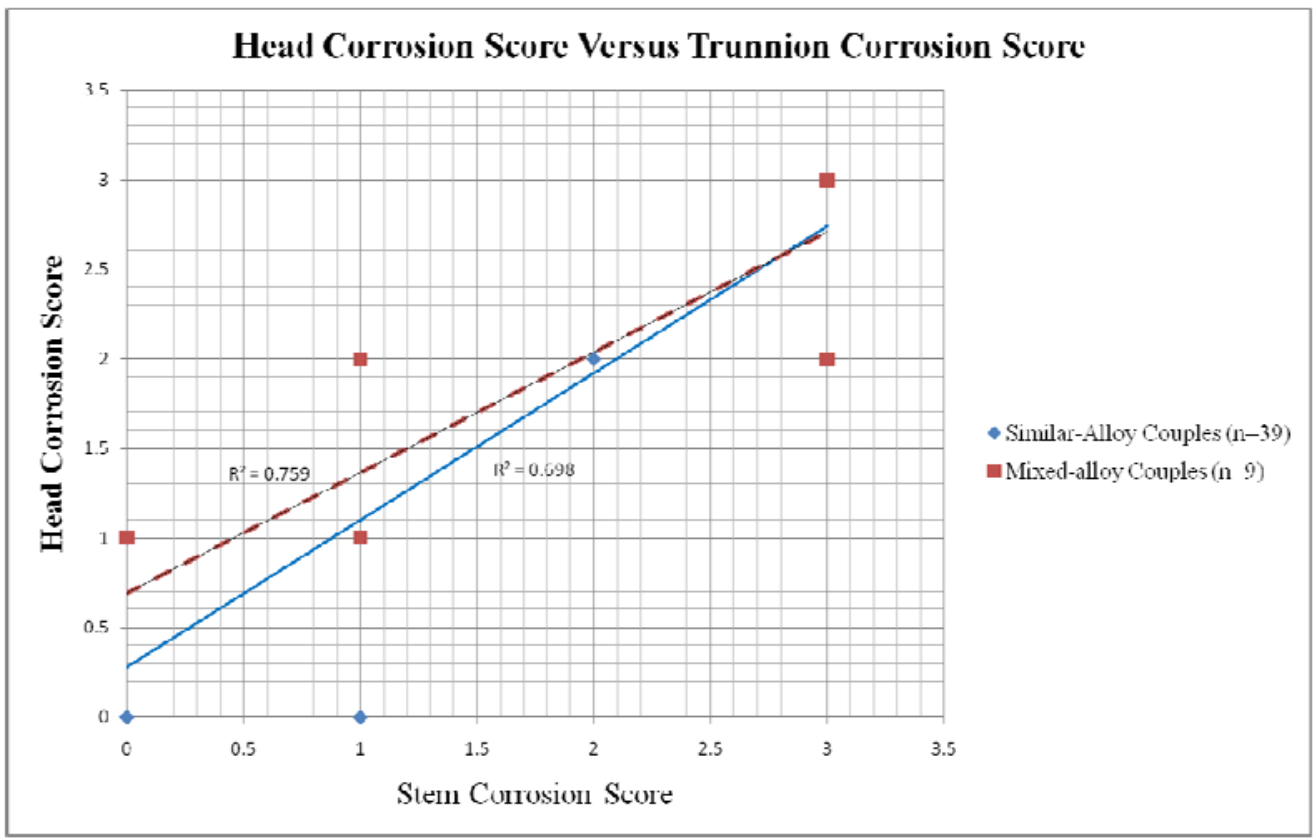

Figure 4.26. Scatter plot of head corrosion score versus stem corrosion scores for similar and mixed alloy couples.

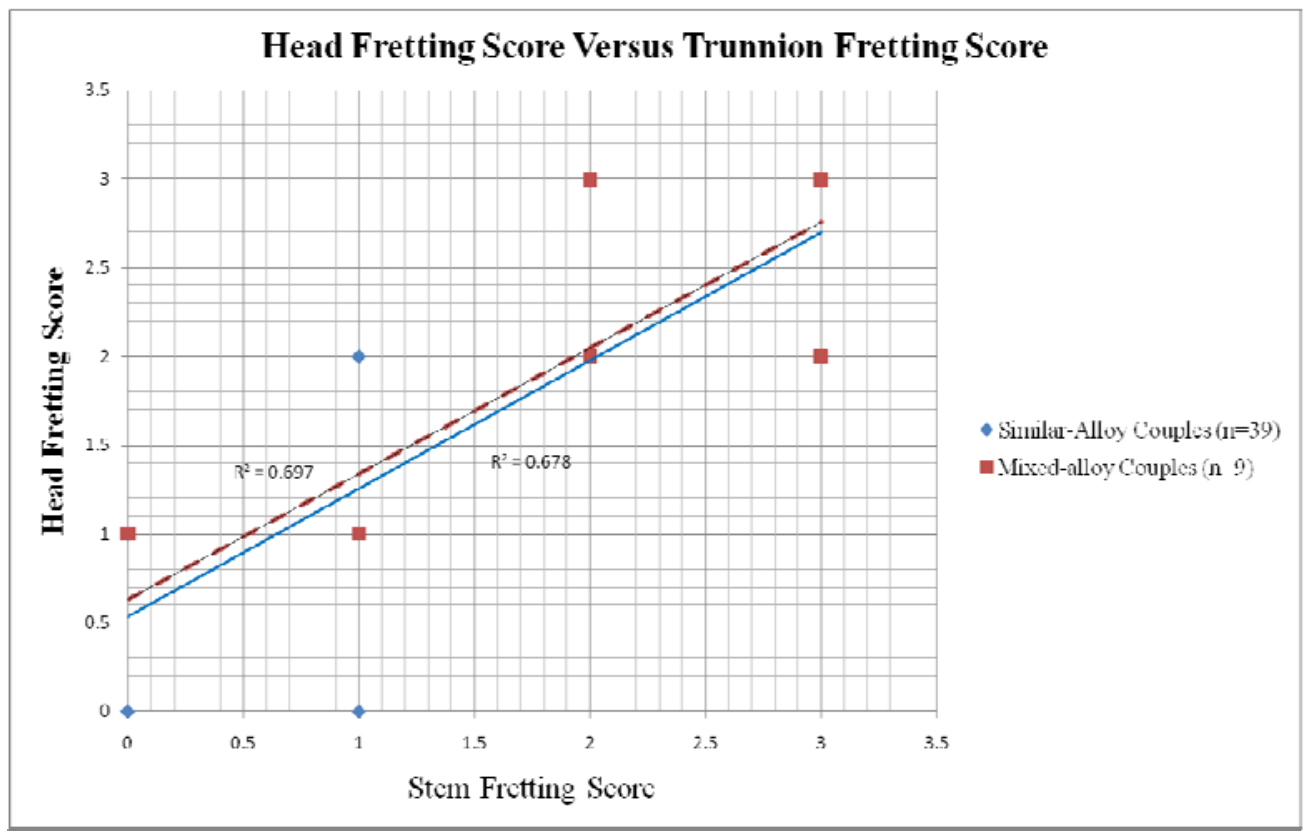

Figure 4.27. Scatter plot of head fretting score versus stem fretting scores for similar and mixed alloy couples. 


\section{CHAPTER V: CONCLUSIONS}

\section{Summary of key findings:}

1) Severe or moderate corrosion/fretting (score 0-1) was observed in $60 \%$ of mixed-alloy prostheses $(n=12)$.

2) Severe or moderate corrosion/fretting was observed in $14 \%$ of similar-alloy prosthesis $(n=36)$, excluding titanium/titanium samples.

3) $100 \%$ of as-cast/dendritic Co-Cr samples demonstrated severe corrosion $(n=2)$.

4) $24 \%$ of wrought low carbon $\mathrm{Co}-\mathrm{Cr}(\mathrm{n}=21)$ demonstrated severe or moderate corrosion/fretting; 18\% when excluding mixed-alloy couples $(\mathrm{n}=17)$.

5) $9 \%$ of high carbon wrought Co-Cr samples $(n=11)$ demonstrated severe or moderate corrosion/fretting; 0\% when excluding mixed alloy couples.

6) $5 \%$ of solution-treated Co-Cr samples $(n=18)$ demonstrated severe corrosion/fretting. Solution treated samples were not found in any mixed-alloy couples.

7) Titanium on Titanium prostheses performed well at the modular interface despite 21 years in-vivo. Note: All failed due to wear at bearing surface.

8) Taper design has the potential to dramatically reduce performance irrespective of material.

8) Trunnion-head moment arm:

- $85 \%$ with MA less than -1.82 hadmild or no corrosion/fretting $(\mathrm{n}=14)$. 
- $41 \%$ with MA greater than $1.14 \mathrm{~mm}$ demonstrated moderate or severe corrosion/fretting $(\mathrm{n}=17)$.

o $75 \%$ with MA greater than $4.11 \mathrm{~mm}$ demonstrated moderate or severe corrosion/fretting $(n=4)$.

9) Of 6 samples with a femoral head size greater than $32 \mathrm{~mm}$ ( $41 \mathrm{~mm}$ to $46 \mathrm{~mm})$, neither demonstrated a corrosion/fretting score greater than 1 .

10) Implantation time was not a determining factor of corrosion or fretting damage.

- $33 \%$ of prosthesis demonstrated severe corrosion or fretting within 5 years in-vivo. Severe corrosion was seen in as little as 3 years.

- Among prosthesis with $>10$ year in-vivo:

o $18 \%$ experienced no corrosion or fretting

o $36 \%$ experienced mild corrosion or fretting

11) When severe or moderate corrosion/fretting was found in any component, severe or moderate corrosion/fretting was always found in the interfacing component, regardless of material.

\section{Design and Material Patterns:}

1) High-carbon wrought alloys were found only in femoral head components.

2) As expected, Co-Cr porous sintered coated stems were not manufactured from wrought/forgings.

3) Large diameters heads $(>32 \mathrm{~mm})$ were all made from castings and had relatively small moment arms. 
4) Co-Cr femoral stems were found to have an average grain size of $139 \mu \mathrm{m}$ (median of $50 \mu \mathrm{m}$ )as compared to $\mathrm{Co}-\mathrm{Cr}$ femoral heads with an average grain size of $37 \mu \mathrm{m}$ (median of $8 \mu \mathrm{m})$. 


\section{CHAPTER VI: FUTURE RESEARCH}

1). Electrochemical testing of various retrieved alloys. Discrepancy between corrosion rates gathered during electrochemical testing and the in-vivo trend for a particular alloy type can indicate to what extent non-material factors are driving the observed in-vivo results.

2) Larger sample size, particularly titanium alloys and as-cast microstructures with more varied combination of features and alloy couple types. Larger sample size for titanium alloys to determine if any particular microstructure has lower or higher incidence rates of corrosion/fretting.

3) Examine bearing surface for wear to determine if alloys performing well at the modular interface are also high performing bearing materials. 


\section{REFERENCES}

[1] "2010 table, procedures by selected patient characteristics-number by procedure, category and age.," ed: US Department of Health and Human Services, 2013.

[2] S. Kurtz, K. Ong, E. Lau, F. Mowat, and M. Halpern, "Projections of primary and revision hip and knee arthroplasty in the United States from 2005 to 2030," J Bone Joint Surg Am, vol. 89, pp. 780-5, Apr 2007.

[3] S. M. Kurtz, E. Lau, K. Ong, K. Zhao, M. Kelly, and K. J. Bozic, "Future young patient demand for primary and revision joint replacement: national projections from 2010 to 2030," Clin Orthop Relat Res, vol. 467, pp. 2606-12, Oct 2009.

[4] C. E. Cadosch D, Gautschi OP, Filgueira L., "Metal is not inert: role of metal ions released by biocorrosion in aseptic loosening--current concepts," J Biomed Mater Res A, vol. 91, pp. 1252-1262, 2009.

[5] D. Cadosch, C. L. Schlett, O. P. Gautschi, H. C. Frei, and L. Filgueira, "[Metal ions: important co-players in aseptic loosening]," Z Orthop Unfall, vol. 148, pp. 393-7, Aug 2010.

[6] C. D. Bolland B, Langton D, Millington J, Arden N, Latham J, "High failure rates with a large-diameter hybrid metal-on metal total hip replacement: clinical, radiological and retrieval analysis," Journal of Bone Joint Surgery, pp. 608-615, 2011 .

[7] T. M. Garbuz DS, Greidanus NV, Masri BA, Duncan CP., "Metal-on-metal hip resurfacing versus large-diameter head metal-on-metal total hip arthroplasty: a randomized clinical trial," Clinical Orthopedic Related Research, pp. 318-325, 2010 .

[8] J. S. Langton D, Joyce T, Gandhi J, Sidaginamale R, and L. J. Mereddy P, Nargol A, "Accelerating failure rate of the ASR total hip replacement," Journal Bone Joint Surgery, pp. 1011-1016, 2011.

[9] H. C. Silva M, Schmalzried TP, "Metal-on-metal total hip replacement," Clin Orthop Relat Res, pp. 53-61, 2005.

[10] J. L. Gilbert, Buckley, C. A., and Jacobs, J. J., "In Vivo Corrosion of Modular Hip Prosthesis Components in Mixed and Similar Metal Combinations. The Effect of Crevice, Stress, Motion, and Alloy Coupling," Journal of Biomedical Materials Research, vol. 27, pp. 1533-1544, 1993. 
[11] E. B. Mathiesen, Lindgren, J. U., Blomgren, G. A., and Reinholt, F. P., "Corrosion of Modular Hip Prostheses," The Journal of Bone and Joint Surgery, vol. 73-B, pp. 569-575, 1991.

[12] J. P. Collier, Surprenant, V. A., Jensen, R. E., and Mayor, M. B., "Corrosion at the Interface of Cobalt-Alloy Heads on Titanium-Alloy Stems," Clinical Orthopaedics and Related Research, pp. 305-312, 1991.

[13] J. J. J. Robert M. Urban, Jeremy L. Gilbert, Stephen B. Rice, Murali Jasty, Charles R. Bragdon, Jorge O. Galante, "Characterization of solid products of corrosion generated by modular-head femoral stems of different designs and materials," Modularity of Orthopedic Implants, pp. 33-44, 1997.

[14] H. J. Cooper, C. J. Della Valle, R. A. Berger, M. Tetreault, W. G. Paprosky, S. M. Sporer, et al., "Corrosion at the head-neck taper as a cause for adverse local tissue reactions after total hip arthroplasty," J Bone Joint Surg Am, vol. 94, pp. 1655-61, Sep 192012.

[15] M. M. Collier JP, Williams IR, Surprenant VA, Surprenant HP, Currier BH., "The tradeoffs associated with modular hip prostheses," Clin Orthop Relat Res, vol. 311, pp. 91-101, 1995.

[16] R. P. Y. Liao, P. Stemmer, M.A. Wimmer, J.J. Jacobs, A. Fischer, L. D. Marks, "New Insights into Hard Phases of CoCrMo Metal-on-Metal Hip Replacements," J Mech Behav Biomed Mater, pp. 39-49, 2012.

[17] A. Kamali, "Hip Joint Tribology," in Modern Hip Resurfacing, D. J. W. McMinn, Ed., ed: Springer International Publishing AG, 2009, pp. 79-89.

[18] T. J. Band, "Materials and Metallurgy," in Modern Hip Resurfacing, D. J. W. McMinn, Ed., ed: Springer International Publishing AG, 2009, pp. 43-63.

[19] K. W. R. Kaisera, C. O’Brien, S. Ramirez-Garcia, D.J. Browne, "The influence of cooling conditions on grain size, secondary phase precipitates and mechanical properties of biomedical alloy specimens produced by investment casting," Journal of the mechanical behavior of biomedical materials, vol. 24, pp. 53-63, 2013.

[20] A. K. Mishra, M. A. Hamby, and W. B. Kaiser, "Metallurgy, Microstructure, Chemistry and Mechanical Properties of a New Grade of Cobalt-Chromium Alloy Before and After Porous-Coating," Cobalt-Base Alloys for Biomedical Applications, vol. ASTM STP 1365, 1999. 
[21] J. V. Giacchia, C. N. Morandoa, O. Fornaroa, and H. A. Palaciob, "Microstructural characterization of as-cast biocompatible $\mathrm{Co}-\mathrm{Cr}-\mathrm{Mo}$ alloys," Materials Characterization, vol. 62, pp. 53-61, 2011.

[22] T. Kilner, R. M. Pilliar, G. C. Weatherly, and C. Allibert, "Phase identification and incipient melting in a cast Co--Cr surgical implant alloy," J Biomed Mater Res, vol. 16, pp. 63-79, Jan 1982.

[23] M. M. L.E Ramírez M Castro , J Lacaze J Lacaze, M Herrera, G Lesoult, "Precipitation path of secondary phases during solidification of the $\mathrm{Co}-25.5 \% \mathrm{Cr}-$ 5.5\%Mo-0.26\%C alloy," Scripta Materialia, 2002.

[24] A. Salinas-Rodriguez, "The Role of the FCC-HCP Phase Transformation During the Plastic Deformation of Co-Cr-Mo-C Alloys for Biomedical Applications," Cobalt-Base Alloys for Biomedical Applications, vol. ASTM STP 1365, 1999.

[25] O. F. J.V. Giacchia, H. Palacio, "Microstructural evolution during solution treatment of $\mathrm{Co}-\mathrm{Cr}-\mathrm{Mo}-\mathrm{C}$ biocompatible alloys," Materials Characterization, pp. 49-57, 2012.

[26] R. M. Berlin, L. J. Gustavson, and K. K. Wang, "Influence of Post Processing on the Mechanical Properties of Investment Cast and Wrought Co-Cr-Mo Alloys," Cobalt-Base Alloys for Biomedical Applications,, vol. ASTM STP 1365, 1999.

[27] H.S. Dobbs and J. L. M. Robertson, "Heat treatment of cast Co-Cr-Mo for orthopaedic implant use," Journal of Materials Science, vol. 1983, pp. 391-401, 1983.

[28] S.-G. A. Lopez HF, "Martensitic transformation in a cast Co-Cr-Mo-C alloy.," Metall Mater Trans A, vol. 39, pp. 8-18, 2008.

[29] H. E. Lippard and R. L. Kennedy, "Process Metallurgy of Wrought CoCrMo Alloy," Cobalt-Base Alloys for Biomedical Applications, vol. ASTM STP 1365, 1999.

[30] K. R. S. John, R. A. Poggie, L. D. Zardiackas, and R. M. Afflitto, "Comparison of Two Cobalt-Based Alloys for Use in Metal-on-Metal Hip Prostheses: Evaluation of the Wear Properties in a Simulator," Cobalt-Base Alloys for Biomedical Applications, vol. ASTM STP 1365, 1999. 
[31] S.-H. Lee, E. Takahashi, N. Nomura, and A. Chiba, "Effect of Carbon Addition on Microstructure and Mechanical Properties of a Wrought $\mathrm{Co}-\mathrm{Cr}-\mathrm{Mo}$ Implant Alloy," Materials Transactions, vol. 47, pp. 287-290, 2006.

[32] H. E. Placko, S.A. Brown, J.H. Payer, "Effects of microstructure on the corrosion behavior of CoCr porous coatings on orthopedic implants," Journal of Biomedical Materials Research, vol. 39, pp. 292-299, 1995.

[33] K. K. Wang, R. M. Berlin, and L. J. Gustavson, "A Dispersion Strengthened CoCr-Mo Alloy for Medical Implants," Cobalt-Base Alloys for Biomedical Applications, vol. ASTM STP 1365, 1999.

[34] A. V. Lombardi, Jr., K. R. Berend, T. H. Mallory, M. D. Skeels, and J. B. Adams, "Survivorship of 2000 tapered titanium porous plasma-sprayed femoral components," Clin Orthop Relat Res, vol. 467, pp. 146-54, Jan 2009.

[35] D. A. L. Andrew H. Schmidt, Joan E. Bechtold, Richard F. Kyle "Assessing morse taper function: The relationship between impaction force, disassembly force, and design variables.," Modularity of Orthopedic Implants, pp. 114-126, 1997.

[36] G. W. Herbert G. Richter, Martin Wimmer, Frank G. Osthues, "Influence of the ball/stem interface on the load bearing capability of modular total hip prostheses," Modularity of Orthopedic Implants, pp. 127-133, 1997.

[37] K. S. Nader A. Nassif, Marcella Elpers Timothy Wright, Douglas E. Padgett, "Taper Design Affects Failure of Large-head Metal-on-metal Total Hip Replacements," Clin Orthop Relat Res, vol. 472, pp. 564-571, 2013.

[38] S. Q. Philippe Hernigou, Charles Henri Flouzat Lachaniette, "One hundred and fifty years of history of the Morse taper: from Stephen A. Morse in 1864 to complications related to modularity in hip arthroplasty," International Orthopaedics, 2013.

[39] G. J. Goldberg JR, Jacobs JJ, Bauer TW, Paprosky W, Leurgans S, "A multicenter retrieval study of the taper interfaces of modular hip prostheses," Clin Orthop Relat Res, pp. 149-161, 2002.

[40] W. L. S. Shilesh C. Jani, Terry W. McLean, Richard D. Lambert, Paul Kovacs, "Fretting Corrosion Mechanisms at Moduluar Implant Interfaces," Modularity of Orthopedic Implants, pp. 211-225, 1997. 
[41] S. C. Sanaz Hariri, James B. Cowan, Charles Bragdon, Henrik Malchau, Harry E. Rubash, "Range of Motion in a Modular Femoral Stem System with a Variety of Neck Options," The Journal of Arthroplasty, vol. 28, pp. 1625-1633, 2013.

[42] J. M. Anna Panagiotidou, Jia Hua, Sarah Muirhead-Allwood, Alister Hart, Gordon Blunn, "Enhanced Wear and Corrosion in Modular Tapers in Total Hip Replacement Is Associated With the Contact Area and Surface Topography," Journal of Orthopaedic Research, vol. 31, pp. 2032-2039, 2013.

[43] F. W. Nicholas Bishop, Robin Pourzal, Alfons Fischer, Marcel Rutschi, Markus Michel, Michael Morlock, "Wear Patterns of Taper Connections in Retrieved Large Diameter Metal-on-Metal Bearings," JOURNAL OF ORTHOPAEDIC RESEARCH, pp. 1116-1122, 2013.

[44] S. V. Collier JP, Jensen RE, Mayor MB, Surprenant HP, "Corrosion between the components of modular femoral hip prostheses," J Bone Joint Surg Br, vol. 74, 1992.

[45] A. A. Stanley A. Brown, Mark D'Onofrio, Curt Flemming, "Effects of neck extension, coverage, and frequency on the fretting corrosion of modular THR broe and cone interface," Modularity of Orthopedic Implants, pp. 127-133, 1997.

[46] J. M. Elkins, J. J. Callaghan, and T. D. Brown, "Stability and Trunnion Wear Potential in Large-diameter Metal-on-Metal Total Hips," Clinical Orthopaedics and Related Research, vol. 472, pp. 529-542, 2013.

[47] J.-M. B. Richard M.R. Dyrkacz, Olanrewaju A. Ojo, Thomas R. Turgeon, Urs P. Wyss, "The Influence of Head Size on Corrosion and Fretting Behaviour at the Head-Neck Interface of Artificial Hip Joints," The Journal of Arthroplasty, vol. 28, pp. 1036-1040, 2013.

[48] R. C. Bill, "Review of factors that influence fretting wear," in Materials evaluation under fretting conditions, ASTM STP 780, S. R. Brown, Ed., ed: ASTM, 1982, pp. 165-181.

[49] N. Ohmae, Tsukizoe, T., "The effect of slip amplitude on fretting," Wear, vol. 27, pp. 281-294, 1974.

[50] A. M. Maurer, Brown, S. A., Payer, J. H., Merritt, K, Kawalec, J. S., "Reduction offretting corrosion ofTi6A14V by various surface treatments," Journal of Orthopaedic Research, pp. 865-873, 1993. 
[51] M. Long, Rack, H. J., "Titanium alloys in total joint replacement a materials science perspective - Review," Biomaterials, vol. 19, pp. 1621-1639, 1998.

[52] P. J. Kennedy, Stallings, L, Peterson, M. B., "A study of surface damage at low amplitude slip," ASLE Transactions, vol. 27, pp. 305-312, 1984.

[53] F. C. Brown S, Kawalec J, Placko H, Vassaux C, Merritt K, Payer J, Kraay M., "Fretting corrosion accelerates crevice corrosion of modular hip tapers," J Appl Biomater, pp. 19-26, 1995.

[54] J. M. Dobromirski, "Variables offretting process: are there 50 of them?," in Standardization of fretting fatigue test methods and equipment, ASTM STP 1159. vol. ASTM STP 1159, H. M. Attia, Ed., ed, 1992, pp. 60-66.

[55] G. H. Sabrina Yvonne Jauch, Kay Sellenschloh, Henning Haschke, Marc Baxmann, Thomas M. Grupp, Michael M. Morlock, "Micromotions at the Taper Interface Between Stem and Neck Adapter of a Bimodular Hip Prosthesis During Activities of Daily Living," JOURNAL OF ORTHOPAEDIC RESEARCH, 2013.

[56] S. Suresh, Fatigue of Materials, 2nd edition (Cambridge University Press, Cambridge 1998), Fatigue of Materials, 2nd edition. Cambridge: Cambridge University Press, 1998.

[57] K. Lyer, "Peak contact pressure, cyclic stress amplitudes, contact semiwidth and slip amplitude: relative effects on fretting fatigue life," International Journal of Fatigue, pp. 193-206, 2001.

[58] T. G. Boltz RE, Handbook of tables for applied engineering science: CRC Press, 1973.

[59] H. J. Clarke EGC, "An investigation into the correlation between the electrical potential of metals and their behaviour in biological fluids," J Bone Joint Surg [Br], vol. 35, pp. 467-473, 1953.

[60] D. J. L. N. Moharrami, O. Sayginer, S.J. Bull, "Why does titanium alloy wear cobalt chrome alloy despite lower bulk hardness: A nanoindentation study?," Thin Solid Films, 2013.

[61] F. MG, Corrosion Engineering. Third Edition., 1986.

[62] "Corrosion," in Elements of Metallurgy and Engineering Alloys, F. C. Campbell, Ed., ed: ASM, 2008. 
[63] A. Acharya, Freise, E., Greener, E. H., "Open-Circuit Potentials and Microstructure of Some Binary Co-Cr Alloys," Cobalt, vol. 47, pp. 75-80, 1970.

[64] M. J. Donachie, Titanium: A Technical Guide, 2nd Edition: ASM International, 2000 .

[65] T. D. Schutz RW, "orrosion oftitanium and titanium alloys. Conference of Titanium," Societe Francaise de Metallurgie, pp. 669-683, 1988.

[66] P. Panigrahi, Y. Liao, M. T. Mathew, A. Fischer, M. A. Wimmer, J. J. Jacobs, et al., "Intergranular pitting corrosion of CoCrMo biomedical implant alloy," $J$ Biomed Mater Res B Appl Biomater, vol. 102, pp. 850-9, May 2014.

[67] S. Virtanen, I. Milosev, E. Gomez-Barrena, R. Trebse, J. Salo, and Y. T. Konttinen, "Special modes of corrosion under physiological and simulated physiological conditions," Acta Biomater, vol. 4, pp. 468-76, May 2008.

[68] R. A. Montero-Ocampo C, "Effect of carbon content on the resistance to localized corrosion of as-cast cobalt-based alloys in an aqueous chloride solution.," $J$ Biomed Mater Res., vol. 4, pp. 441-453, 1995.

[69] G. T. Burstein, C. Liu, and R. M. Souto, "The effect of temperature on the nucleation of corrosion pits on titanium in Ringer's physiological solution," Biomaterials, vol. 26, pp. 245-56, Jan 2005.

[70] D. C. Rodrigues, R. M. Urban, J. J. Jacobs, and J. L. Gilbert, "In vivo severe corrosion and hydrogen embrittlement of retrieved modular body titanium alloy hip-implants," J Biomed Mater Res B Appl Biomater, vol. 88, pp. 206-19, Jan 2009.

[71] J. L. Gilbert, C. A. Buckley, and J. J. Jacobs, "In vivo corrosion of modular hip prosthesis components in mixed and similar metal combinations. The effect of crevice, stress, motion, and alloy coupling," J Biomed Mater Res, vol. 27, pp. 1533-44, Dec 1993.

[72] V. Swaminathan, Gilbert, JL, "Fretting Corrosion of CoCrMo and Ti6Al4V Metallic Biomaterial Interfaces: Model, Method and Behavior," Biomaterials, 2012.

[73] S. R, "The Corrosion Properties of Titanium and Titanium Alloys," in Titanium in Medicine, T. P. Brunette DM, Textor M, Thoms P, Ed., ed: Springer, 2001. 
[74] K. J. Bundy, "Corrosion and other electrochemical aspects of biomaterials," Crit Rev Biomed Eng, vol. 22, pp. 139-251, 1994.

[75] E. E. Hench LL, "Biomaterials - the Interfacial Problem," Advanced Biomedical Engineering, vol. 5, pp. 35-150, 1982.

[76] F. J. F. S.W. Watson, B.W. Madsen, S.D. Cramer, "Methods of measuring wearcorrosion synergism," Wear, pp. 476-484, 1995.

[77] B. R. Cook SD, Clemow AJ, "Corrosion and wear at the modular interface of uncemented femoral stems," The Journal of Bone and Joint Surgery, vol. 76, pp. 68-72, 1994.

[78] E. S. Alan M. Kop, "Corrosion of a Hip Stem With a Modular Neck Taper Junction," The Journal of Arthroplasty, vol. 24, 2009.

[79] T. M. Heiko Meyer, Gesine Goldau, Kathrin Chamaon, Marcel Ruetschi, Christoph H. Lohmann, "Corrosion at the Cone/Taper Interface Leads to Failure of Large-diameter Metal-on-metal Total Hip Arthroplasties," Clin Orthop Relat Res, pp. 3101-3108, 2012.

[80] M. B. C. Selin Munir, Christina Esposito, Anna Sokolovaa, William L. Walter, "Corrosion inmodulartotalhipreplacements:An analysis ofthehead-neck andstemsleeve taper connections," Seminars in Arthroplasty, pp. 240-245, 2013.

[81] M. Sage and C. Gillaud, "Méthode d'analyse quantitative des variétés allotropiques du cobalt par les rayons X," Revue de Metallurgie, vol. 47, pp. 139$144,1950$. 